UNIVERSITÀ DEGLI STUDI DI FIRENZE

DotTorato IN POLITICA ED ECONOMIA DEI PAESI IN VIA DI

SVILUPPO

CICLO XXII

\title{
ADDRESSING HIGH FOOD PRICES: A HOUSEHOLD VULNERABILITY ANALYSIS IN RURAL BURUNDI
}

Candidate: Oscar Maria Caccavale

Tutor: Prof. Andrea Marescotti

Coordinator: Prof. Donato Romano 


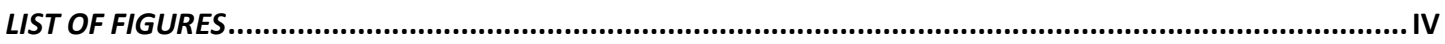

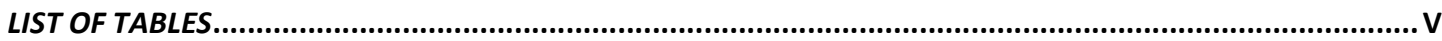

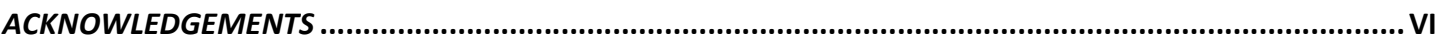

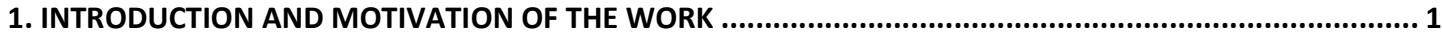

2. HIGH FOOD PRICES DETERMINANTS WITH EMPHASIS ON SPECULATION, HOARDING AND PANIC ......... 4

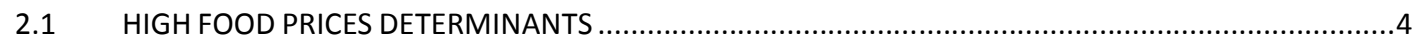

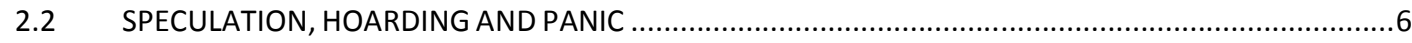

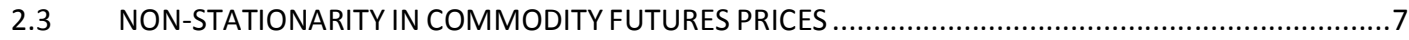

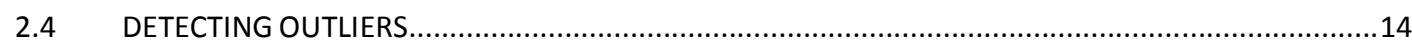

2.4.1 Structural changes in the food price rush (2006-2009) ........................................................21

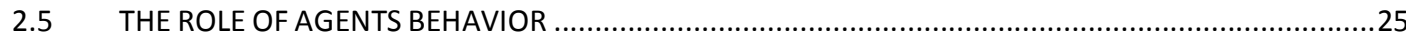

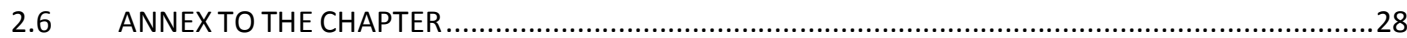

3. HIGH FOOD PRICES AND HOUSEHOLD BEHAVIOR: A REVIEW OF RECEIVED MODELS AND BEYOND...... 30

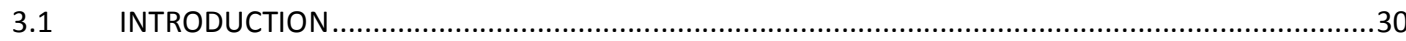

3.2 THE FOOD PRICE CONUNDRUM. ARE HIGH FOOD PRICES PRO-POOR? ......................................31

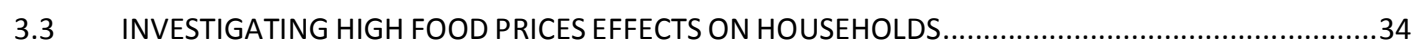

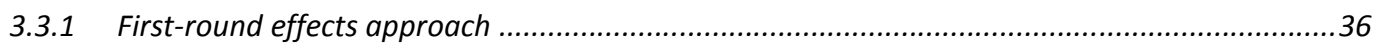

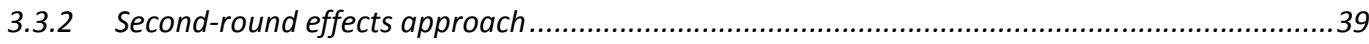

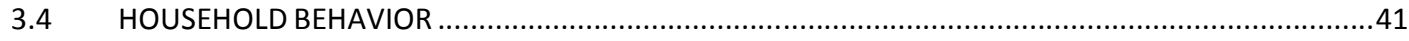

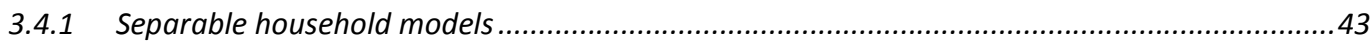

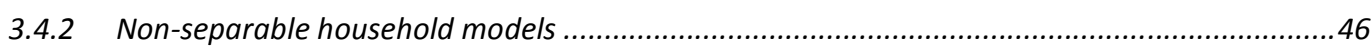

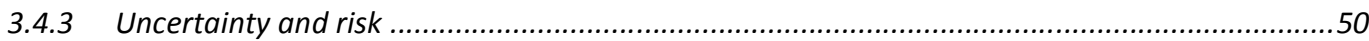

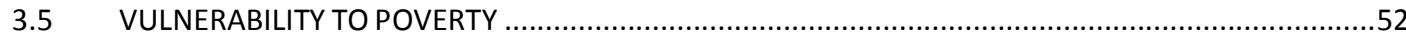

4. MEASURING VULNERABILITY: ALTERNATIVE APPROACHES AND MAIN FINDINGS .............................. 57

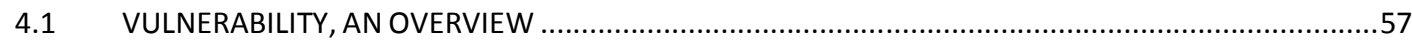

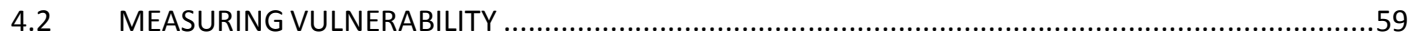

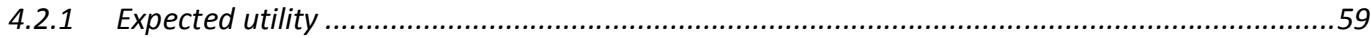

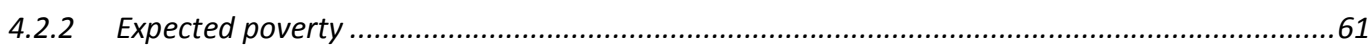

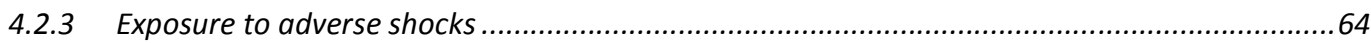

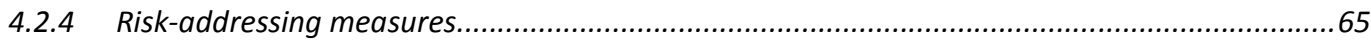

$4.3 \quad$ EMPIRICAL BACKGROUND: MAIN FINDINGS PER COVARIATE ....................................................67 


\begin{tabular}{|c|c|}
\hline \multicolumn{2}{|r|}{ BURUNDI } \\
\hline 5.1 & 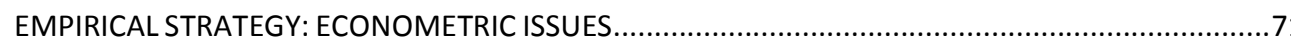 \\
\hline 5.1 .1 & 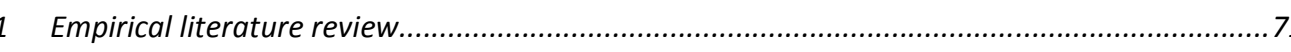 \\
\hline 5.1 .2 & 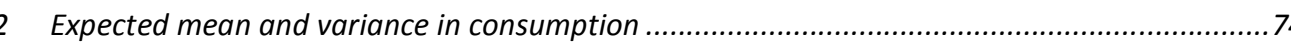 \\
\hline 5.1 .3 & A multilevel approach .................. \\
\hline 5.1 .4 & Model specification....... \\
\hline 5.1 .5 & Empirical strategy \\
\hline 5.2 & THE CASE OF BURUNDI ........................... \\
\hline 5.3 & EMPIRICAL RESULTS AND DISCUSSION...................... \\
\hline 5.3 .1 & 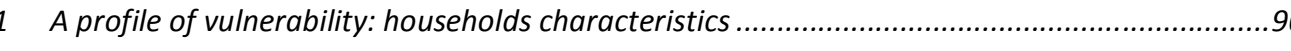 \\
\hline 5.3.2 & A profile of vulnerability including price effects....... \\
\hline 5.4 & 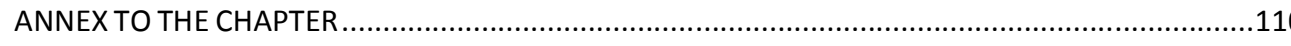 \\
\hline ONCLUI & VG REMARKS \\
\hline
\end{tabular}




\section{List of figures}

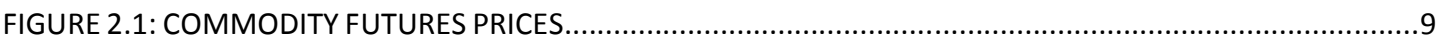

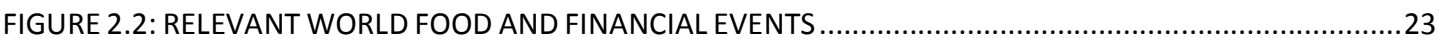

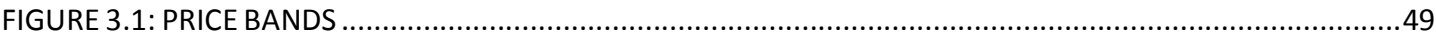

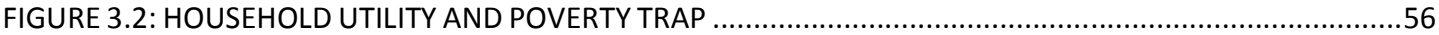

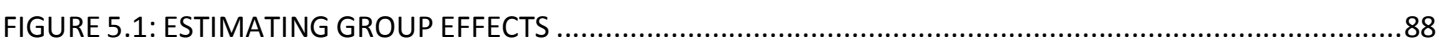

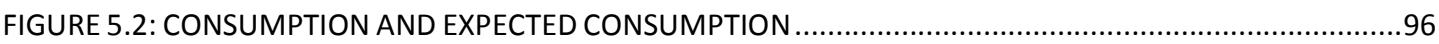

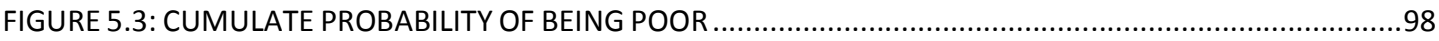

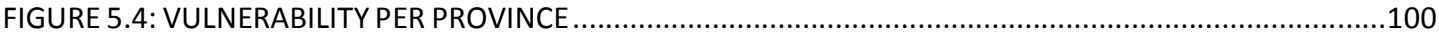

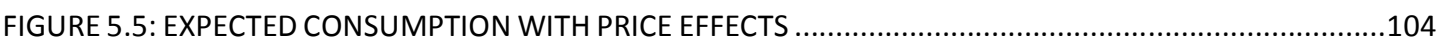

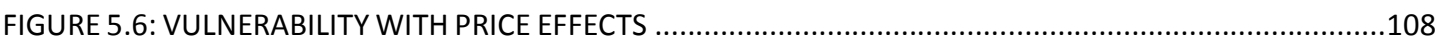

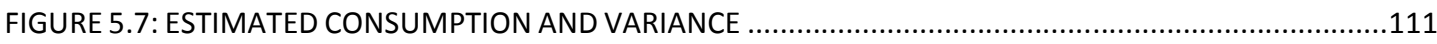

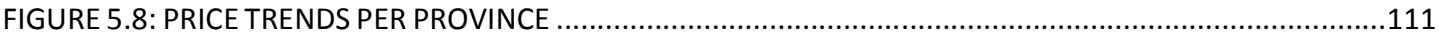




\section{List of tables}

TABLE 2.1: ADF, PP AND NP UNIT ROOT TESTS ON CORN PRICES.

TABLE 2.2: ADF, PP AND NP UNIT ROOT TESTS ON RICE PRICES ….....................................................12

TABLE 2.3: ADF, PP AND NP UNIT ROOT TESTS ON SOYBEAN PRICES …...............................................13

TABLE 2.4: ADF, PP AND NP UNIT ROOT TESTS ON WHEAT PRICES …................................................13

TABLE 2.5: UNIT ROOT TEST ALLOWING FOR ONE STRUCTURAL BREAK: ADDITIVE OUTLIERS ...................17

TABLE 2.6: UNIT ROOT TEST ALLOWING FOR ONE STRUCTURAL BREAK: INNOVATIONAL OUTLIERS ..........17

TABLE 2.7: UNIT ROOT TEST ALLOWING FOR TWO STRUCTURAL BREAKS: ADDITIVE OUTLIERS.................19

TABLE 2.8: UNIT ROOT TEST ALLOWING FOR TWO STRUCTURAL BREAKS: INNOVATIONAL OUTLIERS ......20

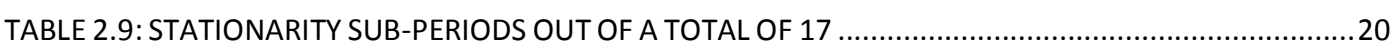

TABLE 2.10: MATCHING FOOD AND FINANCIAL CRISIS WITH ADDITIVE AND INNOVATIONAL OUTLIERS ...27

TABLE 2.11: ROLLING UNIT ROOT TEST ALLOWING FOR ONE STRUCTURAL BREAK - ADDITIVE OUTLIERS. 28

TABLE 2.12: ROLLING UNIT ROOT TEST ALLOWING FOR ONE STRUCTURAL BREAK - INNOVATIONAL

OUTLIERS

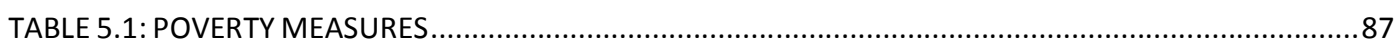

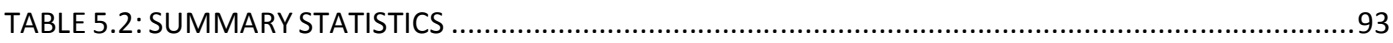

TABLE 5.3: RESTRICTED MAXIMUM LIKELIHOOD RESULT OF (LOG) CONSUMPTION PER ADULT

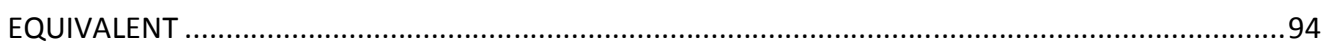

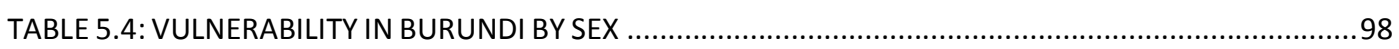

TABLE 5.5: RESTRICTED MAXIMUM LIKELIHOOD RESULTS OF (LOG) CONSUMPTION PER ADULT

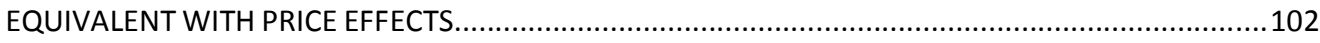

TABLE 5.6: EXPECTED CONSUMPTION PERCENTILES PER LIVELIHOOD GROUP ........................................ 105

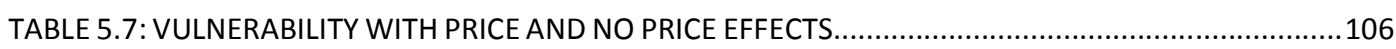

TABLE 5.8: VULNERABILITY BREAKDOWN RATIO: PRICE EFFECTS/NO PRICE EFFECTS .............................107

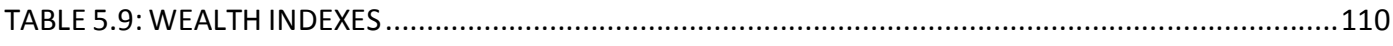

TABLE 5.10: CORRELATION OF HOUSEHOLD MARKET POSITIONS ...................................................... 110

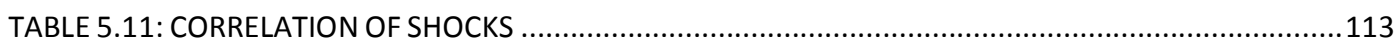


The writing of this dissertation was possible granted to the contribution and assistance of many people.

I would like to thank my supervisor, Andrea Marescotti, and the PhD program coordinator, Donato Romano, for their helpful advice and guidance along the way.

I am exceptionally grateful to Carla Rampichini from the University of Florence, for providing priceless indications for the multilevel analysis, and to Sara Savastano from the University of Tor Vergata, for her useful hints and suggestions on the vulnerability analysis.

I would like to express my sincere gratitude to Giulio Cifarelli from the University of Florence, for his enlightening discussions on food commodity price and crisis, HenkJan Brinkman, World Food Programme, for his comments and Gianluca Mazzone, Bloomberg UK, for sharing with me the international price data.

This work would not have been possible without the kind contribution of the World Food Programme, for very generously providing me with the Burundi households dataset, and in particular I would like to thank Adama Diop-Faye, with whom I am indebted, Joyce Luma, Mihret Bizuneh and Amit Wadhwa.

I really appreciated the Food and Agriculture Organization contribution, for providing me with Burundi price data and in particular I am thankful to Ernest Manirambona and Prosper Ruberintwari.

I would like to thank the PhD Steering Committee members for their trust, and in particular Giovanni Andrea Cornia, and Mario Biggeri for giving me the chance of teaching and his support.

There are so many other people I wish to express gratitude. Among those, Andrea, Lucia and Rosa for easing these years spent together, Marika for following my Mordor wanders, Sara for her friendship, Alessandro, Giuseppe and Massi for sharing the hovel and our midnight and later cooking, Antonio and Michele for that rain-dogs afternoon in Piazza Santo Spirito, and much more. 
Much of this work owes to my mother and father, who nurtured my curiosity with their sustain and love throughout all my life. And to Stella, with whom I share the life, for holding me through my silences and shortcomings and for supporting me every-day.

This work is dedicated to Gino Parrella, because I really miss his words. 



\section{INTRODUCTION AND MOTIVATION OF THE WORK}

After decades of steady food prices, the world witnessed an unusual rush in the price of commodities in the two-year period 2007-2008.

Actually, in the food commodity debate, it is rather incorrect merely referring at high food prices as if they were only a matter of financial activity. The relevance reserved by futures market exchanges is tantamount the same than other commodities, and increasing quantities are being traded daily.

Still, when bread clashes out broke in several countries, the international community set back its chronicles to late '700 century narrative, with the emerging awareness that something completely unusual was arising in the debate.

The present dissertation tackles the food crisis through two distinct standpoints. On the one hand, international price surge is addressed in its most financial view - i.e. the price generation process - and the related information within connected.

On the other, the drawbacks such dynamics may have triggered are analyzed in terms of rural household consumption and production. That is to say how this crisis has turned for a great part of the world population from being purely a financial issue into a matter affecting food provision, or the capability to get adequate amounts of food or not.

Practically, beyond the lines of such considerations, it will be throughout attempted to draw a fil rouge amongst agents' behavior, each differently involved in the food market.

Thence, those investigated will be those involved in the food commodity futures market, being them speculators or governments. It will be explained how such alleged speculation, if proven, must be linked to hoarding policies, implicitly or not put into practice by governments.

Actually, several governments have been running one after the other to gauge food crisis but they have hardly managed to reach their goal. Indeed, it is possible that in a sort of self-fulfilling expectation, hoarding policies had the only outcome of dramatically intensifying the food price surge therefore triggering panic. 
Conversely and subsequently, the objective will be totally reversed towards households, and more specifically towards those with a limited power to cope with food price shocks. In the midst of all this, the attempt to bridge such different perspectives throughout the demeanors put in place during the price crises, which are assumed to be partly outside the area of pure economic rationality in its most orthodox meaning, being such deviations brought about by hoarding and panic on the one hand, and disaster avoidance on the other.

It follows from above that addressing higher food price setbacks towards households mainly pertains to poverty. The main research question that will be considered is whether or not high food prices are pro poor and, if not, which are the households most affected in terms of their vulnerability.

This is not a mundane question, being the linkage with food so relevant for rural households in connection with the full set of economic choices they need put into practice. Hence, by answering to such a plain inquiry, the entire relation shaping household behaviors must be unveiled. The outline followed will thus be organized according to this intent.

Firstly, other contributions will also be reviewed in order to place the subject within the current state of the debate. Afterwards, taking the steps from some general conclusions drawn by the relevant literature, the focus will be shifted on the decisions, which inhere consumption and production choices, in a rural household and price changes framework.

As a matter of fact, a household-model fails to fully grasp the utmost behaviors adopted by the poorest households. Consequently, the production/consumption conundrum turns into a more prosaic theme of whether to starve or not. As a result, a readjusted conceptual definition of a household model that can analyze a spectrum, which considers a wider span of conditions, including being trapped into poverty by their detriment state will be presented.

Since the surge of food prices per se involves a dynamic element, at the household level this issue involves the patterns in and out of poverty, defined in terms of vulnerability to poverty, which is found to be dramatically exacerbated by such a price volatility. Provided poverty is the current state of the world where (rural) households might be constrained into, vulnerability is a less graspable concept, thus challenging several authors in the attempt of measuring it. Accordingly to the 
general framework depicted in these lines, vulnerability as a measure of expected poverty will be chosen, functional to the case study of Burundi.

This dissertation is organized as follows: the first part reviews the possible implications of soaring food prices in terms of speculation and behavioral aspects related to food stock accumulation. The dynamics of commodity futures prices in terms of stationarity and non-stationarity are then described as well as the role of structural breaks in the price generation process. Finally, structural breaks findings are compared against relevant food policy events and financial crisis turmoil.

The second part addresses most specifically the question of high price consequences on rural households, reviewing the literature on first and second-round effects, and linking the main findings with household model theory. The investigation then converges into the field of uncertainty at very low levels of consumption, where the rural poors are the most affected in terms of possible drawbacks related to food price inflation.

The third part conceptualizes these drawbacks in the general field of vulnerability to poverty, assessing and theorizing the received different definitions and measures. Consequently, arising from these contributions, some major findings are reported in order to sketch an operational background for the proceeding empirical part.

The last part addresses the main research issue against the case study, by means of econometric analysis. A multilevel model is presented, to take advantage of the sampling procedure. Full description of the empirical setting is provided, as well as the econometric results. Finally, vulnerability sources influence by soaring prices is measured and broken down, with regards to different household settings.

Concluding remarks attempt to summarize the main findings. 


\section{HIGH FOOD PRICES DETERMINANTS WITH EMPHASIS ON SPECULATION, HOARDING AND PANIC}

\subsection{HIGH FOOD PRICES DETERMINANTS}

The food crisis that affected both developed and developing countries over 20072009 severely hit the agricultural development mainstream policies.

The impact of the crisis is quite impressive. Several riots in almost 38 countries all over the world have burst out as an outcome of food price hikes and food shortage (FAO, 2007). In the first half of 2008, the real price of food commodity prices soared 75\% over the past five years (World Bank, 2008). Almost every food commodity showed sharp increases above the figures of the previous years: wheat, corn, soybean and rice underwent rises far higher than $100 \%$ in the period from mid-2005 and mid2008 (De Janvry and Saudolet, 2008).

The crisis followed the outburst of oil prices, and certainly the latter drove the costs of agricultural inputs and outputs up along the whole value-chain. It would be wrong to assume that only one factor is to be considered as the main reason to the explosion of commodity prices (WFP, 2009; HLTF, 2008). Actually, causes vary from country to country and over time. Whereas some of them are cyclical, other are structural, yet other causes are due to local determinants (IFPRI/CGIAR, 2008).

Among these, scholars and practitioners enlist:

a) weather disruptions which caused negative growth in world cereal production, and an inadequate reaction of the world food system to cope with such shocks (Wiggings, 2008). Moreover "long-term trends that led to slower growth in production and rapid growth in demand contributed to a sharp downward trend in world aggregate stocks of grains and oilseeds that began in 1999" (Trostle, 2008);

b) increased bio-fuel production (IMF, 2008; OECD-FAO, 2008; World Bank, 2008) and rising oil prices, which are increasingly and strongly connected. In fact, "once oil 
prices pass a threshold between US\$60 and US\$70 a barrel of oil, ethanol distilled from grains becomes commercially profitable so that demand for biofuels increases" (Wiggins et al., 2010);

c) higher energy prices which affected, directly and indirectly, food prices by means of higher costs related in general to food production activities. Specifically, this is much true for fertilizers where a complete pass-through occurred, with the practical consequence of actually doubling these costs in Africa (Rapsomanikis, 2009);

d) economic growth in important developing countries (Gilbert, 2008), e.g. India and China, and changes in their consuming patterns, even though there is no agreed consensus on this issue, especially for cereals demand, which is not growing that quickly (Wiggins et al., 2010);

e) soil erosion and chronic under-investments in rural infrastructures and agricultural innovation;

f) US dollar depreciation and financial speculation, which spread from crude oil and metal markets into food commodities markets (Timmer, 2010; Piesse and Thirtle, 2009, Timmer, 2008).

It is estimated that almost 130-155 million people have moved into poverty (World Bank, 2008). Rural areas, where globally $75 \%$ of the poor live, are the most severely hit.

Most commodities are priced in U.S. dollars but purchased in local currencies. The link between a declining dollar exchange rate and the commodity price is relevant to be addressed in order to understand price hikes and their linkages with higher crude oil price, agriculture input prices and an increasing bio-fuels demand.

Thus, while the effects of supply and demand on commodity prices are clear, the effects of changes in the structure of commodity markets, in particular increased speculative activity, are not. Price volatility has increased, partly due to increased trading volumes. Based on existing research, it is impossible to say whether price levels have been influenced by speculative activity (Abbott, Hurt, and Tyner, 2008). Nonetheless, there is growing consensus over the hypothesis of a speculative bubble affecting those markets. 


\subsection{SPECULATION, HOARDING AND PANIC}

There is widespread belief that worldwide soaring prices cannot fully be explained by the recent changes in the supply and demand fundamentals. Besides, there are authors who pointed the finger at speculation.

Technically, speculation in food markets can take the form of risk management, where massive amounts of commodities are purchased with the expectation of a continuing price rise. Those hedgers are usually farmers, commercial traders and processors, who are heavily involved in the actual deliveries of commodities (WFP, 2009). On the other hand, with regard to the futures and options markets, speculation may be an investment strategy, where stocks of commodities are taken off the market in time of shortage - usually by non-commercial traders - in order to drive prices up (Young, 2008).

The idea that speculation was triggered by massive capital outflow from financial into commodity markets is somehow confirmed by the amount of total futures and options contracts traded, which rose significantly in the time period spanning from May 2007 to May 2008 (Robles, Torero and von Braun, 2008).

Thus, evidence of an increased relative incidence of pension, hedge and index funds in the functioning of commodity markets should be addressed with regard to price volatility and to the overall level of spot prices through the arbitrage opportunities (Abbott, Hurt, and Tyner, 2008; Robles, Torero, and von Braun, 2008).

In general, those contracts are not strictly linked to actual deliveries (OECD, 2008). Hence, the amount in metric tons traded in commodity markets, which by far represents the equivalent of more than the real harvest physically available (Young, 2008), creates the perception that food prices are somehow driven also by additional drivers beyond the simple supply and demand factors. If that is what actually happened, and there is no defined consensus even though the path of several food commodities showed abrupt raises and sudden collapses, there might have been a speculative bubble with self-fulfilling expectations on future prices.

In terms of food accumulation, it has been noticed that by taking big amounts of food off the markets, in general considered as a speculative attitude, may also sort an unintended effect of irrational, panic-like, behavior. Hoarding food commodities, 
especially rice, has been influential in deepening the crisis (Timmer, 2008). Throughout the whole chain, starting from the household level and back to traders and processors, increasing rice stocks were gathered in order to find shelter against further increases in spot prices. Moreover, at the national level and to a greater extent, food policies aimed at supporting domestic markets, as well as keeping prices as low as possible, where endorsed by several countries ${ }^{1}$.

The events which occurred in some food markets, with special focus on rice, might be somehow defined as a mania, hysteria, irrationality (Kindleberger, 1978) or panic (Timmer, 2008). That might be the definition of a market bubble.

Briefly, the envisaged price should be the result of both fundamentals and expectations. When a bubble takes place, the price generating process unhinges from this pattern. Albeit a bubble is hardly determinable, the evidence affecting futures and spot prices shows that the arbitrage law has not been working perfectly in several commodity markets, such as corn, rice, soybean and wheat (OECD, 2008; Robles, Torero, von Braun, 2008), where futures and spot prices have not always converged at the time of delivery (WFP, 2009). Thus, the real issue turns out to be whether or not "prices are telling the truth about supply and demand" and "producers, investors, and policymakers [are] receiving the right signals to guide their actions" (Young J. E., 2008).

\section{$2.3 \quad$ NON-STATIONARITY IN COMMODITY FUTURES PRICES}

The assumption that commodity prices were affected by speculation, or at least by panic (Timmer, 2008), needs to be tested towards futures price time series.

The basic idea behind the price generation model refers to the attitude of prices to be caused by a deterministic process where the series fluctuates around a long run mean allowing a finite variance over time. In other words, fluctuations are transitory

\footnotetext{
${ }^{1}$ In its broader sense, defining "banning of exports is no different from hoarding at a national level", the ADB's managing director general, Rajat Nag, chided this over-reaction to soaring food prices (http://www.ft.com/cms/s/0/2a037e5a-102e-11dd-b8d6-0000779fd2ac.html?nclick_check=1).
} 
and random shocks may not have permanent effects in the price generation process, implying stationarity. On the other hand, non-stationary time series, on the basis of their stochastic trend, have no tendency to return to a long-run deterministic path and their variance is time dependent.

In this section, the stationarity hypothesis is tested through different unit root tests in order to assess its reliability as an empirical fact (Perron, 1989). If the series is non-stationary and the first difference of the series is stationary, the series contains a unit root, implying its tendency to explode.

Given their importance in terms of food consumption and the impact of a great volatility of the spot prices on the poor, the performances of corn, rice, soybean and wheat futures prices are investigated in the following sections. Being these commodities not properly homogeneous both in terms of food consumption - rice and wheat are the main staple food, while soybean and corn are also important to feed for livestock or as a source of biomass fuel - and in the ratio between amounts internationally traded and harvested - for example only a very limited percentage of rice $^{2}$ is internationally traded - they are a useful benchmark to address the dynamics of price generation.

Daily prices are used to improve the sampling frequency and gain in power (Choi and Chung, 1995). More, given the extensive number of observations, and in order to investigate smaller time lengths and gain detailed information on the behavior of the time-series, the sampled period, spanning from 2000 to 2009, is sectioned in 17 subperiods lasting six months, from January to June and from July to December, comprehending around 125 observations each.

A preliminary analysis of Figure 2.1 provides a broad indication on futures price trends. As it can be inferred, corn time-series remains quite flat until July 2006 with a slight bump in 2004:I - and afterwards has a constant upward trend from

\footnotetext{
${ }^{2}$ Corn futures contracts are traded in the Chicago Board of Trade; rice futures contracts in the National Commodity and Derivatives Exchange Ltd., the National Multi Commodity Exchange of India Ltd. and the Multi Commodity Exchange of India Ltd.; soybean futures contracts in the Chicago Board of Trade, the South African Futures Exchange, the Dalian Commodity Exchange, the Kansai Commodities Exchange, and the Tokyo Grain Exchange; wheat futures contracts in the Chicago Board of Trade, the Kansas City Board of Trade, and the Minneapolis Grain Exchange.
} 
September 2006, peaking around July 2008. The same happens to wheat, whose price starts to increase around March 2007. Rice prices are more unruly, and their long run towards the spike starts around July 2005. Lastly, soybean is quite steady too, with the exception of a sudden rise, and a consequential abrupt fall, in the period from July 2003 to July 2004. Again the price rush period falls between March 2006 and April 2008 suggesting an anomalous market behavior.

FIGURE 2.1: COMMODITY FUTURES PRICES

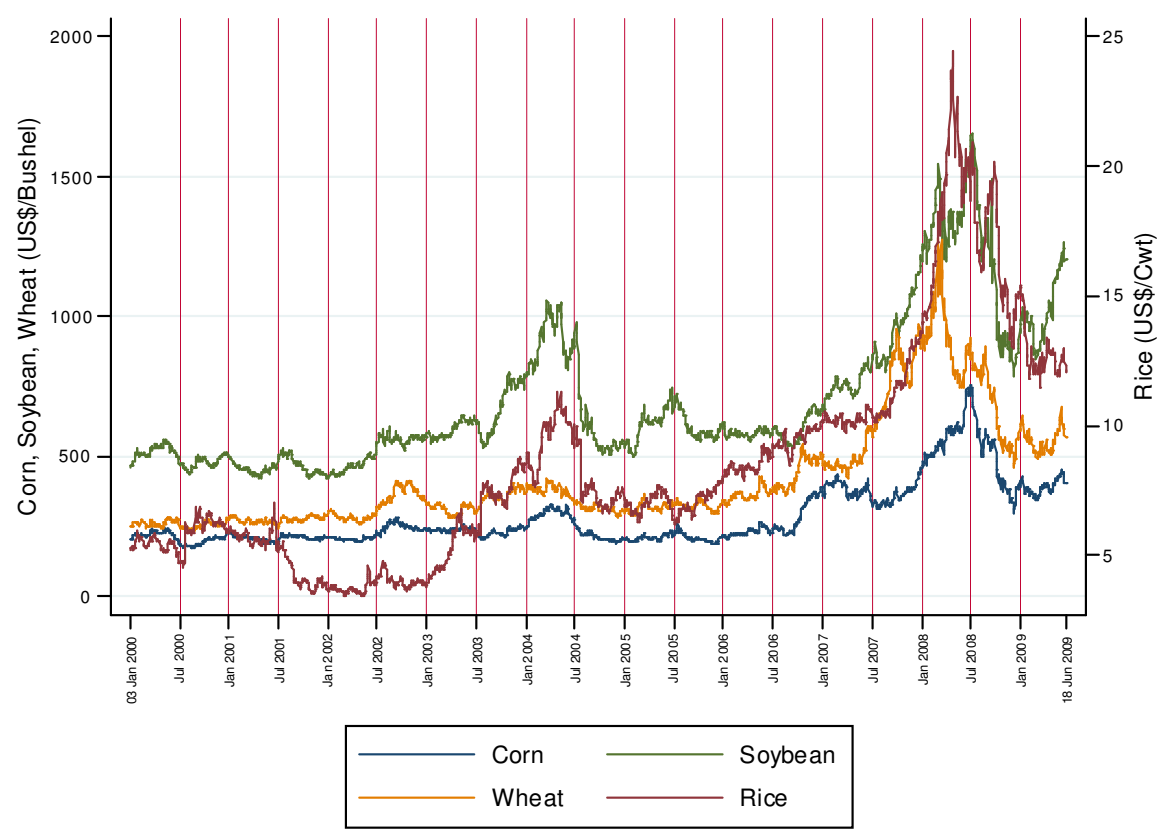

Roughly, the main fluctuations happened in the period July 2003 - July 2004, mainly owing to harvest failures, and since January 2006, with a chase between the four commodities to the higher price. It is noteworthy to highlight that, even after the second half of 2008 peaks and the consequent outburst of prices, evidence of a permanent upward shift in the pattern occurs.

Thus, it could preliminarily be asserted that the commodity futures prices investigated have all followed a growing pattern since mid 2006. Where the price generation process increases systematically as time goes by, and has no strength to move toward its mean (Maddala and Kim, 1998), soaring food prices might have been the result of one of the models below. 
Two widely used unit root tests are used to empirically study the nature of the commodity time series, e.g., the Augmented Dickey Fuller test (Dickey and Fuller, 1979) and the Phillips-Perron Test (Phillips and Perron, 1988) ${ }^{3}$. Both tests investigate, as a null hypothesis, the presence of a unit root, whether the alternative implies that the variable is generated by a stationary process.

Applying the right model implies adding or curtailing reliance to these tests. Hence, it is possible to address the following models, where the first one is by construction the most generic possible:

$$
\begin{aligned}
& Y=\alpha+\beta t+\rho Y_{t-1}+\sum_{i=1}^{k} \varphi_{i} \Delta Y_{t-i}+\varepsilon_{t} \\
& Y=\alpha+\rho Y_{t-1}+\sum_{i=1}^{k} \varphi_{i} \Delta Y_{t-i}+\varepsilon_{t} \\
& Y=\rho Y_{t-1}+\sum_{i=1}^{k} \varphi_{i} \Delta Y_{t-i}+\varepsilon_{t}
\end{aligned}
$$

where $Y$ refers to a commodity price, $\alpha$ is a constant term or drift, $\beta$ is a time trend and $\varepsilon$ refers to a random variable with zero mean and a constant variance $\sigma^{2}$.

A wrong specification of the deterministic part of the model might lead to an underrejecting of the null hypothesis. Thus, in order to avoid a bias towards a unit root, the most general model allowing both the trend and the constant terms will be firstly addressed (Dolado, Jenkinson, and Sosvilla-Rivero, 1990).

As long as the deterministic terms $\alpha$ and $\beta$ are not significant, further investigations allow the model to relax some of its assumptions, by first dropping the trend term and, afterwards, the drift trend. This procedure avoids loss of power ${ }^{4}$ due to inappropriate omissions of exogenous terms (Campbell and Perron, 1991).

\footnotetext{
3 "The distribution theory supporting the ADF/DF tests assumes that the errors are statistically independent and have a constant variance. Phillips and Perron (1988) developed a generalisation of the DF procedure that allows for fairly mild assumptions concerning of the errors" (Stoja and Tucker, 2004). Hereinafter ADF and PP tests.

${ }^{4}$ This loss of power, referring to the omitted terms, might wrongly indicate the presence of a unit root in the process (Enders, 1995).
} 
As put forward before, in order to enhance the flexibility of these tests by focusing on homogeneous periods, the sample has been portioned in different sub-periods. Hence, it would be possible to isolate, for any commodity, the growing, steady or shrinking state and, consequently, point out the model that better suits the data.

The number of lags is determined according to Schwartz Bayeisan Information Criteria $(\mathrm{BIC})^{5}$.

Tables $2.1-2.4$ provide ADF, PP and $\mathrm{NP}^{6}$ test statistics. Evidence of stationarity is found only in 2001, in 2003:17, and in 2008:Il for corn futures prices. Greater evidence can be found for rice in 2000:II , 2001:I, 2004:II, 2007:I, 2009:I. Rejections for soybean fall in 2002:II, 2004:II, and 2006:I, whereas for wheat in 2000:19 , and 2001:II.

So far, evidence of non-stationarity from figure 2.1 is confirmed by the above tests, even thought the rejections in 2007-2008 are in mild contrast with expectations. In the same period, the dynamics of prices are better defined by the presence of a drift and deterministic trend as per corn, rice and soybean. Conversely, evidence of a model with drift is found for wheat futures prices. Lag length usually rests to zero, in accordance with the Schwartz Information Criteria, which tends to reduce the number of lags in the model.

TABLE 2.1: ADF, PP AND NP UNIT ROOT TESTS ON CORN PRICES

\begin{tabular}{|c|c|c|c|c|c|c|}
\hline Year & & ADF & PP & B & NP & L \\
\hline $2000: 1$ & none & -0.436395 & (0) -0.438992 & (2) & -0.438992 & (0) \\
\hline $2000: 2$ & $t, c$ & -2.369597 & (0) -2.509654 & (2) & -4.235300 & (0) \\
\hline $2001: 1$ & $t, c$ & $-4.258467 * * *$ & (1) $-3.567599 * *$ & (6) & $-19.15650 * *$ & (1) \\
\hline $2001: 2$ & $t, c$ & $-4.867126 * * *$ & (0) $-4.833427 * * *$ & (6) & -6.258910 & (0) \\
\hline $2002: 1$ & none & 0.582333 & (0) 0.5948550 & (2) & 0.594855 & (0) \\
\hline $2002: 2$ & c & -1.942030 & (0) -1.886535 & (9) & 0.104603 & (0) \\
\hline $2003: 1$ & c & -2.284061 & (0) $-2.704822 *$ & (4) & -0.322890 & (0) \\
\hline $2003: 2$ & $t, c$ & -2.872855 & (0) -3.109176 & (5) & -7.104460 & (0) \\
\hline $2004: 1$ & c & -1.702713 & (0) -1.800976 & (4) & -0.040059 & (0) \\
\hline $2004: 2$ & $t, c$ & -2.951232 & (0) -2.963508 & (5) & -4.148630 & (0) \\
\hline $2005: 1$ & c & -2.075289 & (0) -2.290949 & (5) & 0.168483 & (0) \\
\hline $2005: 2$ & none & -0.504711 & (0) -0.508873 & (11) & -0.508873 & (0) \\
\hline $2006: 1$ & c & -1.689824 & (0) -1.776970 & (3) & 0.290972 & (0) \\
\hline
\end{tabular}

\footnotetext{
${ }^{5}$ The criteria selected tends to privilege a small number of lags. To find evidence in favour of BIC criteria see Stock (1994).

${ }^{6} \mathrm{Ng}$-Perron unit root test results are described in the next section.

${ }^{7}$ Null hypothesis rejected only in PP test.

${ }^{8}$ Null hypothesis rejected only in ADF test.

${ }^{9}$ Null hypothesis rejected only in PP test.
} 


\begin{tabular}{lllllll}
$2006: 2$ & $\mathrm{t}, \mathrm{c}$ & -1.891074 & $(0)-1.843893$ & $(4)-2.583270$ & $(0)$ \\
$2007: 1$ & $\mathrm{t}, \mathrm{c}$ & -2.198847 & $(0)-2.386125$ & $(3)$ & -6.258130 & $(0)$ \\
$2007: 2$ & $\mathrm{t}, \mathrm{c}$ & -1.694489 & $(0)-1.872673$ & $(5)$ & -6.352940 & $(0)$ \\
$2008: 1$ & $\mathrm{t}, \mathrm{c}$ & -2.121105 & $(0)-2.247982$ & $(5)$ & -9.379280 & $(0)$ \\
$2008: 2$ & $\mathrm{c}$ & $-2.714285 *$ & $(0)-2.597669 *$ & $(4)$ & $-2.315699 * *$ & $(0)$ \\
$2009: 1$ & $\mathrm{t}, \mathrm{c}$ & -2.878200 & $(0)-2.845633$ & $(5)$ & -5.835000 & $(0)$ \\
\hline \hline
\end{tabular}

\section{CRITICAL VALUES}

\begin{tabular}{lllll}
$10 \%$ & $\mathrm{t}, \mathrm{c}$ & -3.150127 & -3.150127 & -14.20000 \\
$5 \%$ & $\mathrm{t}, \mathrm{c}$ & -3.449716 & -3.449716 & -17.30000 \\
$1 \%$ & $\mathrm{t}, \mathrm{c}$ & -4.040532 & -4.040532 & -23.80000 \\
\hline $10 \%$ & $\mathrm{c}$ & -2.580402 & -2.580402 & -5.70000 \\
$5 \%$ & $\mathrm{c}$ & -2.886959 & -2.886959 & -8.10000 \\
$1 \%$ & $\mathrm{c}$ & -3.488585 & -3.488585 & -13.8000 \\
\hline $10 \%$ & none & -1.614866 & -1.614866 &
\end{tabular}

\begin{tabular}{|c|c|c|}
\hline $10 \%$ & none & -1.614866 \\
\hline $5 \%$ & none & -1.943662 \\
\hline
\end{tabular}

$1 \%$ none $\quad-2.585405 \quad-2.585405$

Note: Augmented Dickey-Fuller (ADF), Phillips-Perron (PP), and Ng-Perron (NP) unit root tests are computed with E-Views 6 . The notation "I" in the first column indicates the semester from January to June, whereas the notation "II" indicates the semester from July to December. The following notations represent the exogenous terms that may be included in the model: trend ( $t)$, constant (c), or none. The second column indicates the model that better suits data according to Doldado, Jenkinson and Sosvilla-Rivero (1990) procedure. Numbers in brackets are lag length (L) computed according to the Schwartz Info Criterion and Newey-West bandwith (B) as determined by Bartlett-Kernel. MZa statistics are computed in NP column (Perron, and Ng, 1996). The following notations represent different level of significance: ${ }^{*}$ at $10 \%,{ }^{* *}$ at $5 \%$ and ${ }^{* * *}$ at $1 \%$ (Null Hypothesis: corn time-series has a unit root). Source: Author's elaboration on Bloomberg's data.

TABLE 2.2: ADF, PP AND NP UNIT ROOT TESTS ON RICE PRICES

\begin{tabular}{|c|c|c|c|c|c|c|c|}
\hline Year & & ADF & L & $\mathrm{PP}$ & B & NP & $\mathrm{L}$ \\
\hline $2000: 1$ & none & -0.693496 & (0) & -0.658007 & (1) & -2.88961 & (0) \\
\hline $2000: 2$ & c & $-2.858518 *$ & (0) & 2.916254 & (3) & -1.47301 & (0) \\
\hline $2001: 1$ & C & $-4.116252 * * *$ & (4) & $-2.635005^{*}$ & (8) & $-72.8317 * * *$ & (4) \\
\hline $2001: 2$ & c & -2.236947 & (0) & -2.187128 & (3) & 0.55471 & (0) \\
\hline $2002: 1$ & c & -1.705684 & (0) & -1.908212 & (0) & -5.44703 & (0) \\
\hline $2002: 2$ & c & -1.752091 & (0) & -1.858969 & (2) & -4.34356 & (0) \\
\hline $2003: 1$ & none & 1.1596420 & (0) & 1.249758 & (3) & 0.14949 & (0) \\
\hline $2003: 2$ & c & -1.778252 & (0) & -1.778252 & (2) & 0.12321 & (0) \\
\hline $2004: 1$ & none & 0.4756170 & (0) & 0.446327 & (0) & -1.48804 & (0) \\
\hline $2004: 2$ & c & $-2.881878^{*}$ & (0) & $-2.870565^{*}$ & (4) & -0.70967 & (0) \\
\hline $2005: 1$ & none & -0.486156 & (0) & -0.500077 & (8) & -3.88285 & (0) \\
\hline $2005: 2$ & $t, c$ & -3.127023 & (0) & -3.146217 & (3) & $-17.2379 *$ & (0) \\
\hline $2006: 1$ & $t, c$ & -2.431009 & (0) & -2.492154 & (6) & -12.0252 & (0) \\
\hline $2006: 2$ & $t, c$ & -2.564217 & (0) & -2.797309 & (5) & -12.0191 & (0) \\
\hline $2007: 1$ & c & $-3.123180 * *$ & (0) & $-3.110948 * *$ & (4) & $-16.4123 * * *$ & (0) \\
\hline $2007: 2$ & $t, c$ & -2.865519 & (0) & -2.794572 & (4) & -7.03583 & (0) \\
\hline $2008: 1$ & c & -1.655127 & (1) & -1.639760 & (3) & -0.63375 & (1) \\
\hline $2008: 2$ & c & -1.976560 & (0) & -1.989630 & (3) & -0.20350 & (0) \\
\hline $2009: 1$ & c & $-3.620173 * * *$ & (0) & $-3.618974 * * *$ & (5) & -0.38838 & (0) \\
\hline
\end{tabular}

CRITICAL VALUES

\begin{tabular}{ccccc}
\hline $10 \%$ & $\mathrm{t}, \mathrm{c}$ & -3.150127 & -3.150127 & -14.20000 \\
$5 \%$ & $\mathrm{t}, \mathrm{c}$ & -3.449716 & -3.449716 & -17.30000 \\
$1 \%$ & $\mathrm{t}, \mathrm{c}$ & -4.040532 & -4.040532 & -23.80000 \\
\hline $10 \%$ & $\mathrm{c}$ & -2.580402 & -2.580402 & -5.70000 \\
$5 \%$ & $\mathrm{c}$ & -2.886959 & -2.886959 & -8.10000 \\
$1 \%$ & $\mathrm{c}$ & -3.488585 & -3.488585 & -13.8000 \\
\hline $10 \%$ & none & -1.614866 & -1.614866 & \\
$5 \%$ & none & -1.943662 & -1.943662 & \\
$1 \%$ & none & -2.585405 & -2.585405 & \\
\hline
\end{tabular}


Note: Augmented Dickey-Fuller (ADF), Phillips-Perron (PP), and Ng-Perron (NP) unit root tests are computed with E-Views 6 . The notation ":I" in the first column indicates the semester from January to June, whereas the notation ":II" indicates the semester from July to December. The following notations represent the exogenous terms that may be included in the model: trend ( $t)$, constant (c), or none. The second column indicates the model that better suits data according to Doldado, Jenkinson and Sosvilla-Rivero (1990) procedure. Numbers in brackets are lag length (L) computed according to the Schwartz Info Criterion and Newey-West bandwith (B) as determined by Bartlett-Kernel. MZa statistics are computed in NP column (Perron, and Ng, 1996). The following notations represent different level of significance: ${ }^{*}$ at $10 \%,{ }^{* *}$ at $5 \%$ and ${ }^{* * *}$ at $1 \%$ (Null Hypothesis: rice time-series has a unit root). Source: Author's elaboration on Bloomberg's data.

TABLE 2.3: ADF, PP AND NP UNIT ROOT TESTS ON SOYBEAN PRICES

\begin{tabular}{|c|c|c|c|c|c|}
\hline Year & & ADF & PP & NP & $\mathrm{L}$ \\
\hline $2000: 1$ & c & -2.132284 & (0) -2.047844 & (5) -1.49220 & (0) \\
\hline $2000: 2$ & $t, c$ & -2.149221 & (0) 2.233114 & (4) -5.98312 & (0) \\
\hline $2001: 1$ & c & -2.493600 & (0) -2.433769 & (2) -1.47224 & (0) \\
\hline $2001: 2$ & $t, c$ & -2.679994 & (0) -2.759014 & (5) -7.98480 & (0) \\
\hline $2002: 1$ & $t, c$ & -2.072583 & (0) -2.312196 & (1) -12.0242 & (0) \\
\hline $2002: 2$ & c & $-3.329631 * *$ & (0) $-3.629650 * * *$ & (3) $-9.48395 * *$ & (0) \\
\hline $2003: 1$ & $t, c$ & -3.046783 & (0) -3.072999 & (4) -7.51150 & (0) \\
\hline $2003: 2$ & $t, c$ & -2.727978 & (0) -2.710153 & (1) -3.68169 & (0) \\
\hline $2004: 1$ & C & -1.844114 & (0) -1.903549 & (7) -1.94766 & (0) \\
\hline $2004: 2$ & C & $-3.968839 * * *$ & (0) $-3.812367 * * *$ & (2) 0.26218 & (0) \\
\hline $2005: 1$ & none & 0.801094 & (0) 0.667811 & (5) -0.58738 & (0) \\
\hline $2005: 2$ & C & -2.434056 & (0) -2.447715 & (3) -0.37090 & (0) \\
\hline $2006: 1$ & $t, c$ & $-4.487666 * * *$ & (0) $-4.632482 * * *$ & (5) -7.69461 & (2) \\
\hline $2006: 2$ & $t, c$ & -1.805923 & (0) -1.793329 & (5) -1.52126 & (0) \\
\hline $2007: 1$ & none & 1.604660 & (0) 1.602298 & (3) 0.89284 & (0) \\
\hline $2007: 2$ & $t, c$ & -2.381375 & (0) -2.378564 & (2) -5.32864 & (0) \\
\hline $2008: 1$ & none & 0.962415 & (0) 1.025258 & (5) -0.81386 & (0) \\
\hline $2008: 2$ & $t, c$ & -2.509095 & (1) -2.269748 & (6) -9.20561 & (1) \\
\hline $2009: 1$ & $t, c$ & -1.848455 & (0) -1.712533 & (7) -3.48987 & (0) \\
\hline
\end{tabular}

\begin{tabular}{ccccc}
\multicolumn{6}{c}{ CRITICAL VALUES } & & & \\
\hline $10 \%$ & $\mathrm{t}, \mathrm{c}$ & -3.150127 & -3.150127 & -14.20000 \\
$5 \%$ & $\mathrm{t}, \mathrm{c}$ & -3.449716 & -3.449716 & -17.30000 \\
$1 \%$ & $\mathrm{t}, \mathrm{c}$ & -4.040532 & -4.040532 & -23.80000 \\
\hline $10 \%$ & $\mathrm{c}$ & -2.580402 & -2.580402 & -5.70000 \\
$5 \%$ & $\mathrm{c}$ & -2.886959 & -2.886959 & -8.10000 \\
$1 \%$ & $\mathrm{c}$ & -3.488585 & -3.488585 & -13.8000 \\
\hline $10 \%$ & none & -1.614866 & -1.614866 & \\
$5 \%$ & none & -1.943662 & -1.943662 & \\
$1 \%$ & none & -2.585405 & -2.585405 & \\
\hline
\end{tabular}

Note: Augmented Dickey-Fuller (ADF), Phillips-Perron (PP), and Ng-Perron (NP) unit root tests are computed with E-Views 6. The notation ":I" in the first column indicates the semester from January to June, whereas the notation ":II" indicates the semester from July to December. The following notations represent the exogenous terms that may be included in the model: trend ( $t$ ), constant (c), or none. The second column indicates the model that better suits data according to Doldado, Jenkinson and Sosvilla-Rivero (1990) procedure. Numbers in brackets are lag length (L) computed according to the Schwartz Info Criterion and Newey-West bandwith (B) as determined by Bartlett-Kernel. MZa statistics are computed in NP column (Perron, and Ng, 1996). The following notations represent different level of significance: ${ }^{*}$ at $10 \%,{ }^{* *}$ at $5 \%$ and ${ }^{* * *}$ at $1 \%$ (Null Hypothesis: soybean time-series has a unit root). Source: Author's elaboration on Bloomberg's data.

TABLE 2.4: ADF, PP AND NP UNIT ROOT TESTS ON WHEAT PRICES

\begin{tabular}{|c|c|c|c|c|c|c|c|}
\hline Year & & ADF & L & PP & B & NP & $\mathrm{L}$ \\
\hline $2000: 1$ & c & -2.560345 & (0) & $-2.744055^{*}$ & (2) & -4.87790 & (0) \\
\hline $2000: 2$ & $t, c$ & 2.406114 & (0) & 2.488710 & (2) & -9.58823 & (0) \\
\hline $2001: 1$ & $t, c$ & -2.835367 & (0) & -3.019107 & (4) & -14.0101 & (0) \\
\hline $2001: 2$ & C & $-3.203786 * *$ & (0) & $-3.183417 * *$ & (1) & -2.07208 & (0) \\
\hline $2002: 1$ & none & 0.094252 & (0) & 0.112174 & (4) & -2.48580 & (0) \\
\hline $2002: 2$ & none & -0.022905 & (0) & -0.022516 & (2) & -1.61584 & (0) \\
\hline $2003: 1$ & c & -1.955340 & (0) & -2.052903 & (6) & -4.03574 & (0) \\
\hline $2003: 2$ & c & -2.236577 & (0) & -2.295105 & (1) & -0.83708 & (0) \\
\hline $2004: 1$ & c & -1.833059 & (0) & -1.833059 & (0) & -4.74953 & (0) \\
\hline $2004: 2$ & c & -2.478597 & (0) & -2.521725 & (3) & -3.23132 & (0) \\
\hline
\end{tabular}




\begin{tabular}{lllllll}
$2005: 1$ & $c$ & -2.019997 & $(0)-2.256142$ & $(5)-3.76142$ & $(0)$ \\
$2005: 2$ & $c$ & -1.715761 & $(0)-1.922859$ & $(6)-3.63401$ & $(0)$ \\
$2006: 1$ & none & 0.387547 & $(0)$ & 0.325896 & $(6)-3.31167$ & $(0)$ \\
$2006: 2$ & none & 0.800827 & $(0)$ & 0.824190 & $(4)-0.29527$ & $(0)$ \\
$2007: 1$ & t, c & -1.849179 & $(0)-1.842863$ & $(4)-4.48396$ & $(0)$ \\
$2007: 2$ & c & -1.624800 & $(0)-1.631843$ & $(4)-0.30282$ & $(0)$ \\
$2008: 1$ & none & -0.329358 & $(2)-0.469112$ & $(5)-3.67071$ & $(2)$ \\
$2008: 2$ & none & $-1.699441 *$ & $(1)-1.453441$ & $(4)-0.01459$ & $(1)$ \\
$2009: 1$ & c & -2.340156 & $(0)-2.229458$ & $(7)-4.02310$ & $(0)$ \\
\hline \hline
\end{tabular}

\section{CRITICAL VALUES}

\begin{tabular}{lllll}
\hline $10 \%$ & $t, c$ & -3.150127 & -3.150127 & -14.20000 \\
$5 \%$ & $t, c$ & -3.449716 & -3.449716 & -17.30000 \\
$1 \%$ & $t, c$ & -4.040532 & -4.040532 & -23.80000 \\
\hline $10 \%$ & $c$ & -2.580402 & -2.580402 & -5.70000 \\
$5 \%$ & $c$ & -2.886959 & -2.886959 & -8.10000 \\
$1 \%$ & $c$ & -3.488585 & -3.488585 & -13.8000 \\
\hline $10 \%$ & none & -1.614866 & -1.614866 & \\
$5 \%$ & none & -1.943662 & -1.943662 & \\
$1 \%$ & none & -2.585405 & -2.585405 & \\
\hline
\end{tabular}

Note: Augmented Dickey-Fuller (ADF), Phillips-Perron (PP), and Ng-Perron (NP) unit root tests are computed with E-Views 6 . The notation ":l" in the first column indicates the semester from January to June, whereas the notation ":Il" indicates the semester from July to December. The following notations represent the exogenous terms that may be included in the model: trend ( $t$ ), constant (c), or none. The second column indicates the model that better suits data according to Doldado, Jenkinson and Sosvilla-Rivero (1990) procedure. Numbers in brackets are lag length (L) computed according to the Schwartz Info Criterion and Newey-West bandwith (B) as determined by Bartlett-Kernel. MZa statistics are computed in NP column (Perron, and Ng, 1996). The following notations represent different level of significance: ${ }^{*}$ at $10 \%,{ }^{* *}$ at $5 \%$ and ${ }^{* * *}$ at $1 \%$ (Null Hypothesis: wheat time-series has a unit root). Source: Author's elaboration on Bloomberg's data

Although those tests are widely used but strongly criticized, the evidence on size distortions and low power they produce is widely accepted (Schwert, 1989, De Jong et al., 1992). In particular, the PP test suffers from serious size distortions when there are negative MA errors while the ADF test is less powerful than the PP test even though it does not suffer from these serious size distortions (Maddala and Kim, 1998).

\subsection{DETECTING OUTLIERS}

The over-rejection and under-rejection of the null hypothesis in the ADF and PP framework might be determined by the presence of outliers, which are aberrant observations away from the rest of the data, mainly determined by unusual events, such as changes in economic policies, wars and disaster (Perron, 1989). 
Thus, two approaches are used in this paper to deal with possible inconsistencies occurred in presence of additive outliers. The first, as proposed by $\mathrm{Ng}$ and Perron (1996), modifies the PP test ${ }^{10}$ in order to maintain good power while correcting size distortion problems in the presence of negative MA errors. These proposed unit root tests are robust to negative MA errors with a root close to unity, which might be a consequence of additive outliers. Moreover, as further achievement, the order of MA components and the outliers need not be specified before applying the unit root test (Maddala and Kim, 1998) ${ }^{11}$. Hence, these unit root tests are little affected by systematic outliers (Perron and Rodriguez, 2003).

The results of NP unit root test in Tables 2.1-2.4 are in line with previous ADF and PP statistics, even though null hypothesis rejections still shrink ${ }^{12}$. Only very few periods in the sample reject the null hypothesis of non-stationarity.

The second approach is to get rid of outliers allowing for their endogenous identification (Perron and Vogelsang, 1992, Clemente et al., 1998) ${ }^{13}$. Here outliers are defined additive outliers, when a particular, abnormal, observation does not affect the subsequent ones and innovational outliers, where the effect of a large innovation is perpetrated through the dynamics of the model (Fox, 1972). A model allowing these two different structural breaks was suggested by Perron and Vogelsang (1992), where a set of test statistics ${ }^{14}$ is reckoned both in the Additive Outlier (AO) model - where a sudden change in the mean might be the outcome of recording

\footnotetext{
${ }^{10}$ The statistics proposed as a modification of PP tests are $\mathrm{MZ}_{\rho}$ and $\mathrm{MZ}_{\mathrm{t}}$ plus MSB and MPT. For the sake of simplification, only $\mathrm{MZ}_{\rho}$ statistics are reported in the rest of the paper.

${ }^{11}$ This is in advantage to increased accuracy as compared to the procedures that impose the researcher a previous exogenous identification of outliers, as in Perron (1989).

${ }^{12}$ The NP tests only model with a time trend and a drift or a drift. Provided its comparative purpose towards the ADF and PP tests, where nor a drift and trend or a drift is the model that better suits the sub-period, it is investigated as if it was a model with a drift. The sub-periods graphical analysis provides comfort to this approximation.

${ }^{13}$ Unit root tests may suffer from a bias towards non-rejection driven by a shift in a stationary time series. This issue was first addressed by Perron (1990a). He allowed for the presence of two exogenously identified breaks, namely the 1929 crash and the oil crisis in the 1973. Yet, this outliers treating strategy implies a "trade-off between the power of the test and the amount of information incorporated with respect to the choice of break point" (Perron, 1997).

${ }^{14}$ Following to the works of Banerjee, Lumsdaine and Stock (1992), Zivot and Andrews (1992), and Perron (1990b), Perron and Vogelsang (1992) argued that those class of statistics "are based on the minimal value, over all possible breakpoints, of the $t$ statistic on the sum of the autoregressive coefficients in the appropriate augmented autoregression".
} 
errors, natural disasters or a bizarre day on the stock market - and in the Innovational Outlier (IO) model - where the change takes place gradually, usually driven by an external cause ${ }^{15}$.

Following through this approach, the Dickey Fuller unit root test is thus modified allowing for dummy variables to account for a structural change in the mean and detect outliers in level, permitting a shift under the null hypothesis of a unit root. Thus, the limiting distributions are invariant to a mean shift but not to a change in slope, both in the AO and IO frameworks (Maddala and Kim, 2008).

Hence, according to Perron and Vogelsang (1992) and considering that the shifts are better represented as additive outliers, in the $\mathrm{AO}$ model the change is assumed to take place instantaneously, and the two-step strategy to apply "is to first remove an estimate of the deterministic part of the series and to test if the remaining noise is characterized by the presence of a unit root":

$$
\begin{aligned}
& Y=\alpha+\delta D U_{t}+\tilde{Y}_{t} \\
& \tilde{Y}_{t}=\sum_{i=1}^{k} \omega_{t} D T b_{t}+\rho \tilde{Y}_{t-1}+\sum_{i=1}^{k} \varphi_{i} \Delta \tilde{Y}_{t-i}+\varepsilon_{t}
\end{aligned}
$$

where DU assumes the value 1 when $t>T b$ and 0 otherwise, DTb assumes the value 1 when $\mathrm{t}=\mathrm{Tb}+1$ and 0 otherwise, and $\mathrm{Tb}$ is the break point.

On the other hand, in the innovational outlier model, the change in the mean is supposed to have an effect on the level of the series gradually as well as any other shock to the model (Perron and Vogelsang, 1992):

$$
Y=\alpha+\delta D U_{t}+\phi D T b_{t}+\rho Y_{t-1}+\sum_{i=1}^{k} \varphi_{i} \Delta Y_{t-i}+\varepsilon_{t}
$$

Once additive outliers are detected (table 2.5), the series turn out to be definitively non-stationary, with the only exceptions, at the 10\% of significance, of 2001:II (wheat) and 2006:I (rice and soybean), and 2009:I (rice).

Keeping in mind that the detection of innovational outliers is by far less important in terms of reliability of the unit root test and unlike the majority of the literature ${ }^{16}$,

\footnotetext{
${ }^{15}$ To the extent of this chapter the investigation is limited to additive and innovational outliers. Refer to Tsay (1988) for an extended outliers classification.
} 
table 2.6 shows the results for the innovational outliers model, where similar conclusions may be withdrawn when detecting outliers for corn, soybean and wheat. Unlike the other commodities explored, rice futures prices have been influenced in five different sub-periods by some innovative events.

The detecting power of this approach is limited, by construction, to a single break per period.

TABLE 2.5: UNIT ROOT TEST ALLOWING FOR ONE STRUCTURAL BREAK: ADDITIVE OUTLIERS

\begin{tabular}{|c|c|c|c|c|c|c|c|c|}
\hline Year & $\begin{array}{l}\text { Corn } \\
d u 1\end{array}$ & $\rho-1$ & $\begin{array}{l}\text { Rice } \\
d u 1\end{array}$ & $\rho-1$ & $\begin{array}{l}\text { Soybean } \\
\text { du1 }\end{array}$ & $\rho-1$ & $\begin{array}{l}\text { Wheat } \\
\text { du1 }\end{array}$ & $\rho-1$ \\
\hline $2000: \mathrm{I}$ & $15 / 06 / 00$ & -2.360 & $21 / 06 / 00$ & -2.738 & $19 / 06 / 00$ & -2.937 & $05 / 05 / 00$ & -2.944 \\
\hline 2000 :II & $05 / 10 / 00$ & -1.916 & $24 / 07 / 00$ & -3.492 & 06/09/00 & -2.324 & 19/09/00 & -2.809 \\
\hline 2001 :I & $25 / 04 / 01$ & -4.352 & $14 / 06 / 01$ & -2.300 & $07 / 06 / 01$ & -2.805 & $30 / 01 / 01$ & -3.060 \\
\hline 2001 :II & 08/10/01 & -2.525 & $16 / 08 / 01$ & -3.457 & $13 / 09 / 01$ & -3.332 & $11 / 10 / 01$ & $-4.647^{*}$ \\
\hline 2002 :I & $19 / 06 / 02$ & -2.874 & $30 / 05 / 02$ & -3.340 & $21 / 05 / 02$ & -2.438 & $14 / 06 / 02$ & -2.679 \\
\hline 2002 :II & & -2.691 & 08/08/02 & -4.163 & $22 / 07 / 02$ & -2.319 & $13 / 12 / 02$ & -1.528 \\
\hline 2003 :I & $12 / 05 / 03$ & -3.265 & $01 / 04 / 03$ & -3.789 & 09/04/03 & -4.221 & $28 / 02 / 03$ & -1.849 \\
\hline 2003 :II & $24 / 10 / 03$ & -3.235 & $14 / 11 / 03$ & -3.036 & $03 / 10 / 03$ & -2.935 & $30 / 10 / 03$ & -3.616 \\
\hline $2004: \mathrm{I}$ & $16 / 06 / 04$ & -1.850 & $02 / 03 / 04$ & -3.484 & & -1.096 & $28 / 05 / 04$ & -3.250 \\
\hline 2004 :II & $13 / 09 / 04$ & -4.366 & $19 / 07 / 04$ & -1.056 & $19 / 07 / 04$ & -1.715 & $15 / 11 / 04$ & -3.089 \\
\hline $2005: \mathrm{I}$ & $24 / 05 / 05$ & -2.819 & $16 / 03 / 05$ & -1.236 & $01 / 03 / 05$ & -2.126 & $11 / 03 / 05$ & -2.768 \\
\hline 2005 :II & 08/08/05 & -2.164 & $23 / 09 / 05$ & -2.237 & $10 / 08 / 05$ & -4.303 & $21 / 12 / 05$ & -2.577 \\
\hline $2006: \mathrm{I}$ & $03 / 04 / 06$ & -2.747 & $17 / 05 / 06$ & $-4.679 *$ & $01 / 05 / 06$ & $-4.738 *$ & $18 / 05 / 06$ & -2.453 \\
\hline 2006 :II & $18 / 10 / 06$ & -2.796 & 20/09/06 & -2.821 & $18 / 10 / 06$ & -3.002 & 29/09/06 & -4.358 \\
\hline $2007: \mathrm{I}$ & 27/03/07 & -2.596 & 06/06/07 & -3.940 & $17 / 05 / 07$ & -2.832 & 06/06/07 & -4.252 \\
\hline 2007 :II & $18 / 12 / 07$ & -2.146 & $07 / 11 / 07$ & -1.539 & $30 / 10 / 07$ & -1.805 & 06/09/07 & -2.950 \\
\hline $2008: I$ & 06/06/08 & -2.310 & $13 / 03 / 08$ & -3.059 & 06/06/08 & -3.119 & $02 / 04 / 08$ & -2.535 \\
\hline 2008 :II & $01 / 10 / 08$ & -3.359 & $06 / 10 / 08$ & -2.586 & $10 / 09 / 08$ & -2.933 & 29/09/08 & -3.215 \\
\hline 2009 :I & 04/05/09 & -3.183 & $14 / 01 / 09$ & $-4.576 *$ & 24/04/09 & -3.032 & 04/05/09 & -3.091 \\
\hline
\end{tabular}

TABLE 2.6: UNIT ROOT TEST ALLOWING FOR ONE STRUCTURAL BREAK: INNOVATIONAL OUTLIERS

\begin{tabular}{lllllllll}
\hline \hline & Corn & & Rice & \multicolumn{3}{c}{ Soybean } & \multicolumn{3}{c}{ Wheat } \\
Year & $d u 1$ & $\rho-1$ & du1 & $\rho-1$ & $d u 1$ & $\rho-1$ & $d u 1$ & $\rho-1$ \\
\hline $2000:$ I & $05 / 06 / 00$ & -3.251 & $17 / 04 / 00$ & -4.069 & & -1.951 & $26 / 04 / 00$ & $-4.791^{*}$ \\
$2000:$ II & $13 / 09 / 00$ & -2.245 & $19 / 07 / 00$ & $-6.291^{* * *}$ & $08 / 08 / 00$ & -2.657 & $13 / 09 / 00$ & -3.555 \\
$2001:$ I & $17 / 04 / 01$ & -4.065 & & -4.251 & $29 / 05 / 01$ & -2.686 & $23 / 01 / 01$ & -3.327 \\
\hline \hline
\end{tabular}

\footnotetext{
${ }^{16}$ See, for example, Perron and Rodriguez (2003).
} 


\begin{tabular}{|c|c|c|c|c|c|c|c|}
\hline 2001 :II $10 / 10 / 01$ & $-4.849 * *$ & $17 / 08 / 01$ & -3.809 & $14 / 08 / 01$ & -2.929 & 01/10/01 & -4.048 \\
\hline 2002 : I 03/05/02 & -2.098 & $20 / 05 / 02$ & $-4.847 * *$ & $06 / 05 / 02$ & -1.995 & & -1.905 \\
\hline 2002 :II 13/09/02 & -3.159 & $31 / 07 / 02$ & -4.375 & & -4.059 & $26 / 11 / 02$ & -1.801 \\
\hline 2003 :I $\quad 01 / 05 / 03$ & -4.031 & $17 / 03 / 03$ & -2.895 & $31 / 03 / 03$ & -4.285 & & -2.314 \\
\hline 2003 :II 20/10/03 & -3.915 & $10 / 11 / 03$ & -3.096 & $16 / 09 / 03$ & -3.013 & $16 / 10 / 03$ & -4.289 \\
\hline 2004 :I $\quad 08 / 06 / 04$ & -2.202 & $20 / 02 / 04$ & -3.427 & $12 / 05 / 04$ & -2.707 & $06 / 05 / 04$ & -3.359 \\
\hline 2004 :II $31 / 08 / 04$ & $-4.664 *$ & $20 / 07 / 04$ & $-6.78 * * *$ & & -3.444 & $17 / 11 / 04$ & -3.244 \\
\hline $2005:$ : $12 / 05 / 05$ & -3.514 & 04/03/05 & -1.722 & $15 / 02 / 05$ & -3.233 & $17 / 02 / 05$ & -3.499 \\
\hline 2005 :II $15 / 07 / 05$ & -4.257 & $19 / 09 / 05$ & -3.344 & 01/08/05 & -4.235 & & -3.720 \\
\hline $23 / 03 / 06$ & -2.938 & $10 / 05 / 06$ & $-4.643 *$ & $26 / 04 / 06$ & $-5.479 * * *$ & $03 / 05 / 06$ & -4.071 \\
\hline 2006 :II 05/10/06 & -2.600 & 06/09/06 & -3.157 & $10 / 10 / 06$ & -3.770 & $13 / 09 / 06$ & -3.825 \\
\hline 2007 :I $21 / 03 / 07$ & -2.622 & 07/06/07 & $-5.561 * * *$ & 09/05/07 & -3.725 & 07/06/07 & -3.332 \\
\hline 2007 :II & 0.826 & 29/10/07 & -2.591 & $20 / 08 / 07$ & -1.089 & $17 / 08 / 07$ & -2.768 \\
\hline 2008 :I $\quad 03 / 06 / 08$ & -2.597 & & -2.517 & 02/06/08 & -3.089 & $17 / 03 / 08$ & -3.575 \\
\hline 2008 :II 24/09/08 & -4.215 & 24/09/08 & -4.147 & $11 / 09 / 08$ & $-4.799 *$ & $24 / 09 / 08$ & -3.375 \\
\hline 2009 :I $\quad 27 / 04 / 09$ & -3.343 & & -3.641 & $27 / 04 / 09$ & -3.175 & $05 / 05 / 09$ & -4.021 \\
\hline
\end{tabular}

Thus, Clemente, Montañés and Reyes (1998) emphasized the issue of determining the correct number of breaks and improved the model allowing for two breaks. Accordingly, models [2.4] and [2.5] exploited to test the unit root hypothesis in the case of one structural break, are extended as follows:

$$
\begin{aligned}
& Y=\alpha+\delta_{1} D U_{1 t}+\delta_{2} D U_{2 t}+\tilde{Y}_{t} \\
& \tilde{Y}_{t}=\sum_{i=1}^{k} \omega_{1 t} D T b_{1 t}+\sum_{i=1}^{k} \omega_{2 t} D T b_{2 t}+\rho \tilde{Y}_{t-1}+\sum_{i=1}^{k} \varphi_{i} \Delta \tilde{Y}_{t-i}+\varepsilon_{t} \\
& Y=\alpha+\delta_{1} D U_{1 t}+\delta_{2} D U_{2 t}+\phi_{1} D T b_{1 t}+\phi_{2} D T b_{2 t}+\rho Y_{t-1}+\sum_{i=1}^{k} \varphi_{i} \Delta Y_{t-i}+\varepsilon_{t}
\end{aligned}
$$

Provided these implementations, the chances to have a unit root test biased towards non-rejection is lessened (Perron, 1989). Empirical analysis have illustrated results in marked contrast with the ones obtained when using the ADF test or the Perron and Vogelsang statistics (Clemente et al. 1998). As an evidence, Table 2.7 shows rejections of the null hypothesis for corn (2001:I, and 2007:I), rice (2002:II, 2004:II, 
and 2006:II), and soybean (2007:I), whereas wheat prices are found to be nonstationary in all the considered semesters.

Similarly, Table 2.8 shows that innovative events influenced corn and soybean price generation process respectively in eight and in five sub-periods.

TABLE 2.7: UNIT ROOT TEST ALLOWING FOR TWO STRUCTURAL BREAKS: ADDITIVE OUTLIERS

\begin{tabular}{|c|c|c|c|c|c|c|c|c|c|c|c|c|}
\hline Year & $\begin{array}{l}\text { Corn } \\
d u 1\end{array}$ & $d u 2$ & $\rho-1$ & $\begin{array}{l}\text { Rice } \\
\text { du1 }\end{array}$ & $d u 2$ & $\rho-1$ & $\begin{array}{l}\text { Soybean } \\
\text { du1 }\end{array}$ & du2 & $\rho-1$ & $\begin{array}{l}\text { Wheat } \\
\text { du1 }\end{array}$ & $d u 2$ & $\rho-1$ \\
\hline $2000: I$ & $15 / 03 / 00$ & $07 / 06 / 00$ & -4.473 & $14 / 04 / 00$ & $21 / 06 / 00$ & -3.115 & $20 / 03 / 00$ & $31 / 05 / 00$ & -3.590 & $24 / 02 / 00$ & $05 / 05 / 00$ & -4.103 \\
\hline 2000 :II & I 25/09/00 & $19 / 12 / 00$ & -2.882 & $18 / 07 / 00$ & $24 / 08 / 00$ & -2.169 & $18 / 08 / 00$ & $27 / 11 / 00$ & -2.243 & $19 / 09 / 00$ & & -2.964 \\
\hline 2001 :I & $18 / 04 / 01$ & $18 / 06 / 01$ & $-2.922 * * *$ & $16 / 03 / 01$ & 06/06/01 & -6.375 & 08/03/01 & $25 / 05 / 01$ & -3.750 & $30 / 01 / 01$ & $06 / 06 / 01$ & -5.016 \\
\hline 2001 :II & I 09/10/01 & $12 / 12 / 01$ & -3.310 & 08/08/01 & $31 / 08 / 01$ & -4.101 & $21 / 08 / 01$ & $01 / 10 / 01$ & -4.573 & & $11 / 10 / 01$ & -3.773 \\
\hline 2002 :I & $04 / 04 / 02$ & $08 / 05 / 02$ & -1.244 & $23 / 05 / 02$ & & -2.334 & 04/03/02 & $10 / 05 / 02$ & -3.372 & $25 / 03 / 02$ & $05 / 06 / 02$ & -2.671 \\
\hline 2002 :II & I 06/08/02 & $15 / 10 / 02$ & -4.137 & & 08/08/02 & $-3.436 * * *$ & $24 / 09 / 02$ & $24 / 10 / 02$ & -6.041 & $29 / 08 / 02$ & $25 / 11 / 02$ & -3.895 \\
\hline 2003 :I & $12 / 05 / 03$ & $20 / 05 / 03$ & -3.852 & $14 / 03 / 03$ & $10 / 04 / 03$ & -4.060 & $28 / 03 / 03$ & $23 / 04 / 03$ & -4.814 & $12 / 03 / 03$ & $06 / 05 / 03$ & -2.366 \\
\hline 2003 :II & I 07/08/03 & $24 / 10 / 03$ & -2.582 & $24 / 07 / 03$ & $14 / 11 / 03$ & -3.338 & $15 / 09 / 03$ & $15 / 10 / 03$ & -3.871 & $24 / 07 / 03$ & $30 / 10 / 03$ & -4.460 \\
\hline 2004 :I & $10 / 03 / 04$ & $11 / 06 / 04$ & -2.403 & $02 / 03 / 04$ & $27 / 04 / 04$ & -3.816 & $25 / 02 / 04$ & $18 / 05 / 04$ & -4.269 & $18 / 03 / 04$ & $16 / 04 / 04$ & -3.277 \\
\hline 2004 :II & I 23/07/04 & $15 / 09 / 04$ & -4.998 & $19 / 07 / 04$ & $17 / 09 / 04$ & $-0.924 * *$ & $19 / 07 / 04$ & $09 / 09 / 04$ & -5.810 & $13 / 09 / 04$ & $15 / 11 / 04$ & -3.520 \\
\hline 2005 :I & $11 / 03 / 05$ & $24 / 05 / 05$ & -3.814 & $16 / 03 / 05$ & $16 / 06 / 05$ & -3.269 & $22 / 02 / 05$ & $26 / 05 / 05$ & -4.489 & $01 / 03 / 05$ & $24 / 03 / 05$ & -2.260 \\
\hline 2005 :II & I 08/08/05 & $25 / 10 / 05$ & -3.536 & $23 / 09 / 05$ & $30 / 11 / 05$ & -4.268 & $10 / 08 / 05$ & 01/09/05 & -4.472 & $26 / 09 / 05$ & $25 / 10 / 05$ & -2.087 \\
\hline 2006 :I & $03 / 04 / 06$ & & -2.811 & $17 / 05 / 06$ & 08/06/06 & $-5.173 * * *$ & $28 / 03 / 06$ & $25 / 04 / 06$ & -6.618 & $10 / 05 / 06$ & $01 / 06 / 06$ & -2.853 \\
\hline 2006 :II & I 06/10/06 & 09/11/06 & -4.148 & $23 / 08 / 06$ & $14 / 09 / 06$ & -1.483 & $02 / 08 / 06$ & $18 / 10 / 06$ & -4.034 & $29 / 09 / 06$ & $06 / 11 / 06$ & -4.663 \\
\hline 2007 :I & $27 / 03 / 07$ & $24 / 05 / 07$ & $-2.667 *$ & $21 / 03 / 07$ & 06/06/07 & -5.325 & & $15 / 05 / 07$ & $-2.855^{* *}$ & $16 / 04 / 07$ & 06/06/07 & -5.689 \\
\hline 2007 :II & I 11/09/07 & $06 / 12 / 07$ & -3.613 & $11 / 09 / 07$ & $07 / 11 / 07$ & -4.101 & $11 / 09 / 07$ & $08 / 11 / 07$ & -3.214 & $24 / 08 / 07$ & $10 / 12 / 07$ & -3.378 \\
\hline 2008 :I & $27 / 03 / 08$ & $06 / 06 / 08$ & -4.641 & 04/03/08 & $18 / 04 / 08$ & -3.581 & $18 / 01 / 08$ & $06 / 06 / 08$ & -3.470 & $11 / 02 / 08$ & $02 / 04 / 08$ & -5.124 \\
\hline 2008 :II & I 01/10/08 & $13 / 11 / 08$ & -3.365 & $20 / 08 / 08$ & 09/10/08 & -3.629 & $10 / 09 / 08$ & $07 / 10 / 08$ & -3.448 & 03/09/08 & $07 / 10 / 08$ & -4.355 \\
\hline 2009 :I & 09/03/09 & $04 / 05 / 09$ & -2.940 & $12 / 01 / 09$ & & -3.967 & $24 / 04 / 09$ & 02/06/09 & -3.219 & $05 / 02 / 09$ & $11 / 05 / 09$ & \\
\hline ?. U & 然 & 年 & . & 201 & & S & & 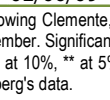 & S & & 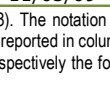 & (1) \\
\hline
\end{tabular}


TABLE 2.8: UNIT ROOT TEST ALLOWING FOR TWO STRUCTURAL BREAKS : INNOVATIONAL OUTLIERS

\begin{tabular}{|c|c|c|c|c|c|c|c|c|c|c|c|c|}
\hline Year & $\begin{array}{l}\text { Corn } \\
d u 1\end{array}$ & $d u 2$ & $\rho-1$ & $\begin{array}{l}\text { Rice } \\
d u 1\end{array}$ & $d u 2$ & $\rho-1$ & $\begin{array}{l}\text { Soybean } \\
d u 1\end{array}$ & $d u 2$ & $\rho-1$ & $\begin{array}{l}\text { Wheat } \\
\text { du1 }\end{array}$ & $d u 2$ & $\rho-1$ \\
\hline 2000 :I & $09 / 03 / 00$ & $05 / 06 / 00$ & -4.068 & $17 / 04 / 00$ & $15 / 06 / 00$ & -5.040 & $09 / 03 / 00$ & $23 / 05 / 00$ & $-4.120 * * *$ & $17 / 02 / 00$ & $08 / 05 / 00$ & -6.054 \\
\hline 2000 :II & I 13/09/00 & $13 / 12 / 00$ & $-5.351 * * *$ & * 19/07/00 & & -6.823 & 08/08/00 & $09 / 11 / 00$ & $-3.902 *$ & $13 / 09 / 00$ & $13 / 12 / 00$ & -5.285 \\
\hline 2001 :I & $17 / 04 / 01$ & & $-4.507 * *$ & $12 / 03 / 01$ & $31 / 05 / 01$ & -5.642 & & $29 / 05 / 01$ & -3.158 & $23 / 01 / 01$ & $16 / 05 / 01$ & -4.375 \\
\hline 2001 :II & I $10 / 10 / 01$ & $28 / 11 / 01$ & -6.350 & $17 / 07 / 01$ & $17 / 08 / 01$ & -4.021 & $14 / 08 / 01$ & $26 / 09 / 01$ & -4.001 & & $08 / 10 / 01$ & -4.523 \\
\hline 2002 :I & $26 / 03 / 02$ & $03 / 05 / 02$ & -2.854 & $24 / 05 / 02$ & $31 / 05 / 02$ & -5.156 & $27 / 02 / 02$ & $06 / 05 / 02$ & -3.049 & $24 / 01 / 02$ & $10 / 06 / 02$ & -3.912 \\
\hline 2002 :II & & $13 / 09 / 02$ & $-4.152 *$ & $12 / 07 / 02$ & $31 / 07 / 02$ & $-5.392 * * *$ & * 26/09/02 & $25 / 10 / 02$ & -6.052 & $28 / 08 / 02$ & $26 / 11 / 02$ & -3.805 \\
\hline 2003 :I & $05 / 05 / 03$ & $15 / 05 / 03$ & -3.855 & 05/03/03 & 03/04/03 & $-3.427 *$ & $31 / 03 / 03$ & $24 / 04 / 03$ & $-5.276 * * *$ & $13 / 03 / 03$ & $07 / 05 / 03$ & -5.992 \\
\hline 2003 :II & I 08/08/03 & $20 / 10 / 03$ & $-4.811 * * *$ & * 21/07/03 & $10 / 11 / 03$ & -6.289 & $02 / 09 / 03$ & $08 / 10 / 03$ & -3.901 & $30 / 09 / 03$ & $16 / 10 / 03$ & -4.926 \\
\hline 2004 :I & & 08/06/04 & -2.463 & $20 / 02 / 04$ & & -3.482 & $17 / 02 / 04$ & $12 / 05 / 04$ & -5.182 & $11 / 03 / 04$ & $06 / 05 / 04$ & -4.034 \\
\hline 2004 :II & I $14 / 07 / 04$ & $31 / 08 / 04$ & $-5.130 * * *$ & * 20/07/04 & $15 / 09 / 04$ & $-7.850 * * *$ & $13 / 07 / 04$ & $02 / 09 / 04$ & -8.892 & & $17 / 11 / 04$ & -4.371 \\
\hline 2005 :I & $15 / 02 / 05$ & $12 / 05 / 05$ & -4.745 & 04/03/05 & 09/06/05 & -2.991 & $15 / 02 / 05$ & $23 / 05 / 05$ & -4.870 & $17 / 02 / 05$ & $16 / 03 / 05$ & -4.487 \\
\hline 2005 :II & & & -3.266 & $19 / 09 / 05$ & $01 / 12 / 05$ & -4.751 & $15 / 07 / 05$ & $11 / 08 / 05$ & -5.037 & & $11 / 10 / 05$ & -2.997 \\
\hline 2006 :I & $09 / 05 / 06$ & $01 / 06 / 06$ & $-3.862 * *$ & $10 / 05 / 06$ & $18 / 05 / 06$ & $-5.875 * * *$ & 29/03/06 & $26 / 04 / 06$ & -6.601 & $03 / 05 / 06$ & & -4.817 \\
\hline 2006 :II & I 13/09/06 & $10 / 10 / 06$ & -3.583 & $17 / 08 / 06$ & $11 / 09 / 06$ & -4.934 & $03 / 08 / 06$ & $10 / 10 / 06$ & $-4.366 * *$ & $13 / 09 / 06$ & $09 / 11 / 06$ & -5.722 \\
\hline 2007 :I & & & $-2.437 * *$ & & 07/06/07 & -5.547 & & 09/05/07 & $-3.988 * *$ & $11 / 04 / 07$ & $13 / 06 / 07$ & -5.519 \\
\hline 2007 :II & I 10/09/07 & $30 / 11 / 07$ & $-3.308 * *$ & $28 / 08 / 07$ & 29/10/07 & -5.854 & 06/09/07 & $02 / 11 / 07$ & -2.716 & $17 / 08 / 07$ & & -3.400 \\
\hline 2008 :I & $19 / 03 / 08$ & $03 / 06 / 08$ & -5.121 & $11 / 02 / 08$ & $19 / 03 / 08$ & -3.276 & & $02 / 06 / 08$ & -3.532 & $20 / 02 / 08$ & $17 / 03 / 08$ & -4.737 \\
\hline 2008 :II & I 15/07/08 & $25 / 09 / 08$ & -4.912 & $14 / 08 / 08$ & $25 / 09 / 08$ & $-3.899 * * *$ & $15 / 07 / 08$ & $11 / 09 / 08$ & -6.283 & $20 / 08 / 08$ & $25 / 09 / 08$ & -4.763 \\
\hline 2009 :I & $10 / 03 / 09$ & & -3.577 & & & -3.788 & $27 / 03 / 09$ & $27 / 04 / 09$ & -4.147 & $09 / 02 / 09$ & $05 / 05 / 09$ & -5.029 \\
\hline "du2 & 然 & ( & - & 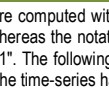 & & 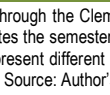 & 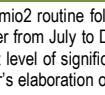 & . & 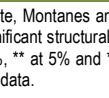 & 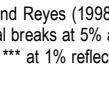 & 8). The no & on "I" in the \\
\hline
\end{tabular}

The overall picture provided in Table 2.9 clears the ground to the stationarity/nonstationarity conundrum. Out of a total number of 17 sub-periods, the unit root hypothesis is rejected only in a few cases for every commodity. The ADF and PP tests in general are slightly more biased towards rejection than the other tests, whereas the detection of structural breaks have somehow improved the results. Thus, the accuracy of the results provided by the NP test and the test allowing for two structural breaks in the additive outlier framework is corroborated by their convergent results.

TABLE 2.9: STATIONARITY SUB-PERIODS OUT OF A TOTAL OF 17

\begin{tabular}{lllll}
\hline \hline & Corn & Rice & Soybean & Wheat \\
\hline ADF & 3 & 5 & 3 & 2 \\
PP & 4 & 4 & 3 & 3 \\
NP & 2 & 3 & 1 & 0 \\
1 Break - AO & 0 & 2 & 1 & 1 \\
1 Break - IO & 2 & 5 & 2 & 1 \\
2 Breaks - AO & 2 & 3 & 1 & 0 \\
2 Breaks - IO & 8 & 5 & 5 & 0 \\
Note: The null hypothesis rejections count does not take into consideration whereas the test rejections occurred at 10\%, 5\%, or \\
1\% level of significance.
\end{tabular}


Having defined non-stationary the majority of the sub-periods, the understanding of price dynamics has further implications. As already mentioned, tables 2.1 up to 2.4 show that the number of lags usually is set to zero ${ }^{17}$. When the latter as well as the non-stationarity hint hold, it is possible to define the series a martingale. With no surprise, withdrawals of this rule are set mainly in 2007:I and in the two semesters of 2008 , providing some evidence that the price generation process deviated from its path.

Nonetheless, the above reported results need be further developed. Next section clears the ground from the 6-month sub-periods, that has the disadvantage of being rather static, addressing the same issues with a dynamic approach and focusing on a limited period, starting from 2006.

\subsubsection{Structural changes in the food price rush (2006-2009)}

The rising attention paid to soaring food prices was followed by a significant number of policy measures to ease the phenomenon and its implications in terms of price volatility and food security. However, it is not clear whether the interventions at the national level worked properly or were the trigger to the rush in commodities prices between September 2006 and September 2008.

Following Timmer $(2008)^{18}$, it is possible to analyze food commodities prices as compared to different government policies and some events related to the financial crisis with the aim of detecting whether the presence of structural breaks was influenced by those events ${ }^{19}$. Hence, Perron and Vogelsang statistics are applied through a rolling scheme, starting from January 2006. Additive and innovational

\footnotetext{
${ }^{17}$ Further evidence is provided by the Ljung-box test.

${ }^{18}$ Timmer (2008) analysed rice futures prices referring to different trade events in that market.

19 The present section by no means should be considered a cause-effect analysis, rather an events analysis.
} 
outliers are detected using a rolling 6-month sample, and moving one month ahead until the period is exhausted ${ }^{20}$.

The number of outliers detected would depend on the relative incidence of the outlier itself during the rolling period, with the practical advantage of assessing its significance both under a statistical and a persistency categorizing factor.

The unit root tests definitively fail to reject the non-stationarity hypothesis. Corn and wheat are found to be non-stationary towards the whole rolling period, whether the null hypothesis is rejected in three sub-periods for rice (2006:1-2006:6, in 2008:12-2009:5, and in 2009:1- 2009:6) and in one for soybean (2006:1-2006:6). These results are all in line with Table 2.5 and partially with Table 2.7. Thus, these inconsistent sub-periods (2008:12-2009:5 and 2009:1-2009:6 for rice) are tested again allowing for two structural breaks, with the result of failing to reject the null hypothesis.

In the annex to the chapter, only significant additive and innovational outliers are reported $^{21}$. Out of a maximum total number of 37 , the results show that additive outliers detected are all significant (with two exceptions only for corn and wheat) ${ }^{22}$. The rolling scheme allows for the repetition of outliers ${ }^{23}$. Thus, taking into account their persistence, the final number of significant $\mathrm{AO} / \mathrm{IO}$ outliers to be considered is: corn $23 / 19$, rice $19 / 22$, soybean $22 / 19$, and wheat $23 / 15$.

Keeping these results in mind, the next issue addresses the economics behind the above shown statistics.

\footnotetext{
${ }^{20}$ Provided the rolling scheme determines 37 sub-periods, the count of additive and innovational statistically significant - outliers might be up to that figure per each. Thus, the choice of the model allowing for one structural break is demanded for the sake of reducing the total number of possible outliers.

${ }^{21}$ See tables 2.11 and 2.12. A blank space in columns du1 is left where the outlier detected is found to be not significant.

22 On the other hand, the total number of statistically not significant innovational outliers detected for corn, rice, soybean, and wheat is, respectively, 7, 2, 1 and 5 (see Table 2.12).

${ }^{23}$ Every date in the sample is tested six different times, allowing the rolling scheme to move ahead its 6month window. Thus, a single outlier might be found significant in 6 different sub-periods as well.
} 
In order to achieve this goal, a time list of events is provided in Figure $2.2^{24}$. At a first glance, the marked events seem to fall where at least one of the four timeseries has a shift.

FIGURE 2.2: RELEVANT WORLD FOOD AND FINANCIAL EVENTS

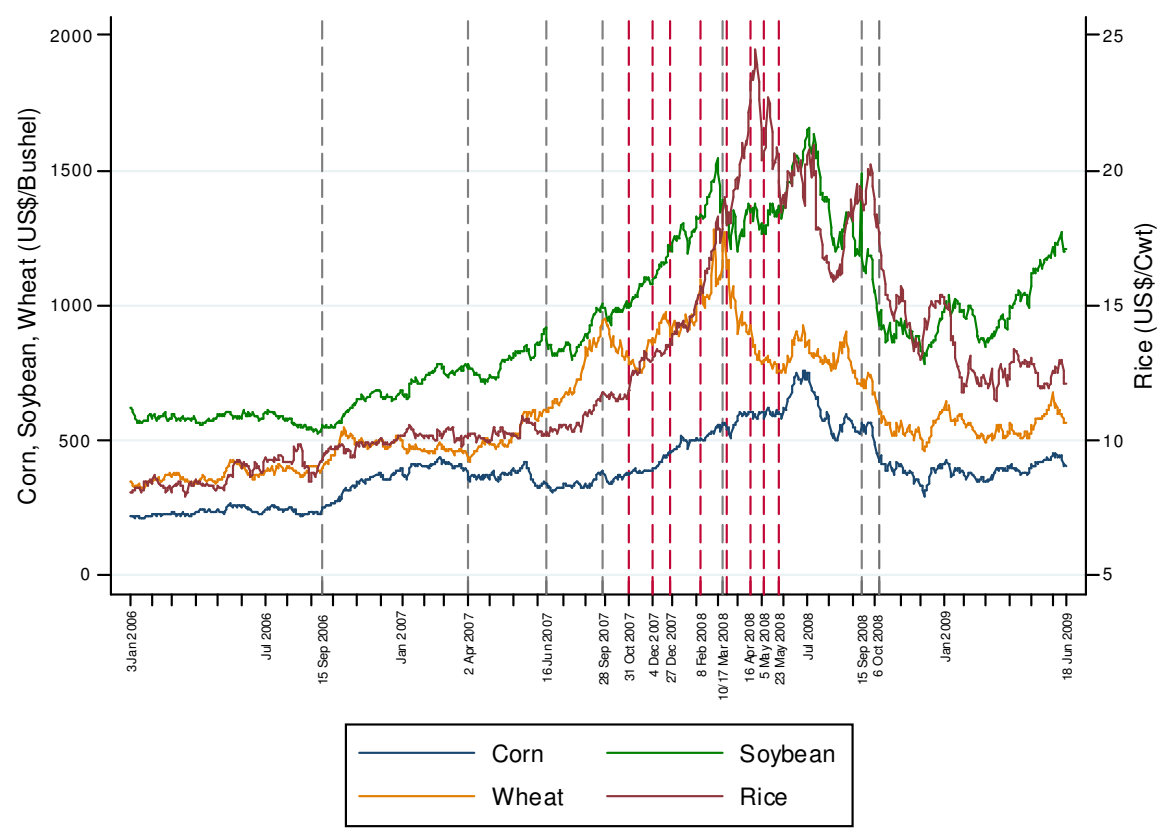

Table 2.10 matches those events with the additive and innovational outliers detected in tables 2.11 and 2.12. An X is listed if the outliers fall in a 6-day period starting from the day when the relevant event occurred.

Recalling Fox's definition on the effects of outliers in the dynamics of the model (1972), the incidence in the food crisis of the reported events is thus investigated using as a rule of thumb that additive outliers are simply abnormal observations not affecting the subsequent ones, whereas innovational outliers have a self perpetrating effect.

Following this interpretation, the first three events in the timeline after the onset of soaring price - the initial phase of the sub-prime mortgages collapse and Vietnam's export ban - have had an impact only in terms of additive outliers, probably because

\footnotetext{
${ }^{24}$ The dash red lines refer to food policy events, whereas the dash gray lines refer to financial events.
} 
they were not recognized as the earlier crackles of the crisis. From hereinafter, subsequent export bans declared by the Governments of India ${ }^{25}$, Argentina, Egypt and USA $^{26}$ affected the price generation process as innovational outliers given their relevance both in terms of population and in terms of their size in the international trade. The contagion from the financial crisis jumped in the commodities markets when wheat futures prices presented three close innovational outliers in occasion of Dow Jones lowest record and Bearn Sterns rescue plan, plus another export ban declared by India. The same events had controversial feedback in the corn sector, both in terms of $\mathrm{AO}$ and $\mathrm{IO}$.

There is no or little match between the subsequent ten events and the other dates. In fact, those events did not occur in foreground countries, and could be classified in the framework of the food riots burst when the food crisis hit the most or in not unexpected policy measures adopted to face the issue of constantly upward prices.

Oddly, at this stage, only the second Philippines' tender on rice is detected as an innovational outlier for the rice sector ${ }^{27}$. In the period between April and May 2008, a number of events succeeded one another which might have altered the outliers detection reliability producing controversial statistics, as in the case of the Japan's rice release, often described as the turning point in the hiking of rice prices $\left(\right.$ Timmer, 2008) ${ }^{28}$.

Passing through Table 2.10, after the Lehman Brothers bankruptcy, the loan offered to AIG seems to be of seminal importance being followed by three innovational outliers. These events might have been so relevant because they averted - at least in terms of expectations of agents - an overall financial collapse, and a subsequent contagion to commodities markets driven by hedge funds.

\footnotetext{
${ }^{25}$ Conversely not the second export ban, probably depending on the short time occurred from the first one.

${ }^{26}$ This event determined an additive outlier in the wheat sector, probably as an immediate response to the shock of the announcement, and also, in a roundabout way, the first of five innovational outliers in the rice sector.

${ }^{27}$ It is noteworthy that these two tenders $-16^{\text {th }}$ April and $5^{\text {th }}$ May - fall exactly before and after the peak in the rice futures prices on Wednesday $23^{\text {rd }}$ of April 2008. This might be one reason of the failed detection of the first tender date as an innovational outlier.

${ }^{28}$ Nonetheless, as a further evidence of the goodness of the matching rule, off-table, an additive outlier is detected three days before the Japan rice release announcement.
} 


\subsection{THE ROLE OF AGENTS BEHAVIOR}

The argument that food commodities have been influenced by speculation, which has been driving futures prices beyond their fundamentals, is sound appealing in order to address the recent world food crisis.

Even though a bubble detection is beyond the aim of this dissertation, which in this introductory chapter deals with the issue of non-stationary and the presence of structural breaks in the futures prices time-series of corn, rice, soybean and wheat, some clear evidence suggested by the price generation process might be defined as well.

Globally, with the few exceptions described, once the time-series are cleared by additive outliers, the investigated food commodities prices suggest a non-stationary behavior. This is mainly true in the period starting from September 2006, where the presence of a time trend might have driven the price boom as well.

On the other hand, evidence from the (innovational) outliers detection shows how two types of effects have been influential in the dynamics of prices, i.e. the chain of export bans in between late 2006 and early 2007 - that somehow altered the dynamics of supply and demand - and the Fed rescue plans started in September 2008. Thus, it might be advocated that the previous set of events has triggered the food prices rush, whereas the latter has been influential to give a halt. This evidence strongly suggests that fear of contagion between different markets and a general panic piled up along the timeline, probably being more pervasive than simple speculation. None that the latter has not occurred, of course, but cause-effect hypothesis probably should be reversed.

A possible field of further research, here not explored but often between the lines, is whether or not the dynamics behind the investigated food commodities met the market efficiency hypothesis (Fama, 1970). Tables 2.1-2.4 and Table 2.9 suggest that futures prices mostly performed in a non-stationary fashion, with the majority of the sub-periods relatable to random walks with drift or pure random walks. The exceptions from this scheme might suggest the possibility that high food prices occurred because agents adapted their behaviors as the crisis carried forward. In other words, deviations from the random walks hypothesis might imply "considerably more complex market dynamics, with cycles as well as trends, and panics, manias, 
bubbles, crashes, and other phenomena that are routinely witnessed in natural market ecologies" (Lo, 2004). As a matter of fact, corn, rice, soybean and wheat soaring prices showed rather different timing and extent, suggesting that their different incidence in terms of food consumption in countries were the food crisis hit the most, as well as their utilization as bio-fuel and their relevance as financial commodities, might have differently influenced their upward rush.

This introductory chapter addressed food price crisis only in its most financial fashion, leaving aside all other possible roots enlisted in section 2.1. In the remainder of the dissertation the focus will be reversed on rural households, provided they are those supposed to be hit the most by such a price volatility. Actually, skyrocketing prices might severely affect households and force them to rely on their cash savings or on other coping strategies, that can span from money borrowing, intake reduction and food habit changes, up to healthcare and schooling cost cutbacks, which might hinder their resilience chances.

In general, those who are able to increase their production may benefit from higher food prices, still a very limited amount of rural households are food sellers and can scale-up their yields and gain from such a scenario. According to FAO (2009), a "supply response has been concentrated mostly in the developed countries and, among developing countries, Brazil, China and India. With the exception of these three, cereal production actually fell between 2007 and 2008 in developing countries", thus calling attention on the consequences across rural households in terms of vulnerability. 


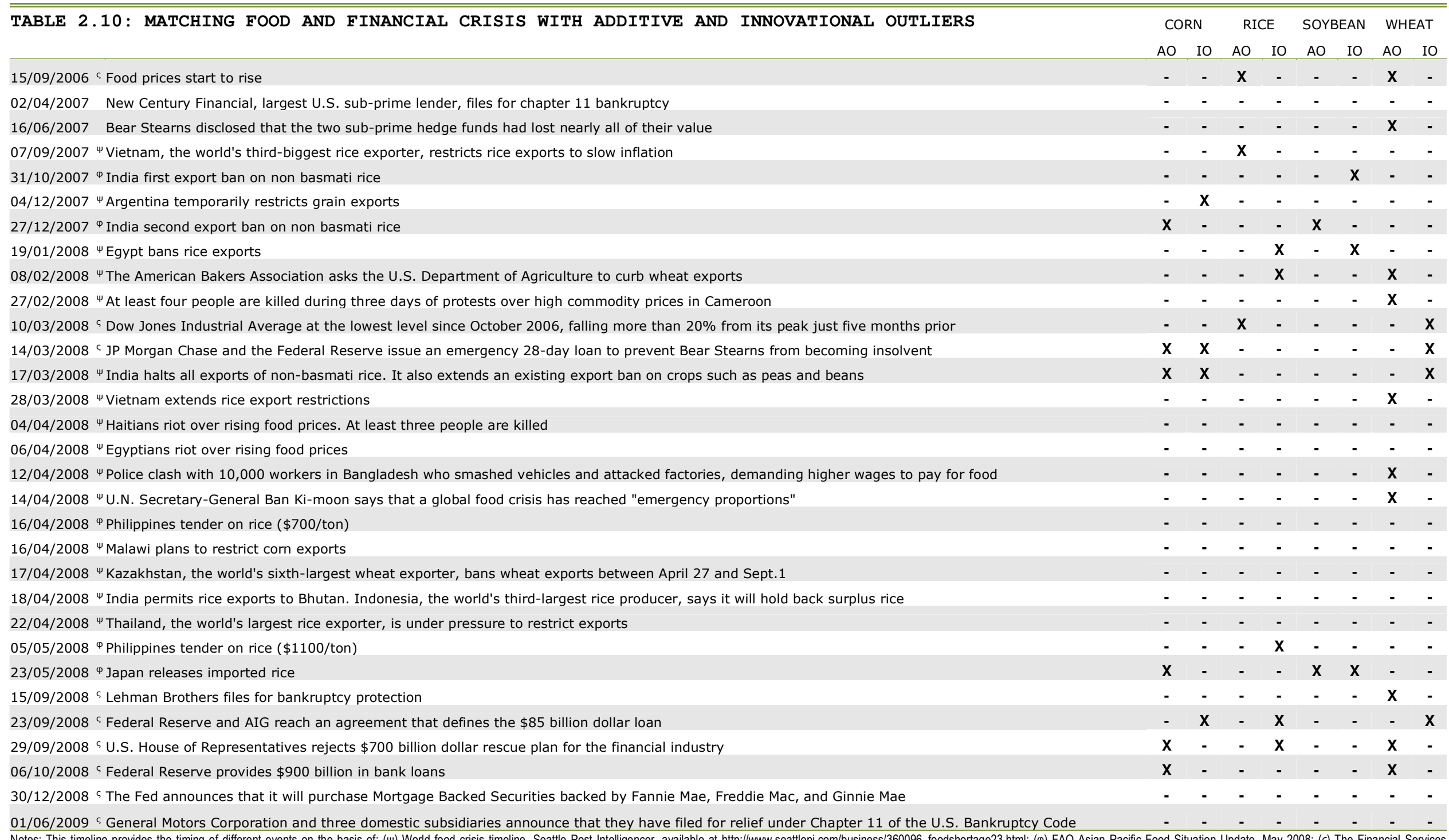

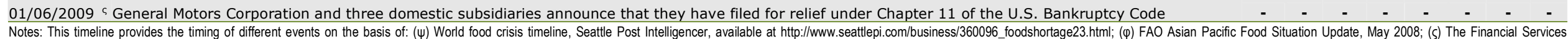

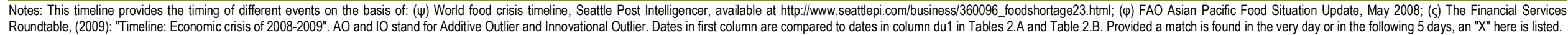




\title{
2.6 ANNEX TO THE CHAPTER
}

\author{
TABLE 2.11: ROLLING UNIT ROOT TEST ALLOWING FOR ONE STRUCTURAL BREAK - ADDITIVE \\ OUTLIERS
}

\begin{tabular}{|c|c|c|c|c|}
\hline & Corn & Rice & Soybean & Wheat \\
\hline Rolling six-months period & du1 & du1 & du1 $\quad \rho-1$ & du1 $\quad \rho-1$ \\
\hline $2006: 1-2006: 6$ & $03 / 04 / 06-2.747$ & $17 / 05 / 06-4.679 * * *$ & $01 / 05 / 06-4.780 * * *$ & $18 / 05 / 06-2.453$ \\
\hline $2006: 2-2006: 7$ & $03 / 04 / 06-3.069$ & $17 / 05 / 06-2.247$ & $25 / 04 / 06-4.240$ & $15 / 05 / 06-3.597$ \\
\hline $2006: 3-2006: 8$ & $03 / 04 / 06-2.496$ & $17 / 05 / 06-3.424$ & $02 / 08 / 06-3.379$ & $15 / 05 / 06-3.901$ \\
\hline $2006: 4$ - 2006:9 & $21 / 09 / 06-2.623$ & $17 / 05 / 06-2.991$ & $02 / 08 / 06-3.667$ & $20 / 09 / 06-2.607$ \\
\hline $2006: 5-2006: 10$ & $06 / 10 / 06-3.466$ & $28 / 08 / 06-3.198$ & $18 / 10 / 06-2.183$ & $29 / 09 / 06-4.385$ \\
\hline $2006: 6-2006: 11$ & $18 / 10 / 06-2.379$ & $20 / 09 / 06-3.128$ & $18 / 10 / 06-2.406$ & $29 / 09 / 06-3.950$ \\
\hline $2006: 7-2006: 12$ & $18 / 10 / 06-2.796$ & $20 / 09 / 06-2.821$ & $18 / 10 / 06-3.068$ & $29 / 09 / 06-4.358$ \\
\hline $2006: 8$ - 2007:1 & $18 / 10 / 06-2.612$ & $02 / 11 / 06-2.594$ & $18 / 10 / 06-2.841$ & 29/09/06-2.985 \\
\hline $2006: 9-2007: 2$ & $09 / 11 / 06-2.272$ & $15 / 12 / 06-3.440$ & 24/01/07-1.699 & $29 / 09 / 06-2.662$ \\
\hline $2006: 10-2007: 3$ & $05 / 01 / 07-3.054$ & $15 / 12 / 06-3.915$ & $18 / 01 / 07-3.247$ & $04 / 01 / 07-4.148$ \\
\hline $2006: 11-2007: 4$ & $27 / 03 / 07-2.179$ & $20 / 12 / 06-4.089$ & $18 / 01 / 07-3.400$ & $11 / 01 / 07-3.978$ \\
\hline $2006: 12-2007: 5$ & $27 / 03 / 07-2.679$ & $20 / 12 / 06-4.349$ & $24 / 01 / 07-3.337$ & $23 / 04 / 07-3.372$ \\
\hline $2007: 1-2007: 6$ & $27 / 03 / 07-2.596$ & $06 / 06 / 07-3.940$ & $17 / 05 / 07-2.832$ & $06 / 06 / 07-4.252$ \\
\hline $2007: 2-2007: 7$ & $05 / 07 / 07-2.471$ & $06 / 06 / 07-3.938$ & $18 / 05 / 07-3.481$ & $06 / 06 / 07-3.807$ \\
\hline $2007: 3-2007: 8$ & $26 / 06 / 07-3.380$ & $06 / 06 / 07-3.983$ & $18 / 05 / 07-3.428$ & $18 / 06 / 07-1.682$ \\
\hline $2007: 4-2007: 9$ & $13 / 06 / 07-2.156$ & $05 / 09 / 07-3.245$ & $05 / 09 / 07-2.063$ & 06/09/07-1.362 \\
\hline $2007: 5-2007: 10$ & $13 / 06 / 07-2.295$ & $11 / 09 / 07-3.713$ & 05/09/07-3.193 & $06 / 09 / 07-2.067$ \\
\hline 2007:6 - 2007:11 & $22 / 10 / 07-2.326$ & $07 / 11 / 07-2.168$ & $21 / 09 / 07-2.549$ & $24 / 08 / 07-3.158$ \\
\hline $2007: 7-2007: 12$ & $18 / 12 / 07-2.146$ & $07 / 11 / 07-1.539$ & $30 / 10 / 07-1.805$ & $06 / 09 / 07-2.950$ \\
\hline 2007:8 - 2008:1 & $18 / 12 / 07-2.818$ & $12 / 11 / 07-1.576$ & $29 / 11 / 07-2.321$ & $03 / 12 / 07-2.669$ \\
\hline $2007: 9$ - 2008:2 & $18 / 12 / 07-2.677$ & $15 / 02 / 08-1.241$ & $27 / 12 / 07-1.721$ & $11 / 02 / 08-1.851$ \\
\hline $2007: 10-2008: 3$ & $27 / 12 / 07-2.584$ & $04 / 03 / 08-1.625$ & $27 / 12 / 07-2.271$ & $11 / 02 / 08-2.050$ \\
\hline $2007: 11-2008: 4$ & $18 / 01 / 08-2.328$ & $04 / 03 / 08-2.750$ & $27 / 12 / 07-2.911$ & $28 / 02 / 08-1.306$ \\
\hline $2007: 12-2008: 5$ & $18 / 03 / 08-3.190$ & $04 / 03 / 08-2.998$ & $18 / 01 / 08-3.196$ & $14 / 04 / 08-2.607$ \\
\hline $2008: 1-2008: 6$ & $06 / 06 / 08-2.310$ & $13 / 03 / 08-3.059$ & $06 / 06 / 08-3.119$ & $02 / 04 / 08-2.535$ \\
\hline $2008: 2-2008: 7$ & $27 / 05 / 08-2.049$ & $16 / 07 / 08-1.953$ & $27 / 05 / 08-3.213$ & $02 / 04 / 08-3.452$ \\
\hline $2008: 3-2008: 8$ & -2.116 & $16 / 07 / 08-2.228$ & $27 / 05 / 08-2.369$ & $02 / 04 / 08-4.111$ \\
\hline $2008: 4-2008: 9$ & $28 / 07 / 08-1.973$ & $20 / 05 / 08-2.146$ & $10 / 09 / 08-1.930$ & $03 / 09 / 08-2.986$ \\
\hline $2008: 5-2008: 10$ & $08 / 10 / 08-1.844$ & $16 / 10 / 08-2.126$ & $10 / 09 / 08-2.183$ & $19 / 09 / 08-2.990$ \\
\hline $2008: 6$ - 2008:11 & $08 / 10 / 08-1.843$ & $16 / 10 / 08-2.140$ & $10 / 09 / 08-2.163$ & $19 / 09 / 08-3.207$ \\
\hline 2008:7 - 2008:12 & $01 / 10 / 08-3.359$ & $16 / 10 / 08-2.586$ & $10 / 09 / 08-2.933$ & $29 / 09 / 08-3.215$ \\
\hline 2008:8 - 2009:1 & $07 / 10 / 08-3.819$ & $16 / 10 / 08-1.801$ & $10 / 09 / 08-2.478$ & 19/09/08-3.119 \\
\hline $2008: 9-2009: 2$ & $07 / 10 / 08-3.779$ & $16 / 10 / 08-2.095$ & $10 / 09 / 08-2.085$ & $07 / 10 / 08-3.495$ \\
\hline 2008:10-2009:3 & $03 / 12 / 08-1.374$ & $14 / 01 / 09-4.027$ & $29 / 12 / 08-2.491$ & -2.382 \\
\hline $2008: 11-2009: 4$ & -3.622 & $14 / 01 / 09-2.911$ & $26 / 03 / 09-2.435$ & -1.831 \\
\hline 2008:12-2009:5 & $04 / 05 / 09-2.796$ & $14 / 01 / 09-4.911 * * *$ & $24 / 04 / 09-2.776$ & $19 / 05 / 09-2.506$ \\
\hline $2009: 1-2009: 6$ & $04 / 05 / 09-3.183$ & $14 / 01 / 09-4.576 * * *$ & $24 / 04 / 09-3.032$ & $04 / 05 / 09-3.091$ \\
\hline
\end{tabular}


TABLE 2.12: ROLLING UNIT ROOT TEST ALLOWING FOR ONE STRUCTURAL BREAK INNOVATIONAL OUTLIERS

\begin{tabular}{|c|c|c|c|c|}
\hline & Corn & Rice & Soybean & Wheat \\
\hline Six-months period & du1 & du1 & du1 $\quad \rho-1$ & du1 \\
\hline $2006: 1$ - 2006:6 & $23 / 03 / 06-2.938$ & $10 / 05 / 06-4,643 * * *$ & $01 / 05 / 06-4,78 * * *$ & $03 / 05 / 06-4,071$ \\
\hline $2006: 2-2006: 7$ & $27 / 03 / 06-3.171$ & $18 / 05 / 06-4,199$ & $26 / 04 / 06-4,559 * * *$ & $03 / 05 / 06-5,353 * * *$ \\
\hline $2006: 3-2006: 8$ & -2.496 & $18 / 05 / 06-3,539$ & $03 / 08 / 06-3,528$ & $03 / 05 / 06-4,997 * * *$ \\
\hline $2006: 4-2006: 9$ & -3.041 & $05 / 05 / 06-3,012$ & $03 / 08 / 06-3,723$ & $03 / 05 / 06-2,615$ \\
\hline $2006: 5-2006: 10$ & $05 / 10 / 06-2.602$ & $06 / 09 / 06-3,26$ & $10 / 10 / 06-2,271$ & $26 / 09 / 06-4,168$ \\
\hline $2006: 6-2006: 11$ & $05 / 10 / 06-2.435$ & $11 / 09 / 06-3,324$ & $10 / 10 / 06-2,874$ & $13 / 09 / 06-3,997$ \\
\hline $2006: 7$ - 2006:12 & $05 / 10 / 06-2.6$ & $06 / 09 / 06-3,157$ & $10 / 10 / 06-3,595$ & $13 / 09 / 06-3,825$ \\
\hline $2006: 8$ - 2007:1 & $13 / 09 / 06-2.538$ & $27 / 10 / 06-2,906$ & $10 / 10 / 06-3,16$ & $13 / 09 / 06-3,707$ \\
\hline $2006: 9-2007: 2$ & -2.061 & $27 / 10 / 06-4,461$ & 09/01/07-2,068 & $13 / 09 / 06-3,519$ \\
\hline $2006: 10-2007: 3$ & $08 / 01 / 07-3.327$ & $27 / 10 / 06-4,149$ & 09/01/07-3,985 & $29 / 12 / 06-4,44$ \\
\hline $2006: 11-2007: 4$ & -2.761 & $18 / 12 / 06-4,844 * * *$ & $09 / 01 / 07-4,69 * * *$ & $29 / 12 / 06-4,144$ \\
\hline $2006: 12-2007: 5$ & $28 / 03 / 07-2.688$ & $01 / 05 / 07-4,261$ & $09 / 01 / 07-3,177$ & $29 / 12 / 06-3,092$ \\
\hline $2007: 1$ - 2007:6 & $21 / 03 / 07-2.622$ & $07 / 06 / 07-5,561 * * *$ & $09 / 05 / 07-3,725$ & $07 / 06 / 07-3,332$ \\
\hline $2007: 2$ - 2007:7 & $15 / 06 / 07-3.253$ & $07 / 06 / 07-4,575 * * *$ & $09 / 05 / 07-3,276$ & $25 / 05 / 07-2,951$ \\
\hline $2007: 3-2007: 8$ & $14 / 06 / 07-4.361$ & $07 / 06 / 07-4,977 * * *$ & 09/05/07-3,913 & $-0,879$ \\
\hline $2007: 4-2007: 9$ & $14 / 06 / 07-3.435$ & $28 / 08 / 07-3,469$ & $20 / 08 / 07-1,763$ & $17 / 08 / 07-1,184$ \\
\hline $2007: 5-2007: 10$ & $14 / 06 / 07-3.266$ & $28 / 08 / 07-4,543$ & $30 / 08 / 07-3,022$ & $17 / 08 / 07-2,318$ \\
\hline $2007: 6-2007: 11$ & $14 / 06 / 07-2.819$ & 29/10/07 -1,553 & $06 / 09 / 07-2,416$ & $17 / 08 / 07-2,942$ \\
\hline $2007: 7-2007: 12$ & 0.826 & 29/10/07-2,591 & 20/08/07 -1,089 & $17 / 08 / 07-2,768$ \\
\hline $2007: 8$ - 2008:1 & $30 / 11 / 07-2.123$ & 29/10/07-1,916 & $01 / 11 / 07-1,627$ & $15 / 11 / 07-3,072$ \\
\hline $2007: 9$ - 2008:2 & $07 / 12 / 07-2.323$ & $23 / 01 / 080,163$ & $23 / 01 / 08-1,045$ & $23 / 11 / 07-1,025$ \\
\hline $2007: 10-2008: 3$ & $07 / 12 / 07-2.148$ & $22 / 01 / 08-0,315$ & $30 / 11 / 07-2,115$ & $30 / 01 / 08-2,434$ \\
\hline $2007: 11-2008: 4$ & $07 / 12 / 07-1.932$ & $-1,709$ & $22 / 01 / 08-2,629$ & $-1,342$ \\
\hline $2007: 12-2008: 5$ & $19 / 03 / 08-3.318$ & $11 / 02 / 08-2,257$ & $22 / 01 / 08-3,072$ & $17 / 03 / 08-2,548$ \\
\hline $2008: 1-2008: 6$ & 03/06/08 -2.597 & $06 / 03 / 08-2,517$ & 02/06/08 -3,089 & $17 / 03 / 08-3,575$ \\
\hline $2008: 2-2008: 7$ & -2.393 & $11 / 07 / 08-2,58$ & $28 / 05 / 08-4,116$ & $17 / 03 / 08-4,456$ \\
\hline $2008: 3-2008: 8$ & $01 / 07 / 08-2.112$ & 09/07/08 -3,835 & $-2,789$ & $12 / 03 / 08-4,505$ \\
\hline $2008: 4-2008: 9$ & $01 / 07 / 08-2.436$ & $08 / 05 / 08-2,927$ & $15 / 07 / 08-2,843$ & $20 / 08 / 08-3,774$ \\
\hline $2008: 5-2008: 10$ & $01 / 07 / 08-2.085$ & $02 / 10 / 08-2,418$ & $11 / 09 / 08-3,147$ & $24 / 09 / 08-2,548$ \\
\hline $2008: 6-2008: 11$ & 02/07/08 -2.397 & $24 / 09 / 08-3,063$ & $11 / 09 / 08-3,291$ & $20 / 08 / 08-3,126$ \\
\hline $2008: 7-2008: 12$ & 24/09/08 -4.215 & $24 / 09 / 08-4,147$ & $11 / 09 / 08-4,799 * * *$ & $24 / 09 / 08-3,375$ \\
\hline 2008:8 - 2009:1 & $25 / 09 / 08-4.737 * * *$ & $24 / 09 / 08-3,659$ & $11 / 09 / 08-5,858 * * *$ & 20/08/08 -3,593 \\
\hline $2008: 9-2009: 2$ & $25 / 09 / 08-4.758 * * *$ & $24 / 09 / 08-3,552$ & $11 / 09 / 08-5,693 * * *$ & $24 / 09 / 08-3,883$ \\
\hline 2008:10-2009:3 & -3.818 & 08/01/09 -4,656*** & $18 / 12 / 08-3,767$ & $-2,819$ \\
\hline 2008:11-2009:4 & $04 / 12 / 08-3.597$ & $08 / 01 / 09-4,537$ & $18 / 12 / 08-2,249$ & $-3,028$ \\
\hline 2008:12-2009:5 & $27 / 04 / 09-3.265$ & $08 / 01 / 09-5,128 * * *$ & $27 / 04 / 09-3,117$ & $-2,225$ \\
\hline 2009:1 - 2009:6 & $27 / 04 / 09-3.343$ & $-3,641$ & $27 / 04 / 09-3,175$ & $05 / 05 / 09-4,021$ \\
\hline
\end{tabular}




\section{HIGH FOOD PRICES AND HOUSEHOLD BEHAVIOR: A REVIEW OF RECEIVED MODELS AND BEYOND}

\subsection{INTRODUCTION}

There has been broad consensus that high food prices severely hit the poor, mostly in rural areas (FAO, 2008).

The way households might be affected by price surges allows a twofold research approach. The first contemplates the possible gains or losses derived from an exogenous price shock, and it is broadly achievable analyzing the position that households play in the food market, namely whether they are net food buyers or net food sellers. This literature strand envisages a direct effect on welfare, determined by a change in the household food supply and demand, and an indirect effect, when the economy adjusts to reflect new prices. The second infers at a deeper level, namely the way rural households behave, and unveils implicitly peasant household model dynamics, where production and consumption patterns need be assessed.

Although the causality is to reverse, having a certain net position in the food market depends on a broad set of constraints which are at the basis of any household model (De Janvry and Saudolet, 2004), this counter-intuitive approach might be quite helpful, provided that the principal aim of the present work will not directly focus on the effects of high food prices on households in terms of production and consumption. Albeit the latter will not be set aside, the focus will be on rural poverty, and the perception of poverty in a high food prices framework.

Within this insight, the main goal will be to understand the way an exogenous price shock affects households in a frame where rural poor behaviors are necessarily channeled by risk and uncertainty. Actually, the focus will be specifically on the future prospects of wellbeing or destitution (Dasgputa, 1993) a household would face, deriving by the lack or presence of resources and capabilities to satisfy future needs (Chauduri, 2003). 
Thus, this chapter is organized as follows. The first part will review the recent strand of literature on high food prices, and the way an international exogenous shock, via market transmission, is supposed to affect the rural poor in developing countries. Provided this background, the second part will address the household-model theory with a special focus on the literature in the presence of transaction cost and market failures, which better suits the economics of developing countries.

With these foregoing insights, the last part of the chapter will investigate household behaviors affected by uncertainty in a contest of severe deprivation, where the increase of vulnerability and the risk of poverty would be the principal outcome stemming from high food prices.

\subsection{THE FOOD PRICE CONUNDRUM. ARE HIGH FOOD PRICES PRO- POOR?}

The main household income-generating activity takes place in the agricultural sector for almost 45 percent of the population in the world (Bussolo, De Hoyos and Medvedev, 2009). The consequences of misleading policies oriented towards agricultural development (Barrett and Dorosh, 1996), determined poverty to have been higher in rural areas than in urban centers (World Bank, 2008). As a result, food prices decreased relentlessly since the nineties and until the second half of 2006.

The surge of food prices experienced in the 2006-2008 two-year period has recently been claimed as a reverse categorizing factor from the above trend. Actually, it has been argued that higher food prices might distress households from poverty and inequality throughout consumption and income channels (Deaton, 1989; Ravallion, 1990; Ravallion and Van de Walle, 1991). “Ceteris paribus, higher food prices would transfer income from food buyers to sellers and thereby on average from richer to poorer households. In this sense, the impact of higher food prices can be interpreted as pro-poor" (Aksoy and Isik-Dikmelik, 2008).

The outcome of an increase in commodity food prices would be the balance between a loss in purchasing power - consumption effect - and a gain in monetary income income effect. The former implies a reduction of household welfare in order to 
guarantee a fixed consumption basket in times of price volatility. The latter reflects the ability to entail an increase in monetary income that would occur when the household members are, directly or indirectly, involved in agricultural sound activities which is, in general the case in most developing countries. These opposite results have uncertain effects on rural households.

In case of a positive pass-through effect ${ }^{29}$, an increase in international food commodity prices would be followed by an increase in domestic food prices and a redistribution of resources from the non-agricultural into the agricultural sector (De Hoyos and Medvedev, 2009). The redistribution of welfare calls the households' net position ${ }^{30}$ in the food market and the incidence and severity of poverty. Provided the great majority of poor households live in rural areas (Bussolo, De Hoyos and Medvedev, 2009), the upshot of food prices could help reduce poverty and inequality granted new prices turn into higher incomes for farmers via profit and wage increases (Brown, 1979, Tyagi, 1979 and Lipton, 1984).

The dynamic above proposed implies a set of conditions to be assessed. The passthrough from international to domestic prices is generally influenced by domestic markets depending on market prices distortion (i.e. subsidies or other government price controls) and the level of market access guaranteed to households. Being a function of the farms size heterogeneity, the latter implies, among other things, poor infrastructure and less than perfect domestic markets characterized by lack of competition (Levinsohn, 1996). Besides, having an indirect impact on the goods purchased, the incidence of transportation, fuel, and fertilizers expenditure patterns are other sources of concern in addressing the household-level effect of current prices (Benson et al., 2009).

Nonetheless, there has been a growing dread between scholars and practitioners about the supposed redistributive outcomes of higher food prices (De Hoyos and Medvedev, 2009).

\footnotetext{
${ }^{29}$ The extent of the pass-through is an issue that needs to be tested accurately. Nonetheless most of the literature limits its tests to an hypothetical rise (Ivanic and Martin, 2008, among the others). Unfortunately, in the frame of the present work, data limitation excluded the feasibility of such an investigation in the Burundi case study.

30 " $A$ household is defined as a net producer (consumer) of agricultural products when the monetary income it derives from merchandising these products is greater (smaller) than the amount spent on them" (De Hoyos and Medvedev, 2009).
} 
According to Ivanic and Martin (2008), the share of the population living below the poverty line has increased in eight out of nine countries investigated as a consequence of higher food prices. Food inflation is identified as a source of vulnerability which hits mostly rural households (Friedman and Levinsohn, 2002), whether or not second-effect wage responses caused by higher prices were addressed in the analysis (Ravallion, 1990).

Definitely, there is a large body of evidence which challenges the idea that high food prices are fairly pro-poor, supporting the theory that higher food prices deteriorate households' income (Aksoy and Isik-Dimelik, 2008). As a result, the livelihoods of those involved in the agricultural markets, even if self-employed farmers, wageworkers in the agricultural sector, and rural landowners, might be negatively influenced as well.

Hence, the growing belief is that high food prices mostly affect net food buyers who implicitly are the poorest category within households - even in rural areas (Ravallion 1990; Seshan and Umali-Deininger, 2007; Byerlee, Myers and Jayne 2006; Ivanic and Martin 2008).

Moreover, if incomes in rural areas are strongly interdependent, the effects of food inflation might jump across different households groups, influencing at first net food sellers', besides net food buyers' income ${ }^{31}$ (Porto, 2005). This is mostly true where a multiplicative effect between agricultural and non-farm incomes arises, via local linkages and multipliers effects (Mellor 1976; Hagglade and Hazell 1989; Block 1999; Datt and Ravallion 1998; Rock 2002; Foster and Rosenzweig 2004; Hagglade et al., 2007).

Still, a relevant part of the total budget allocated for household consumption is provided by the agricultural sector, which in turn has to be considered definitely relevant in the depiction of production/consumption patterns in rural areas (De Hoyos and Medvedev, 2009).

\footnotetext{
${ }^{31}$ Aksoy and Isik-Dikmelik (2008) ponder on the income sources linkages in rural areas. In case of dependency, they find that an income change for net food sellers might have an indirect effect on net food buyers incomes. Otherwise, only first round effect would hold.
} 
Following this strand of literature, Aksoy and Isik-Dimelik (2008) compare the sources of income between net food buyers and sellers ${ }^{32}$ according to the household head occupation in nine different countries. They find evidence that half of the households investigated are marginal net food buyers, and a price increase would have a tiny impact on their welfare. Conversely, depending whether the households are better off or not, the consequences of surging food price may differ. In fact, among the poor, higher food prices negatively distress net buyers the most, whereas, "among the rich, the opposite is true; that [...] net food buyers are richer". As noted, this corroborates the claim that the majority of the population in most developing countries is likely to be adversely affected (Benson et. al., 2009).

\subsection{INVESTIGATING HIGH FOOD PRICES EFFECTS ON HOUSEHOLDS}

As previously referenced, a number of contributions monitoring the microeconomic impact of the crisis have emerged (Ivanic and Martin, 2008; Aksoy and Isik-Dikmelik, 2008; Dessus et al., 2008; Rios et al., 2008, among the others), mainly through a partial equilibrium analysis and/or price shock simulations. In the short and mediumterm, the outcomes deriving from international higher food prices are investigated according to the degree of pass-through into the domestic market, the incidence and severity of poverty among net food producers versus net food consumers, and the extent to which higher food prices might translate into higher income for farmers (De Hoyos, Medvedev, 2009).

The extensive literature, which analyzes the impact of food commodity price changes over households, corroborates this conundrum. Depending on the motivations of the research and the specific goals pursued, two main strands can be listed: those investigating first-order effects, determined by the household's net

\footnotetext{
32 They introduce seven income categories, including subsistence production, income from livestock, income from cash crops, wage income from agriculture and non-agriculture, income from business, and other income.
} 
position on food supply or demand, and those canvassing second-order effects, when distributional impacts of price changes take place over time and the quantities produced are adjusted to reflect the new set of prices in the economy.

Thus, it is possible to broadly conceptualize these contributions provided by the authors on the basis of the foresight of the effects:

\section{$\checkmark$ First-round effects approach \\ $\checkmark$ Second-round effects approach}

The main difference lies in the appropriate detail level to be included, and the stage of analytical completeness arising from the inner dynamics investigated, which needs an extensive set of assumptions behind the models to be specified. In fact, limiting the assessment to the first-order upshots has the distinctive feature to take advantage of all the information available from a survey, including the household characteristics, their income sources, and their expenditure patterns.

Thus, although usually exploiting "simple, static, disequilibrium model[s]", these short-run inquiries are straightforward in studying the incidence of price changes on the poor, provided they might implement "anything other than demand-side responses to adverse welfare shocks" (Barrett and Dorosh, 1996). Actually, when considering the impact on poverty, it would be crucial to address particularly extensive second-order effects in order to allow for a change in general equilibrium patterns (Chen and Ravallion, 2003; Ivanic and Martin, 2008). This is seldom the case since commodity price booms are typically short-lived (Deaton and Laroque, 1992). Thus, taking advantage of non-parametric techniques, the impact of rice price changes was addressed through a range of different country and commodity data: among the others Deaton (1989) used rice data from Thailand, as well as Barrett and Dorosh (1996) from Madagascar and Hoang and Glewwe (2009) from Viet Nam, besides Budd (1993) used data from Cote d'Ivoire, Loening and Oseni (2007) from Ethiopia, whereas cross countries studies were accomplished by Wodon et al. (2008a) for twelve West and Central African countries, Ivanic and Martin (2008) for nine African countries, and Zezza et al. (2008) for eleven countries. 
On the other hand, the long-term effects approach endows with a refined and comprehensive framework where partial and general equilibrium dynamics are modeled to investigate both changes in food quantities supplied and demanded, as well as employment, wage fine-tuning and technological innovation. Within this strand it is possible to list Ravallion (1990), Boyce and Ravallion (1991), Rashid (2002), Christaensen and Demery (2007), inter alii.

\subsubsection{First-round effects approach}

As it would be clearer in the following paragraphs, a rural household combines two fundamental microeconomic analysis units: the household and the firm (Singh, Squire and Strauss, 1986). Therefore, it faces both production and consumption choices under price volatility. The net impact of a food price change was addressed using profit and expenditure functions to depict production activities and consumption patterns. Deaton (1989) provided a useful methodology for such an analysis using household survey data. This methodology was widely extended and emphasized by subsequent papers (Barret and Dorosh, 1996; Klytchnikova and Diop, 2006; Ivanic and Martin, 2008; Wodon et al., 2008b; Hoang and Glewwe, 2009).

In Deaton's seminal paper (1989), rice inflation in Thailand was tackled using a nonparametric methodology. His straightforward idea was to assess the compensating variation needed in order to keep the household's utility ${ }^{33}$ level at the same level as before, thus summarizing the shift in welfare following a certain price change, and considering production and consumption activities distinctly, insofar looking at the effects on income generation and the cost of living, according to:

$$
\frac{\Delta B}{x}=\left(\frac{p_{i} \cdot q_{i}}{x}-\frac{p_{i} \cdot y_{i}}{x}\right) d \ln p_{i}
$$

where $\Delta B$ is the household welfare effect deriving from a price change $(p)$ of the good $i,(p \cdot q) / x$ and $(p \cdot y) / x$ are respectively the food budget share and the value of

\footnotetext{
33 It is possible to represent the utility level using an indirect utility function to characterize the household's welfare (i.e. a percentage of real expenditures) or through a household's profit function.
} 
production as a fraction of total household expenditures - which, at the aggregate level, can be proxied by the household's agricultural sales and food production divided by its total income or consumption (Wodon et al., 2008b). Deaton (1989) defined the term in brackets as "the elasticity of the cost of living with respect to the price of good i", suggesting that it would turn into a negative value for net producers, and a positive value for net consumers.

Deaton's main finding is that higher rice prices are expected to provide direct benefits to rural households, being those in the middle of the income distribution the ones whose incomes gain the most as an immediate effect of the redistribution provided by the new set of prices, whereas poorest and richest households are less influenced.

The above conclusions contrast somewhat with Barrett and Dorosh (1996) results who improved Deaton's non-parametric techniques as follows:

$B_{p p}=\frac{\left(F_{s}-C_{s}\right) B_{y}[\varepsilon+\beta(\eta-R)]}{p_{s}}$

where subscripts stand for partial derivates, $B_{y}$ is the marginal utility of income (which is assumed to be positive), and $F_{s}-C_{s}$ refers to the net balance of a staple food $s$ (i.e. rice output less consumption), being it positive if the household is a net seller and, vice-versa, negative if it is a net food buyer. Besides, equation [3.2] includes a set of marketable surplus coefficients - i.e. its budget share $B^{34}$, price elasticity $\varepsilon$ and income elasticity $\eta$ - and a relative risk aversion factor $R^{35}$. According to the authors, the clue of the welfare effect depends on the price volatility risk aversion, lying whether or not $R>\eta+\varepsilon / \beta$ and, ultimately, depending on the magnitude of

\footnotetext{
${ }^{34}$ That is: $\beta=\frac{p_{s} \cdot\left(F_{s}-C_{s}\right)}{y}$

${ }^{35}$ Namely the Arrow-Pratt coefficient of relative risk aversion. See Barrett and Dorosh (1996) for a detailed description.
} 
the marketable surplus budget share $B^{36}$. Thus, this first-order welfare effect might be summarized by the elasticity of real income with respect to a price change.

The authors find evidence that a rice price increase would benefit relatively wealthier farmers more than smaller farmers, without any further and significant regards to middle-income households. Moreover, they suggest rice price risk aversion among poorest farmers, pointing up that "rice-farming households routinely share or store even from a negative marketable surplus position". In fact, depending on the high vulnerability to price volatility, on behalf of the non-idiosyncratic risk faced when their principal crop price rises, not only their households' rice supply dampens with a subsequent reduction of income, but also consumption levels of the main item are affected.

Zezza et al. (2008) deal with the immediate impact of high food prices on household welfare too, using 11 Living Standard Measurement Studies ${ }^{37}$. They investigated the relation between household welfare and surging food prices with a special focus on a bundle of characteristics, i.e. access to assets and markets and livelihoods strategies to understand who are the main gainers and losers in a poverty reduction perspective. They differentiated the analysis across homogeneous household groups ${ }^{38}$ in order to understand their vulnerability to surging food prices, finding positive evidence between some households characteristics - i.e. the amount of accessible land, the education level, the number of people in the household - and the magnitude of gains and losses. Between sub-groups, the authors find further evidence that female-headed households are the ones who actually lose the most depending on their consumption patterns and the gender obstacles they face in food production.

Hoang and Glewwe (2009) improved this strand of analysis allowing for different purchasing and retail prices too. They stress the importance of focusing on real

\footnotetext{
${ }^{36}$ The authors assume that $R$ always exceeds $\eta$ for staples. See Barrett and Dorosh (1996) for further details.

${ }^{37}$ They exploit the now well-known framework $\frac{\Delta B}{x_{0}}=\frac{\Delta p^{p}}{p_{0}^{p}} \cdot \frac{p^{p} \cdot y}{x_{0}}-\frac{\Delta p^{c}}{p_{0}^{c}} \cdot \frac{p^{c} \cdot q}{x_{0}}$, where the superscripts refer to the prices at which production is valued $(p)$ and the prices at which consumption is valued $(c)$.

${ }^{38}$ They draw attention to the following household characteristics: location (urban or rural), welfare level, land ownership status and livelihood strategy.
} 
household expenditures brought on by food price changes, thus shifting the focus from food production and consumption to household food sales and purchases (i.e. net food sales). Middle income groups are found to gain the most from increased food prices, whereas, according to further grouping, the rural non-poor gain more than the rural poor. The authors also calculate the immediate impact and the secondorder effect of rice price changes, finding the latter (which implies a substitution effect) negligible.

Focusing on poverty impacts, Ivanic and Martin (2008) estimate the immediate outcomes of real small price changes on poverty headcount and poverty gap, using data from a nine low-income-country sample in a partial equilibrium framework. They also consider to some extent the wage effects for unskilled labor. Again, their findings stress that higher food prices most likely would increase poverty both in urban (with no surprise, depending on the prevalence of net food buyers) and rural areas, where there might be some gainers, even though the overall poverty impact would be negative. Typically net sales matter when considering staple food, provided relative production share out of total output value might be (partially) offset by higher consumption expenditures.

\subsubsection{Second-round effects approach}

The literature results provided in the former paragraph are somehow questioned when second-round effects are taken into account.

Since the magnitude of rural poverty is concentrated largely in two countries (i.e. China and India), Polaski et al. (2008), address this issue through a general equilibrium model, simulating changes in the prices of rice and wheat in India. They concentrate their analysis on different social groups, including the most vulnerable ones, and find that an increase of rice would benefit the most poor households, whose income would gain up to six percent from a fifty percent increase in the price of that commodity. This achievement would be determined chiefly by labor markets adjustments. Quite surprising (and in partial contrast with Zezza et al., 2008), they find evidence that gainers are among all levels of education and without gender distinction. Conversely, a simulated price reduction would hurt sharper. In fact, by simulating an opposite price change, rural households income would get hurt up to 
twelve percent (whereas in the former and opposite simulation the income gather were around six percent), with a collapsing unskilled labor demand, and a consequent spillover from rural into urban labor markets.

Chen and Ravallion (2003) estimate first and second order effects of China's access to WTO. In particular, they simulated price changes induced by trade-policies through a general equilibrium model, finding that "the decline in rural income is due to the drop of wholesale prices for most farm products, plus higher prices on education and health care". Nonetheless, they find only a small impact on mean household income, inequality and the incidence of poverty. This outcome is probably unfolded by the benefits achieved by rural household from non-farm labor wages increases and consumers' price drops ${ }^{39}$.

Conversely, De Hoyos and Medvedev (2009) linked survey data with a computable general equilibrium model covering 63 percent of the population in developing countries $^{40}$. Global poverty would increase after a rise in world agricultural prices ${ }^{41}$, with differences across regions determined by income sources and households density around each poverty line. Albeit a 5.5 percent increase in food prices would increase poverty by 0.6 points at the extreme poverty line, again, they stress that "poverty consequences of higher food prices are substantial, but that the implied total poverty elasticity of high prices (taking indirect effects into account) is much lower than the first-order, or direct, elasticity".

A computable general equilibrium model was also introduced by James et al. (2008), examining long-term adjustments induced by price changes to the economies of a net grain exporter (China) and a net grain importer (Indonesia). In China grain production expanded to detriment of other agricultural sectors. Rural households, especially agriculture-specialized households, would benefit the most from improved agricultural terms of trade. Differently, in Indonesia, producers shift their yields into the domestic market, thus being the households hit the worst. In the end, those who suffered the most by grain price hikes, thus facing a bitter incidence of poverty,

\footnotetext{
39 "The gain from the price changes induced by trade reform, [...] depends on the consumption, labor supply and production choices of the household, which depend in turn on prices and [household] characteristics" (Chen and Ravallion, 2003).

${ }^{40}$ Although China is excluded.

${ }^{41}$ They link soaring agricultural prices with first-generation biofuels demand.
} 
were those who were unable to react producing food crop surpluses, like urban lowincome, rural low-income, and landless farmers, or those with a nonfood cropproducing specialization.

Other two studies based on CGE models, even if not directly focused on high food prices but rather on market liberalization politics, provide comfort and strength to the above results ${ }^{42}$. In fact, Hertel et al. (2006) find that "higher food prices consistently push more of the non-agriculture, self-employed and the transfer dependent households into poverty", whereas Minot and Goletti (2000) observe that "higher prices have a positive effect on rural income and a mixed but slightly favorable impact on poverty", hurting the urban poor and rice-deficit households.

\subsection{HOUSEHOLD BEHAVIOR}

So far, the literature contributions reviewed provide empirical results of the effects of high food prices on households but do not endow a clue to theoretically understand the phenomenon. Yet, these surveys are quite straightforward in order to point out few general issues that need be categorized in further detail. Most obviously, among the others, there is a set of topics to be highlighted:

$\checkmark$ consequences vary by country, by region and by commodity, with the result that it is not possible to foresee an aforethought impact;

$\checkmark$ nonetheless several papers test a full and equal transmission effect from international into domestic prices, its real extent differs and matters in the assessment across countries and households;

\footnotetext{
${ }^{42}$ An overall treating of those models goes beyond the purpose of this dissertation. Nonetheless, as already mentioned, computable general equilibrium models are a sophisticated framework of equations whose conclusions need be carefully handled, being "highly dependent on assumptions made about functional forms, closure rule, and parameters, as well as the composition of the groups subject to investigation" (De Maio et al., 1999).
} 
$\checkmark$ first and second round effects contrast somehow, albeit the formers might be preferred in order to test household poverty sensitiveness;

$\checkmark$ the dichotomy between net food buyers and net food sellers rural households is a quite necessary assumption to be hold, whereas it is useful to take into account the odds that a household might shift between a position into the other, depending on several possible shocks. Moreover, the net position for a given household in a single commodity market can also substantially differ within the same season due to climate unevenness in most developing countries. Most likely, it can occur between the rainy and the dry season;

$\checkmark$ vulnerability to price volatility depends on the capacity to arrange production and consumption decisions to the new set of prices available on the market. This should be a function, among others, of land ownership, the presence of unskilled labor market and the access to agricultural technology (i.e. fertilizer, irrigation) to allow additional yields;

$\checkmark$ gender setbacks have wider consequences on female-headed households that are found to have been particularly adversely affected by the food price surge.

Thus, the understanding of the theoretical background influencing household welfare changes within the frame of soaring food prices need be assessed against these results. Above all, provided a full set of constraints faced, the explanation of rural household behavior should shed light onto the nature itself of their decision making, whereas specific economics postulations are sought in their production and consumption decisions. By means of that, this work implicitly stands between the lines ${ }^{43}$ of those who proceed "to apply formal economic calculus to the analysis of peasant behaviour" (De Janvry, Fafchamps, and Sadoulet, 1991).

As already mentioned throughout the chapter, farm households have a dual economic nature, which determines their peculiarity in the understanding of their economic

\footnotetext{
43 The peasant utility maximization sought or its absence is proposed by De Janvry, Fafchamps, and Sadoulet (1991) as the key concept to compare the positions held by the so-called formalist school (Firth, 1946; Forman, 1975; Tax, 1953; Cook, 1966) against the substantivist school, who rejected the use of formal economic analysis in the understanding of peasants behaviour (Polanyi, 1944; Dalton, 1961; Vergopoulos, 1978).
} 
nature. In fact, "the peasant unit of production is both a family and an enterprise", allowing that "it simultaneously engages in both consumption and production" (Ellis, 1992). Farming is supposed to be the main commitment and contribution to the household's livelihoods, nonetheless, it may well be that members of the households are involved in other off-farm activities depending on the available market circumstances.

A key feature is the safe and tenured access to land, where land is meant not only as a production factor, but also as a long-term protection from adverse hazards including price volatility exposure. Other rural dwellers might also be involved in the farming system, but the distinction between peasants on one side, and landless laborers, plantation workers, pastoralists on the other, is straightforward to foresee their vulnerability to exogenous shocks. Besides, also the labor market depicts its own peculiarity - where the supply and demand drivers are channeled throughout the predominance of family labor whose enlargement or reduction settlements contribute dramatically to employment and wage pass-through in times of changing food prices.

In rural areas, economic agents represent - or are influenced by - these peculiarities plus a sort of market integration degree factor, defined as the "partial integration into markets" level and the "limitations in the operation of market principles" (Friedmann, 1980) ${ }^{44}$. Hence, being "market failures [...] so pervasive for farm households that they have been used as a definitional characteristic of peasantries" (De Janvry and Saudolet, 2004), rural households behavior in a contest of high food prices ought to reflect these insights.

\subsubsection{Separable household models}

Hitherto, the preceding intuitions provide some useful caveats, which need further conceptualization.

\footnotetext{
44 "Peasants are households which derive their livelihoods mainly from agriculture, utilise mainly family labour in farm production, and are characterised by partial engagement in input and output markets which are often imperfect or incomplete" (Ellis, 1993).
} 
The twofold characteristics of a household, defined both as a family and as an enterprise, determine its decision process to be sequential or integrated. In other words, a household allocates its inputs to gain a certain level of production for a selected number of activities, with the idea of maximizing its profits ${ }^{45}$. Consequently, consuming patterns would be the outcomes resulting from previous production-bounded choices, and have no possible spillovers on future ones. Thus, the level of income is the linkage between household production and consumption choices. In this view the household budget is assumed to be "endogenous and depends on production decisions that contribute to income through farm profits" through a positive farm profit effect which is additional to the standard Slutsky effect in case of higher prices (Taylor and Adelman, 2003).

Formally, it is possible to address the problem by dividing the analysis according to the three agents behaviors incorporated in the household model: the producer, the consumer and the worker (De Janvry and Saudolet, 1995). They are all affected by exogenous variables, such as cash crop prices, household demographic and tenure constraints, time, fixed productive asset endowments and production technology in their maximization function (Singh, Squire and Strauss, 1986).

By doing so, the following notations will hold: $\mathrm{q}$ are both the inputs and outputs, where the latter are the crops produced within the household (food crop $q_{f}$ and cash crop $q_{c}$ ) and the former are the inputs used (i.e. fertilizer $q_{x}$ and labour $q_{l}$ ). Accordingly, on the consumption side, the household consumes food $\left(c_{f}\right)$, a manufacture good $\left(c_{m}\right)$ and home time $\left(c_{l}\right)^{46}$.

Thus, the producer issue is to maximize profits:

$$
\begin{aligned}
& \underset{q}{\operatorname{Max}} \pi=p_{c} q_{c}-p_{x} q_{x}-w q_{l} \\
& \text { s.t.: } \quad g\left(q_{c}, q_{x}, q_{l} ; h^{p}\right)=0
\end{aligned}
$$

\footnotetext{
45 According to Schultz (1964), farm families in developing countries were "efficient but poor", thus following the profit maximization in their production decisions.

${ }^{46}$ In literature often referred to as "leisure" time. In Chayanov household utility maximization model, the focus is mainly on the family-labor-allowance subjective decisions made by the households (Thorner et al., 1966).
} 
being $w$ the wage for salaried labor. The constraint is the production function where $h^{p}$ defines a set of fixed household characteristics linked to production, such as farm size, land and capital.

On the other hand, the household may decide either to self-consume, and implicitly buy, its own produced goods and time endowments, or to address its consuming patterns through market. Therefore, the consumer problem is to maximize her utility:

$\underset{c_{f}, c_{m}}{\operatorname{Max}} u\left(c_{f}, c_{m} ; h^{c}\right)$

s.t.: $\quad y=p_{f} q_{f}+p_{m} q_{m}$

where $h^{c}$ is a set of household characteristics and $y$ is the income at disposal.

Finally, a key assumption in a model as such is the possibility to shift from home to waged labor and vice-versa, depending on labor demand fluctuations. Hence, the household decouples its production target from family labor by means of consuming more or less home-time and filling the gap with hired employees. Thus, the worker problem is to maximize utility with respect to income and home time:

$$
\begin{aligned}
& \underset{c_{l}, y}{\operatorname{Max}} u\left(c_{l}, y ; h^{w}\right) \\
& \text { s.t.: } \quad y+w c_{l}=w e
\end{aligned}
$$

where $e$ is worker's total time endowment, made up of home time $c_{l}$ and worked time $q_{l}$, and $h^{w}$ refers to a set of worker's characteristics. Accordingly, the household integrates the above problems as follows:

$$
\begin{aligned}
& \underset{c_{f}, c_{m}, c_{t}}{\operatorname{Max}} u\left(c_{f}, c_{m}, c_{l} ; h\right) \\
& \text { s.t.: } \quad g\left(q_{f}, q_{x}, q_{l} ; h^{p}\right) \\
& p_{f} c_{f}+p_{m} c_{m}+w c_{l}=\pi+w e=y^{*}
\end{aligned}
$$


where again $\pi=p_{f} q_{f}-p_{x} q_{x}-w q_{l}$ is the farm restricted profit ${ }^{47}$ and $h$ is the combination of the full set of household characteristics $h^{p}, h^{c}$ and $h^{w}$.

Here, the household first resolve its producer problem in equation [3.3], defining a $\pi^{*}$. Then, using this maximum level of profit achievable, the consumer/worker problem in equation [3.6] can be solved.

With perfect markets, the resulting effect of a food price increase determines input marginal product to raise in order to hire inputs up to equate their new price. Thus, as already mentioned above, the effect on the consumer side combines two different and opposite in sign effects, and is a priori ambiguous depending on the slope of the utility function as well as the magnitude of the profit effect. Conversely, on the food production labor demand-side, it definitively increases according to the improved marginal product of labor (Taylor and Adelman, 2003).

A model like the one here exposed - defined separate or recursive model - presumes that all prices are exogenous and decisions are sequential, implying markets to work perfectly (Lau et al., 1981; Ahn et al., 1981). Nonetheless, at least in developing countries, a number of market failures should be accounted for, thus clearing the ground from the aforementioned statement.

Thus, when referring to the categories of production and consumption linked to market failures, it has to be introduced what in literature is known as the nonseparable farm household model (Singh, Squire and Strauss, 1986).

\subsubsection{Non-separable household models}

Typically, "a market may fail for a particular household when it faces wide price margins between the low price at which it could sell a commodity or factor and the high price at which it could buy that product or factor" (De Janvry and Saudolet, 1995). In other words, the household might prefer to quit a given market when its

\footnotetext{
${ }^{47}$ Equation 6.2 is the combination of the cash constraint $p_{x} q_{x}+p_{m} c_{m}=p\left(q_{f}-c_{f}\right)+w l$ and the time constraint $e=c_{l}+q_{l}$.
} 
subjective price - derived from its supply-demand balance - falls inside a defined price band (Key, Sadoulet and de Janvry, 2000), thus deciding that it would be better to choose for self-sufficiency whereas participating in that market.

This definition is household specific and does not necessarily imply market nonexistence for a given commodity. Actually, the market exists, but the corresponding commodity becomes non-tradable for that specific household. In general, when transaction costs $\tau$ bite, they directly reflect poor infrastructure, a value-chain overcrowded by intermediaries or local monopolistic merchants, lack of information, supervision and hired labor, and opportunity costs.

Moreover, harvests reflect covariate risks ${ }^{48}$, thence determining that usual household net position in the local market, characterized by a food surplus to be sold or a food deficit to be purchased, is somewhat hinged by other households' net positions, with the consequence that local prices are pro-cyclically affected and households quit the market according to wider or narrower price bands. In fact, "the shallower local food and labor markets are, the more prices can be expected to be positively correlated with movements in shadow prices, trapping the household within the range of self-sufficiency" (De Janvry, Fafchamps and Saudolet, 1991). Accordingly, when the supply-side fluctuates, high elasticity of food demand enhances the prospects that a net seller would decide not to trade, whereas when the demandside fluctuates, high elasticity of food supply urges net-buyers to self-sufficiency as well. This phenomenon is exacerbated by risk aversion and credit constraints as well.

When one of the above market failures applies, then the commodity involved becomes non-tradable for the household, implying that its price is endogenous and not directly observable, being the equilibrium between the marginal utility of goods and home-time, and the marginal productivity of labor. In this case, the internal shadow price satisfies the equilibrium condition between household's output and its demand for food (Strauss, 1986; de Janvry, Fafchamps and Sadoulet, 1991).

By contrast with separable models, the decision process spurting from a conceptualization as such, implies that the production decisions, i.e. the choice

${ }^{48}$ The transmission from the international into the domestic market represents a covariate risk $\rho^{c}$ which would affect all the households in the neighborhood at the same time, thus amplifying procyclically its effects. 
between food and cash crops or the use of inputs, are influenced by the consumer characteristics.

Thus, the household has to maximize its utility function with regards to its income constraint for the tradable commodities $(T)$, its production technology, and the equilibrium conditions for tradables and non-tradables (NT), which are assumed to be in competition for fixed inputs utilization (typically land or labor, when these markets are missing). This problem has been investigated by several authors (De Janvry, Fafchamps and Saudolet, 1991; De Janvry and Saudolet, 1995; Omano, 1998;

De Janvry and Saudolet, 2004) according to the following model:

$$
\begin{array}{ll}
\operatorname{Max}_{c, q} & u\left(c_{f}, c_{m}, c_{l} ; h\right) \\
\text { s.t.: } & \sum_{i \in T}\left[\left(p_{i}-\tau\right) \delta^{S E L L}+\left(p_{i}+\tau\right) \delta^{B U Y}\right] \cdot\left(q_{i}+e_{i}-c_{i}\right)+R+s \geq 0 \\
& g\left(q ; h^{p}\right)=0 \\
& p_{i}=\bar{p}_{i}, i \in T \\
& q_{i}+e_{i}=c_{i}, i \in N T
\end{array}
$$

where $\delta^{S E L L}$ and $\delta^{B U Y}$ are dummy variables which assume the values $(1,0)$ for net sellers and $(0,1)$ for net buyers, $R$ are budget transfers (i.e. remittances) and $s$ are savings. The Lagrangian associated with the constraints maximization problem is:

$$
\begin{aligned}
L= & u\left(c ; z^{h}\right)+\lambda\left\{\sum_{i \in T}\left[\left(p_{i}-\tau\right) \delta^{S E L L}+\left(p_{i}+\tau\right) \delta^{B U Y}\right] \cdot\left(q_{i}+e_{i}-c_{i}\right)+R+s\right\}+\phi g\left(q_{i} ; h^{p}\right)+ \\
& +\sum_{i \in N T} \mu\left(q_{i}+e_{i}-c_{i}\right)
\end{aligned}
$$

which implies that optimal consumption and production must respectively satisfy the following first-order conditions, which are partial derivates of $u$ and $g$ as far as the variables $\mathrm{c}$ and $\mathrm{q}$, in order to have an interior solution: 


$$
\begin{aligned}
& u^{\prime}=\lambda \sum_{i \in T}\left[\left(p_{i}-\tau\right) \delta^{S E L L}+\left(p_{i}+\tau\right) \delta^{B U Y}\right]+\mu \\
& \phi g^{\prime}=-\lambda \sum_{i \in T}\left[\left(p_{i}-\tau\right) \delta^{S E L L}+\left(p_{i}+\tau\right) \delta^{B U Y}\right]-\mu
\end{aligned}
$$

When the household is a seller or a buyer, its price would respectively be:

$$
\begin{aligned}
& p_{S E L L}=p_{i}-\tau \\
& p_{B U Y}=p_{i}+\tau
\end{aligned}
$$

Conversely, in case it is bounded to self-sufficiency, its shadow price would fall inside the above price bands, being the ratio between the marginal utility of endowments in non-tradable and marginal utility of cash:

$$
p_{i}=-\mu / \lambda
$$

Market price risk attitude and food availability influence price bands width that in turn broadens in the instance of an exogenous shock like higher food prices. In figure 3.1 , households are driven towards autarky when this is the result stemming from higher transaction costs.

FIGURE 3.1: PRICE BANDS

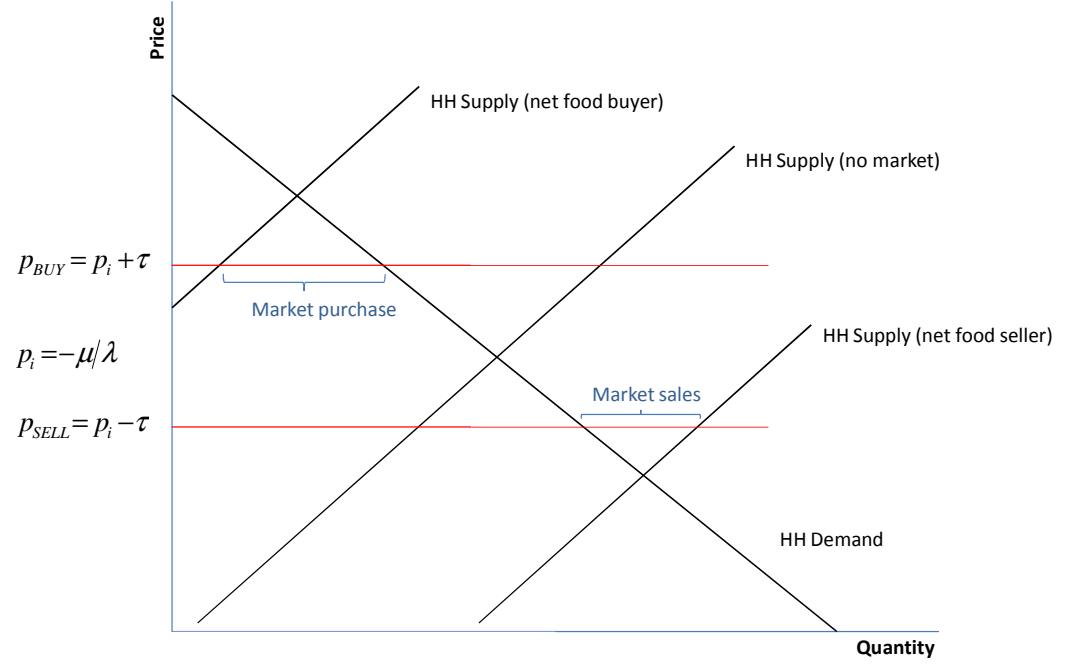


Moreover, provided no changes in production technology or land assets can be put in place in the short run, the resulting occurrence of increased food production entails de-emphasizing cash crop production. In fact, the heterogeneity of endowments as well as transaction costs and covariate risks settle market participation alternatives on household and determine those who are bounded to quit the market to adjust their production and consumption decisions accordingly.

Households with a limited endowments set, usually affected by limited access to land tenures in primis, and by a thin credit market consequently, face an exogenous price shock through consumption smoothing strategies focusing on less risky farm yields and poor investments, with the aim of guaranteeing a secure income flow (Alderman and Paxson, 1994), but with the practical chance to hinder their future income generation process. These outcomes are emphasized in case of missing labor markets and relative workforce abundance, when households might be tied up to less income generating farm activities and foreclosed from off-farm work.

Insofar, "the decision of whether or not to participate in a market is endogenous and discrete, shaped by the household's reservation or shadow price and by the price band, including transaction costs" (Taylor and Adelman, 2003). Consequently, the market participation decision process will be assessed in the following paragraph.

\subsubsection{Uncertainty and risk}

The above approach does not address the existence of uncertainty and risk provided by natural hazards (weather, pests, diseases and natural disasters), market fluctuations, social uncertainty (insecurity associated with control over resources, such as land tenure and state interventions), and man-made disasters (Ellis, 1992).

In fact, market failure participation, which determines the household to plummet the market, is also fuelled by uncertainty and risk $^{49}$, and farmers subjective

49 Despite most of the literature uses the terms risk and uncertainty as synonyms, Ellis (1992) distinguishes between risk and uncertainty according to the occurrence probability of an event or a set of events. In the case of risk, this probability can be attached and it is the expected frequency measured out of one, whereas uncertainty reflects the events whose occurrence likelihood is not knowable and therefore no probability is possible to attach. Within the frame of farm economics, he further advocates 
probabilities associated to uneven events consequently. Moreover, whether the household participates in the market or not, it is likely to be adversely affected by a price change via shadow prices adjustments caused by factor market linkages (Dyer, Boucher and Taylor, 2005).

In general, credit and insurance lack constraints foster rural households to adjust their decision making to prevent their business from high risk-related activities and secure their income stream as far as they can (Dasgupta 1993).

According to von Neumann-Morgenstern's (1944) expected-utility function, the peasant's attitude towards risk should be embodied in its utility function, determining that consumption smoothing would be preferable for a risk-averse household rather than put into gear choices that might determine a fluctuating consumption stream. Thus, rural household literature often depicts small-scale farmers as risk-averse because in case of seasonal production failures, they cannot afford to fully cover their needs and are at risk of starvation. Thence, risk attitude has to be offset with ex ante strategies at disposal. In fact, some farmers might act as if they were risk adverse because of their constraints and market imperfections (Roumasset, 1976; Eswaran and Kotwal, 1989 and 1990), especially “in developing countries where market imperfections are prominent and consumption and production decisions are non-separable" (Mendola, 2007).

In the aftermath, when the household income is at tremendous low levels, "only a discrete addition to income can lift it out of the mire" (Dasgupta, 1993) and its utility function would be flat at the lowest levels of income, with an abrupt increase in the closeness of the threshold income level. Therefore, only after a safety-first threshold is secured, farmers might be willing to choose according to the expected utility framework.

Under similar stressful requirements, to secure their households needs, the perception of uncertainty might distress households from pure utility seeking

that risk refers to "subjective probabilities attached by farm decision to the likelihood of occurrence of different events", thus reflecting the whole set of uncertain event a farmer need to face in its whole decision process. Under this view, uncertainty now refers to the wide variety of uncertain events, spanning from natural disaster to price volatility, to which farmers "will attach various degrees of risks, according to their subjective beliefs of occurrence of such events". In the continue I will refer to the latter definition. 
conducts, and the decision to participate or not in the market switches the field of investigation from the utility maximization theory above underlined into a more household behavioral-bounded approach. This is much true where ex post risk coping mechanisms are not accessible, granted access to credit and formal insurance markets were not approachable.

Hence, this has also been referred to as the disaster-avoidance survival algorithm (Lipton, 1968; Mosley and Verschoor, 2005). In a more sophisticated shape, farmers might first secure their basic needs, lowering their acceptable subjective risk and constraining their decision making accordingly, in order to secure their income at a minimum income level, following a safety-first rule of thumb (Roy, 1952; Telser, 1955; Kataoka, 1963). A paramount motivating factor for the household is to control its assets to the extent that it can cover its future consumption/income streams through a probability statement $P(x<d) \leq \alpha$, where $\mathrm{x}$ is a random variable, i.e. income return from farming activities or consumption, $d$ is a fixed targeted level, defined as the minimal wealth required for physical existence or even a disaster threshold, under which the household could severely suffer from starvation, and $\alpha$ is the probability of failing to achieve the target. Clearly, provided the uncertainty of its prospects, what constitutes a disaster depends on the individual. Several authors have emphasized this criterion in many empirical and theoretical works (Lipton, 1968; Masson, 1974; Roumasset, 1976; Moscardi and De Janvry, 1977; Kunreuther and Wright, 1979; Shahabuddin and Feeny, 1987; Ellis, 1992).

Moreover, facing such a critical issue in the present represents a mire for the future, as far as mental skills or physical power are lessened by current low consumption flows (Dasgupta, 1997), thus implying "not only low current utility, but also the prospect of utility losses in the future through this consumption-productivity linkage" (Zimmerman and Carter, 2003).

\subsection{VULNERABILITY TO POVERTY}

So far, risk has been depicted as the originating factor determining the outflow from the profit maximization framework. The attitude towards risk is usually referred to 
as in relation with time-biting constraints, when the household may be ex ante credit or liquidity constrained, and/or ex post involved in consumption smoothening. Conversely, risk aversion would be countenance of the concavity of the utility function (Rosenzweig and Binswanger, 1993).

Indeed, at certain income levels, it has been argued that safety-first demeanors are more plausible to be pursued in order to prevent the household to face what has been defined as a disaster for the household, and the poor behave differently because having so little to lose they are desperate, provided that "beyond some points, having less to eat really stop mattering [...] or stops mattering in the mind of someone who is not yet there but is thinking of it as a possibility" (Banerjee, 2001).

In other words, in order to account for their loss aversion and provided poor households have a steeper loss function, sensitiveness to wealth-decrease rather than to increases should matter the most. Hence, a deeper concern for wealthchanges rather than for wealth-levels stems out (Kahneman and Tversky 1979; Mullainathan and Thaler, 2000).

Indeed, whether or not to tackle investment activities with high-expected returns (Lipton 1968; Rosenzweig and Binswanger 1993) may not be the outcome of risk preferences. Actually, it might be tailored to the household circumstances, which hinders the possibility to cope with ex-post consumption risk with potentially significant implications for long-term poverty (Yesuf and Bluffstone, 2009).

In fact, Dercon and Christiansen (2007) find evidence that poor households are reluctant to adopt modern inputs (i.e. fertilizers), insofar they are unable to protect against downside risk, thus perpetuating their poverty roots and remaining put with low return activities, even if they might not be more risk averse than richer households. Moreover, provided subsistence constraints and agent heterogeneity, asset-accumulation paces determine the pursuit of activities in terms of risk level and prospect returns (Dercon, 1998). Therefore, notwithstanding their risk attitude, households with a proper set of consumption insurance strategies against shocks behave differently than the poorest households (Eswaran and Kotwal 1990; Rosenzweig and Binswanger 1993; Mosley and Verschoor 2005; Dercon and Christiaensen 2007). 
Consequently, those who are poor are trapped by their current wealth state to detriment of future improvements. Specifically, smallholders may be particularly unwilling to undertake innovative investment actions being reluctant to borrow or take other risks that might preclude their future control over their limited assets (Eswaran and Kotwal, 1986; Morduch, 1993 and 1995). This facet accounts households for the fear of losses and is referred to as poverty as vulnerability which is "almost literary the opposite of having too little to lose" (Banjerlee, 2001).

Following this conceptual shape, poverty as well as uncertainty and risk contributes in explaining households decisions oddities, when safer strategies with lower returns are preferred, thus trapping households equipped with lower coping strategies in poverty. Since extreme poverty, vulnerability and insecurity emphasized by price volatility are relevant factors in most rural developing countries, incorporating "into a model the strong points from both the behavioral and full optimality approaches, [...] seems an appropriate descriptive device" (Mendola, 2007).

Thus, the household faces a dual utility problem. Under the circumstance $\alpha$ that it would incur into a close-to-depletion consumption level $P(c<d)$, it would pursue decisions as to equal the disaster utility level matched with consumption $c_{d}$. Otherwise, it would follow its expected utility maximization pattern subject to idiosyncratic $\left(\rho^{i}\right)$ and covariate $\left(\rho^{c}\right)$ risks, depending on its attitude towards risk:

$$
\begin{aligned}
& u(c)=\left\{\begin{array}{l}
u\left(c_{d}\right) ; \quad P(c<d) \leq \alpha \\
\operatorname{Max} E u\left(c_{f}, c_{m}, c_{l} ; h \mid \rho^{i}, \rho^{c}\right) ; \quad P(c \geq d)=1-\alpha
\end{array}\right. \\
& \text { s.t.: } \quad \sum_{i \in T}\left[\left(p_{i}-\tau \cdot \rho^{c}\right) \delta^{S E L L}+\left(p_{i}+\tau \cdot \rho^{c}\right) \delta^{B U Y}\right] \cdot\left(q_{i}+e_{i}-c_{i}\right)+R+s \geq 0 \\
& \\
& g\left(q ; h^{p} ; \rho^{i} ; \rho^{c}\right)=0 \\
& p_{i}=\bar{p}_{i}, i \in T \\
& q_{i}+e_{i}=c_{i}, i \in N T
\end{aligned}
$$


In Figure 3.2, the solid line represents the frontier of all expected utility levels satisfying the maximization problem. The covariate risk (i.e. derived from a price shock) amplifies the price bands. In the horizontal part of the line, the household quits the market, finding the autarchic choice more convenient. On the bottom edge of the price bands, the household becomes a net food seller, whereas in the upper bound it is a net purchaser. The dash line in red indicates the disaster line associated with the consumption c with a chance of occurrence $\alpha$. Depending on the position of this safety-first threshold with respect of the expected utility frontier, the household might incur in a poverty trap. In fact, following the example in Figure 3.2, it would be pushed to the disaster avoidance line instead of attempting to move on up to higher utilities. The point-dashed line refers to the utility deriving from a consumption granted at the poverty-line level. Under the hypothesis in figure 3.2, household utility would need an exogenous push in order to quit the poverty trap and enter in the frontier of expected utilities as to maximize its consumption/producing decision.

Hence, poor households aimed at preserving their livelihoods are more inclined at lowering their consumption rather than using their productive assets as a buffer stock $^{50}$. By doing so, they indirectly jeopardize their assets in the long term (Dercon and Hoddinott 2005), for instance by withdrawing their children from work (Dasgupta, 1997; Gubert and Robillard, 2008) or lowering their nutritional intake (Giesbert and Schindler, 2010) because, at those lowest utility levels, in the occurrence of a shock, "the true distinction lies in households' choices regarding what type of capital - physical, financial, social, or human [...] - that they should draw down given an income shock" (Hoddinott, 2006).

\footnotetext{
${ }^{50}$ Conversely, better-off households would allow for the opposite strategy.
} 
FIGURE 3.2: HOUSEHOLD UTILITY AND POVERTY TRAP

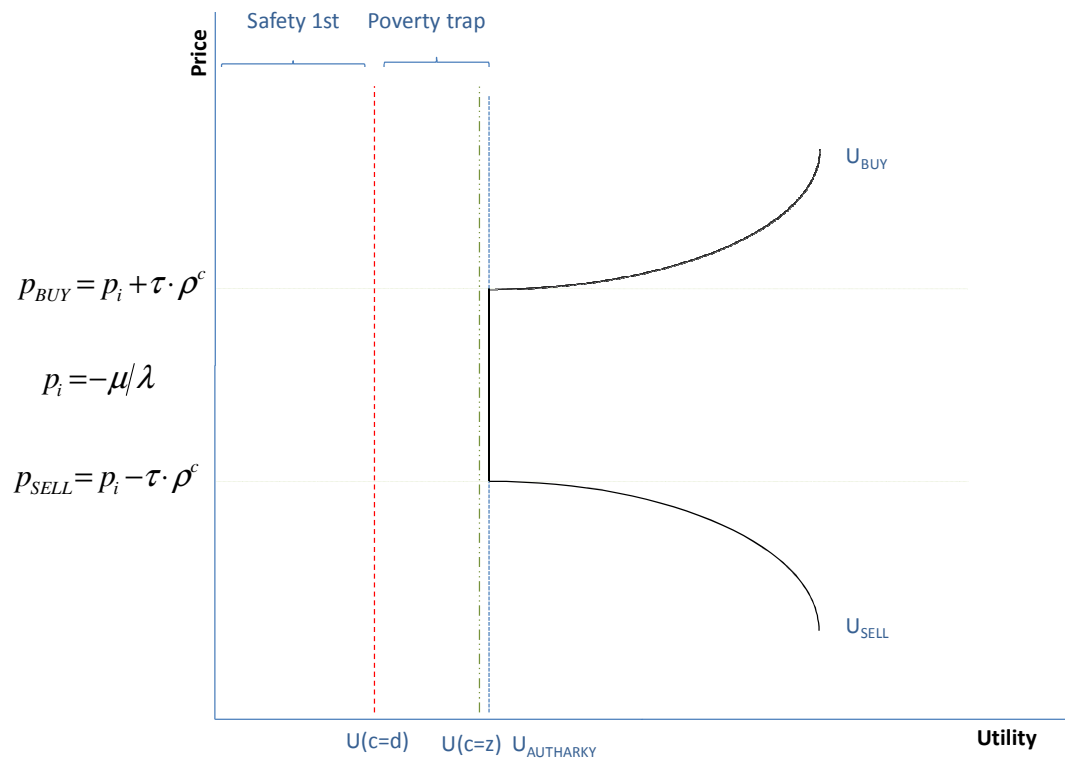

Thus, under this behavior framework, identifying the household status in relation to the poverty threshold and their asset holdings (Zimmerman and Carter, 2003) is likely to be of seminal importance to address higher food prices effects. Nonetheless, what really matters is not the static description of a poverty line, rather the patterns in and out of poverties (Addison et al. 2009), that are defined by vulnerability to poverty, which in turn depends upon low endowments and risks, thus being further enhanced by food price volatility. 


\section{MEASURING VULNERABILITY: ALTERNATIVE APPROACHES AND MAIN FINDINGS}

\subsection{VULNERABILITY, AN OVERVIEW}

High food prices typically insist and strengthen their effects on those who are less in the circumstances of coping with them. Among those, the rural poor, whose livelihoods are less incline to secure the effects of adverse shocks, are the ones assumed to be hit the most.

An in-depth focus on vulnerability is desirable in order to assess the outcomes derived from a risky environment. Besides, at a first glance, vulnerability is a smooth concept, and no defined agreement on its definition has been found so far, thus stimulating a huge amount of different contributions. Indeed, a vast literature has emerged on this subject, with different strands related to its definition and empirical methods used to assess its magnitude.

Vulnerability can be considered a forward-looking concept. In fact, if on the one hand those who are currently constrained into poverty could actually be tomorrow's poor their future status is prone to (almost) unpredictable outcomes. This may be the outcome of a limited endowments set at disposal, either or erratic and beyond one's command events. On the other hand, under dicey and unfavorable circumstances, those who are currently not poor, even though relatively well-off, might well find themselves in the marshes tomorrow. At a glance, "what really matters is the ex-ante risk that a household will, if currently non-poor, fall below the poverty line, or if currently poor, will remain in poverty" (Chauduri, Jalan and Suryahadi, 2002), which carries forward several implications.

In fact, the likely outcome of the incidence of risk in terms of future wellbeing deserves notice. Actually, what is currently observable and measurable today, and which in turn determines the current poverty level of a household, should be assessed in a forward-looking prospect. Thus, because the definition of vulnerability 
infers at future status, time plays a key role. Against this framework there is a further pillar to be included, which actually is the core of the vulnerability definition itself: the measure of wellbeing that might be affected.

Hereinabove, three were the key words emphasized: the measure of wellbeing, risk, and time. Hence, against these benchmarks, a review of the literature will be carried forward.

In fact, with respect of the first, there are two main strands that hold up vulnerability as a measure of low expected utility (Ligon and Schechter, 2003; Schechter, 2006; Erasado, 2008; Rayan, 2010) or highly expected poverty (Christiaensen and Boisvert, 2000; Chauduri, Jalan and Suryahadi, 2002; Christiaensen and Subbarau, 2004; Sarris and Karfakis, 2007, among the others).

With regards to the second, it is possible to enlist literature addressing vulnerability as a measure of a selected shock impact (Glewwe and Hall, 1998; Ligon and Schechter, 2003; Christiaensen and Subbarau, 2004; Alderman, Hoddinott and Kinsey, 2006) or, differently, in terms of consumption fluctuations within a population (Townsend, 1994, 1995; Udry, 1995; Jalan and Ravallion, 1999, Christiaensen and Boisvert, 2000; Dercon, 2003).

Finally, the latter refers to the methodology pursued. In fact, in order to advocate for time dimension, households should be observed throughout a certain time horizon. Thus, panel data are the most suitable ground to fulfill such a requirement. Unfortunately, in most developing countries, data availability is very poor, and crosssections normally are the only data at disposal of the researcher. Therefore, the forward-looking dimension forces literature in terms of data constraints, and consequently, in terms of the methodology to be chosen to assess vulnerability.

Thus, this chapter will review the above briefly introduced literature and its major empirical findings. 


\subsection{MEASURING VULNERABILITY}

As a first evidence arising from the above mentioned circumstances, there is a close link between poverty and vulnerability. Actually, this is mostly stressed among those households with a limited set of endowments who, in a given time horizon, might account for different spells in and out poverty (Banejee and Newmann, 2000) depending on the shocks faced and the coping strategies they were able to put in practice. The erratic results that may arise from a snapshot as such advocate a more subtle insight. Such instability and unpredictability, which decline to a broader feeling of vulnerability, contribute to exacerbate the poverty condition the poor go through up to unbearable levels (WB, 2001; Schechter, 2006). It can be defined as the magnitude of the threat of future poverty, where threat refers to "the likelihood of suffering poverty in the future, and to the severity of poverty in such a case" (Calvo and Dercon, 2005).

In fact, not only the objective status which infers to the well being of a household at a given time is to be accounted for, but also something that is more indefinable and related to risk perception or, better, preparedness. As it was put forward in section 3.5, it can be argued that household decisions not only are influenced by the presence of uncertainty but, in a more severe fashion, they are definitely affected by the current status of deprivation.

Thus, along the socio-economic factors that need to be addressed to construct a measure of vulnerability, actually something that would be definable as a behavioral threshold must be always accounted for, at least in the lights of defining and interpreting vulnerability.

\subsubsection{Expected utility}

So far, in order to provide a judgment measure of household well being, it has been assumed that both the dependent variable, being itself consumption or income, as well as the risk faced, should be taken into account. Furthermore, the inclusion of risk preferences in vulnerability measure could be advocated by moral hazard behavior (Christiaensen and Subbarao, 2005). 
By doing so, Ligon and Schechter (2003) suggest a utilitarian framework where vulnerability is the net outcome between the utility associated with a certaintyequivalent consumption $\left(c^{e}\right)^{51}$, and the household expected consumption expenditures:

$$
V_{i}\left(c^{e}\right)=\left[U_{i}\left(c^{e}\right)-U_{i}\left(E c_{i, t}\right)\right]+\left[U_{i}\left(E c_{i, t}\right)-E U_{i}\left(E\left(c_{i, t} \mid \bar{x}\right)\right)\right]+\left[E U_{i}\left(E\left(c_{i, t} \mid \bar{x}\right)\right)-E U_{i}\left(c_{i, t}\right)\right]
$$

Where the first term in brackets is a measure of poverty which determines that "an additional unit of expected consumption has diminishing marginal value in reducing poverty", as far $E c_{i}$ approaches $c^{e}$, being the utility function increasing and concave. Furthermore, the remaining two terms refer to a measure of risk faced by household $i$, which is broken into an aggregate measure of risk conditional to a vector of aggregate variables $\bar{x}$, and an idiosyncratic component. Here, the overall vulnerability depends not only on the mean in household consumption, but also on its variation.

Thus, provided this approach allows to break down the utility function into poverty and risk, capturing both the idiosyncratic and the aggregate features, in principle it would be possible to "identify whether vulnerability affects those with low asset levels, unfavorable settings or low returns to assets" (Gaiha and Imai, 2004).

The main assumptions following from above refer to the choice of the utility function $^{52}$, and in devising of a way to estimate conditional expectations (Schechter, 2006). Such a measure would be sensitive not only to the threats faced, but also to positive outcomes, provided the fear of starvation is compensated by its contrary scenario (Calvo and Dercon, 2005).

Although arising from a different perspective, Cunningham and Maloney (2000) propose a continuous set of weights, derived from marginal utilities of consumption, to be applied to arbitrarily small changes in family income. In fact, nonetheless they define vulnerable "those with a 'high' probability of falling below the poverty line,

\footnotetext{
${ }^{51}$ This should be a risk-free and zero inequality threshold, which implies that every household receives the expected per capita consumption bundle without uncertainty.

52 Where the curvature reflects household preferences and the utility function takes the form: $u(c)=c^{1-\rho} /(1-\rho)$, and $\rho=2$ is the household's relative risk-aversion (Ligon and Schechter, 2002; Hardaker et al., 2004; Rayhan, 2010).
} 
or of falling further in poverty", still they speculate about the inconsistencies in vulnerability-measure approaches based on poverty. In fact, they call attention to variability in relative social positions, especially those insisting among middle class workers, stressing that the full set of coping strategies put in place might be unsuitably measured ${ }^{53}$.

\subsubsection{Expected poverty}

The expected utility approach suffers for its inherent wickedness, namely the definition of the utility associated with the lowest level of wellbeing. Albeit, to some extent, all theoretical frameworks have to indulge with somewhat harsh assumptions in order to describe complex phenomena, here the issue turns to be definitely relevant. In the light of sections 3.4.3 and 3.5, it would hardly be admissible to allow the poorest households to grant some utility ranking to their future destitution, being tomorrow's hunger and pain beyond one's knowledge and judgment (Shackle, 1965; Kanbur, 1987). Even at higher levels of well-being, the utility framework involves individual preferences to be correctly estimated, with the succeeding methodological and data hardness, including overestimation of risk aversion due to utility function curvature (Just and Pope, 2003) and barely-information about individual-preferences (Griffin, 1986). Thus, Christiaensen and Subbarao (2005) "prefer not to cast [their] vulnerability measure in an individual utilitarian framework, but rather like to think of a social planner who accounts for the depth of consumption shortfalls in a consistent and uniform manner across all individuals, irrespective of their risk preference".

\footnotetext{
53 "It is not obvious that we shouldn't care about the middle class workers who, upon becoming unemployed, may nonetheless have to take defensive measures that may have strong and persistent negative social effects, such as pulling children out of school. Further, in the same way that poverty lines are, to some degree constructs that recognize relative social position, it is also not clear that variability in itself shouldn't receive some weight: perhaps a large fall by an upper middle class family should not be given a zero weighting while a small fall by a marginal poor family gets much higher weighting. Finally, the discreteness imposed by the poverty line adds additional complications. For instance, how do we weight $1 \%$ income fall of a family infinitesimally above the poverty line compared to that of family infinitesimally below?" (Cunningham and Maloney, 2000).
} 
An alternative way to gauge vulnerability entails and implements poverty assessments. The literature here cited is set on the ground of Foster, Greer and Thorbecke (1984) family of poverty measures that are widely used throughout poverty literature. It is worth recalling their most general feature adapted for the $i$ th household ${ }^{54}$ :

$P_{\alpha, i, t}=\left(\frac{z-c_{i, t}}{z}\right)^{\alpha},(\alpha \geq 0)$

where $\alpha$ is a measure of the sensitivity of the poverty index and $z$ is the poverty line. Considering $F\left(c_{i, t+1}\right)$ as the cumulative distribution, and $f\left(c_{i, t+1}\right)$ the density function of expected consumption (or whatever other focal variable ${ }^{55}$ ), it follows from above that vulnerability can be defined as follows (Fishburn, 1977; Foster et al., 1984; Christiaensen and Boisvert, 2000; Chauduri, 2003):

$$
\begin{aligned}
& v_{\alpha, i, t}=E\left[P_{\alpha, i, t}\left(c_{i, t+1}\right) \mid F\left(c_{i, t+1}\right)\right] \\
& =\int\left(\max \left\{0, \frac{z-c_{i, t+1}}{z}\right\}\right)^{\alpha} d F\left(c_{i, t+1}\right) \\
& =F(z) \int_{c_{t+1}}^{z}\left(\frac{z-c_{i, t+1}}{z}\right)^{\alpha} \frac{f\left(c_{i, t+1}\right)}{F(z)} d c_{i, t+1}
\end{aligned}
$$

\footnotetext{
${ }^{54}$ A detailed compendium of FGT poverty measures, including properties and drawbacks of headcount index (when $\alpha=0$ in section 4.1), poverty gap index $(\alpha=1)$ and squared poverty gap index ( $\alpha=2$ ) goes beyond the aim of this dissertation. In a very digest notation, quoting Haughton and Khandker (2009), the first measures the proportion of the population that is counted as poor, the second adds up the extent to which individuals on average fall below the poverty line and can be considered as the minimum cost of eliminating poverty with regards to the poverty line, whilst the third squares the poverty gap and implicitly bestows a higher weight to households falling below the poverty line. In addition to FGT measures, the Sen-Shorrocks-Thon index combines the headcount index, the poverty gap index applied to the poor and a term with the Gini coefficient of the poverty gap ratios, thus measuring the proportion of the poor people, the depth of their poverty, and the distribution of welfare among the poor. Finally, the Watts index is computed by dividing the poverty line by income, taking logs, and finding the average over the poor, thus fulfilling the focus, monotonicity and transfer axioms which are found to be pivotal in any good poverty measure (Ravallion and Chen, 2001). More recently, Foster (2009) suggested a new family of chronic poverty measures where time dimension is included.

55 For example, Christiaensen and Boisvert (2000) assess future caloric consumption, defying food vulnerability by the probability now of being undernourished in the future.
} 
By connecting vulnerability and poverty, Chauduri, Jalan and Suryahadi (2002) define vulnerability as "a forward-looking or ex-ante measure of household's well-being, whereas poverty is an ex-post measure of a household's well-being (or lack thereof)".

In their seminal work, time dimension turns out to be crucial in dodging limited panel data constraint. In fact, once the analysis focus is carried forward to a subsequent period $t+1$ in the future, it will hence be possible to measure the resulting poverty by defining it as the ex-post recognition of a well-being measure determined by a set of households characteristics (Deaton, 1992) by means of a probability distribution realization previously marked out at time $t$. Thus, in this forward-backward time framework, that probability realization at time $t+1$ can be assessed as the yardstick for household vulnerability at time $t$. So that, by opting for consumption expenditure as the measure of well-being, and defining the probability distribution within the grounds of poverty literature, a vulnerability measure implicitly allowing time dimension - even though estimated from cross-section data - would be available ${ }^{56}$ and can formally be written as:

$v_{i, t}=\operatorname{Pr}\left(c_{i, t+1} \leq z\right)$

where $z$ is the social threshold (here defined as the poverty line) beneath which a household may be considered poor. Pritchett, Suryahadi and Sumarto (2000), set the threshold probability with a 50-50 odds ratio and expand the time horizon to ponder for more risk associated and thus higher vulnerability.

\footnotetext{
56 "This implies that while the poverty status of a household is concurrently observable - i.e., with the right data we can make statements about whether or not a household is currently poor - the level of vulnerability is not. We can estimate or make inferences about whether a household is currently vulnerable to future poverty, but we can never directly observe a household's current vulnerability level" (Chauduri, Jalan and Suryahadi, 2002). For a discussion on the limitations of this approach see later (section 4.3.1).
} 


\subsubsection{Exposure to adverse shocks}

Another definition of vulnerability is granted in terms of exposure to adverse shocks and changes in socio-economic status (Glewwe and Hall, 1998; Cunningham and Maloney, 2000; Amin, Rai and Topa, 1999; Dercon and Krishnan, 2000). Similarly to the expected poverty approach, the smoothing consumption literature sets a threshold beyond which consumption changes - or income fluctuation - following a shock would determine vulnerability, as a result of limited coping ability. In this case the threshold is not external, as like in the measures taking advantage of the poverty line, but internal, and the vulnerability definition is definitively tailored on the change spread borne by the household. So that, in a different light, it is not the absolute upshot of a consumption shock that matters, even if it turns out to be extremely severe in terms of household well-being, but its extent. It follows that poor households, albeit in a distressing situation, may not necessarily be considered vulnerable.

Glewwe and Hall (1998) provide as example subsistence farmers in remote areas, which are "usually poor but their relatively autarchic status limits the impact of national and international economic events". Conversely, they point out that nonpoor households vulnerability is seldom addressed, thus focusing on market-induced vulnerability. Households more susceptible to economic shocks, because their income are sensitive to regional or international conditions beyond their command, or relying on limited income diversification and unsteady livelihoods, might put in place a large set of ex-post smoothing behaviors. Those strategies foster or rely on asset depletion, direct production of consumption goods, increased labor force participation, borrowing, public insurance schemes, informal insurance networks, labor diversification and reallocation, reconfiguration of expenditure patterns away from investment in human capital (Glewwe and Hall, 1998; Christiaensen and Subbarao, 2004). All former schemes are yet very limited for several households (Barrett, Reardon and Webb, 2001), and often forestalled by ex-ante behaviors. Actually, these vulnerability measures does not assess ex-ante smoothing mechanisms besides consumption (or income) outcomes.

More recently, Dutta, Foster and Mishra (2010) somehow addressed similar issues related to vulnerability measures, specifically by criticizing the literature failure to 
heed how depth a fall below the poverty line might be. They hence propose a measure which should improve previous methodologies by merging the consumption smoothing and the expected poverty approaches. Still, similar to the approach reviewed in this section, they strongly claim poverty and vulnerability being distinct concepts and axiomatically advance a measure including both the individual threshold - and the standard of living ${ }^{57}$ - typical of consumption smoothing and the social threshold (i.e. poverty line).

The need for a vulnerability measure at the individual level based on welfareeconomic axiomatic foundations was previously highlighted and developed by Basu and Nolen (2006), Calvo and Dercon (2005, 2007) and Calvo (2008). Punctually, Calvo and Dercon $(2005,2007)$ propose, inter alia, the focus axiom ${ }^{58}$, which implies that outcome changes above the poverty line ought be disregarded in order to not compensate worsening changes, thus ensuring vulnerability to be sensitive only to negative outcomes, and the risk sensitive axiom, which claims that vulnerability would be lower if an expected outcome "were attained in all states of the world and uncertainty were thus removed", implying that greater risks raise vulnerability.

\subsubsection{Risk-addressing measures}

Notwithstanding the mainstream literature upholds one of the measures above cited, this strand of literature refers to a less homogeneous class of papers, where risk is explicitly addressed as an outstanding issue to get a measure of vulnerability.

Based on the axiomatic assumptions outlined before, Povel (2010) proposes an approach to vulnerability which explicitly accounts for household downside risk perception, which is supposed to be influenced only by future outcomes occurring below the household wellbeing level. The author correctly evidences how a

\footnotetext{
57 "Our methodology explicitly accounts for individual's current standard of living since it may convey important elements about a person's vulnerability. In this context the standard of living represents a broad set of factors including individual's assets and income along with other dimensions of well-being such as health" (Dutta, Foster and Mishra, 2010).

${ }^{58}$ Other axioms are: symmetry over states, continuity and differentiability, normalization, probabilitydependent effect of outcomes, probability transfer, and constant relative risk sensitivity (Calvo and Dercon, 2005, 2007).
} 
perceived or not perceived risk determines the household to put in place or not a set of ex-ante strategies that in a way alter its vulnerability to shocks. Once perceived risk occurrence and severity are scored, this proposed measure assigns an index of deprivation to every state of the world for each household, allowing for different attitudes towards risk specification. Yet, even if this approach is promising, "admittedly, the use of this information implies the stringent assumption" that respondents are able to assess the severity of impacts across different future events without having some sort of a reference scale" (Povel, 2010).

Cafiero and Vakis (2006) point out that "even an optimistic survey of this literature [those above reviewed] leaves the reader with a general sense of skepticism on the possibility to use any of the existing measures of vulnerability in a fully satisfactory way". Actually, they go further in their criticism, by rejecting the prevalent distinction between a static and a forward-looking concept which, in the twofold vulnerability to poverty approach, are assumed to be the core. Hence, in the lights of socially intolerable consequences deriving from a shortfall in well-being, the inability to appropriately manage risk is the suggested device for measuring poverty, without assuming any further difference with vulnerability. In addition, according to their position, poverty measurement embedding risk would wipe off too compelling assumptions, including the definition of a distribution to estimate future events and the stationary implied by assuming that the future is going to be similar to the past. Thus, a redefined "augmented" poverty line ${ }^{60}$ accounting for the cost of insurance against risk is proposed ${ }^{61}$.

Finally, taking his steps from a similar pattern, Scaramozzino (2006) applies the analysis of vulnerability in the context of food security through risk management. He advances a Value-at-Risk (VaR) methodology where "the worst loss that can be expected, given a specified level of probability (denoted as the confidence level)" is measured, namely the probability to fall below a specified nutritional critical

\footnotetext{
${ }^{59}$ Furthermore, the author addresses the issue of the heuristics of probabilities, depicting the heuristic of representativeness, of adjustment, of availability as possible drawbacks in self attribution of perceived risk.

60 In the frame of FGT poverty measures, they define augmented poverty line as the "poverty line that includes the minimum amount of consumption required to achieve basic needs plus the cost needed for acquiring enough insurance" (Cafiero and Vakis, 2006).

61 "However, even this risk premium cannot be estimated on the basis of events that have never occurred in the past and hence have unknown probability" (Christiaensen and Sarris, 2007).
} 
threshold. This approach allows the researcher to a measure whether the household strategy may not prevent it "from making decisions that could yield a potentially large expected outcome and that only entail a moderate amount of risk".

\subsection{EMPIRICAL BACKGROUND: MAIN FINDINGS PER COVARIATE}

So far the major findings as well the empirical strategies employed within the frameworks above reviewed have not been mentioned yet. A comprehensive review per covariate, including all the frame of references, goes beyond the scope of this section. Anyway, for the sake of plainness, it can be helpful to put forward some of the major results.

Household size

A large family size might contentiously affect household vulnerability. In fact, on the one side economies of scale help satisfy needs at lower cost (Deaton and Paxson, 1998). Moreover, in case an endogenous shock would occur, a larger bulk of available labor-supply within the household members provides a diversification of income activities, through non-farm activities or through temporary migration. Yet, according to Ligon and Schechter (2003), having an increasing number of employed members ends the household up to cope with more risks from unobservable sources. On the other side, when income diversification strategies are limited, average consumption can be reduced, and the variance of future consumption can also be larger.

Gender

Female-headed households suffer for a broadly gender-related economic gap, typically put forward by cultural and social norms. There are several factors underlying this bias, which can be explained by uneven access to market and land in many developing countries, restricted access to formal credit markets due to limited 
collateral at disposal, lacking of insurance markets, and discrimination in employed labor (for a throughout review see Klasen, Lechtenfeld and Povel, 2010). However, the subsequent claim requiring female-headed households to be more likely poor has been questioned (Lipton and Ravallion, 1995) and found disagreeable empirical findings. Indeed, the analysis should switch from a gender to an intra-gender comparison (Chant, 2008), where dependency ratios and adult equivalence scales ought be addressed, as well with education bias and remittances, in order to involve a de jure or de facto distinction among female-headed households (Quisumbing et al., 2001; Klasen, Lechtenfeld and Povel, 2010).

Nonetheless, even though female headed households might have the same or higher expenditures levels compared to male-headed households, they face greater expenditure variability depending on fewer coping strategies options at disposal, and hence are supposed to be more inclined to vulnerability to shocks (Pritchet et al., 2000). Conversely, some evidence attributes a higher aggregate risk faced by households headed by men (Glewwe and Hall, 1998; Rayhan, 2010).

More striking, in a preliminary analysis for Thailand and Vietnam households, when de jure or de facto distinction is allowed among female-headed households, high vulnerability to poverty is found only for the former (Klasen, Lechtenfeld and Povel, 2010). Addressing this issue may provide empirical strength to the refusal of the "rhetoric-fuelled stereotype that households headed by women are at a disadvantage in all the dimensions of vulnerability in comparison to those headed by men" (Waite, 2000).

\section{Education}

Schultz (1975) speculates that educated individuals are less vulnerable even though their ex-ante exposure to risk might be the same compared to other individuals. Thanks to their higher ability to adapt to changing circumstances, they might show a propensity to innovation and quickly adapt to new income opportunities. Besides, they can use assets more efficiently, and generally liaise with higher awareness or contracting clout. Evidence is found in Christiaensen and Subbarao (2004). At higher education levels, the average vulnerability and headcount vulnerable rate are found to be lower by Pritchett, Suryahadi and Sumarto (2000), by increasing expectations 
of future consumption (Jha and Dang, 2008), also with regards to both aggregate and idiosyncratic sources of risk (Rayhan, 2010). Adult females education is a (negative) significant determinant of the variability of consumption, because uneducated females hardly would succeed in mitigate consumption variability shocks (Sarris and Karfakis, 2006). Less education might also unfold unexpected results with regards to female headed household, which are not supposed to suffer for higher vulnerability per se, but might experience higher vulnerability as a consequence of lower education compared to men (Glewwe and Hall, 1998).

Land

In countries where the prevalent economic structure is based on agriculture, land is the driver to address poverty reduction in rural areas. The more a country economic network is heavily damaged, the more enhanced land access becomes the most efficient and effective tool for household to face rural poverty and its dire effects, whenever other household strategies might be limitedly exploited, including off-farm activities, money transfers and migration (Caccavale, 2005). In fact, empirical evidence associates land with higher incomes (World Bank, 2007), whilst landless laborer - being typically asset poor - are prone to be negatively affected by uneven shocks (Sen, 1981).

Thus, empirical findings addressing vulnerability often focus on land. Amazedly, Pritchet et al. (2010) find land ownership results to be disagreeing comparing two different datasets. In fact, by taking into account one dataset at time, both landed and landless rural households face lower average vulnerability, higher per capita expenditures means and lower poverty rates versus the other group. Conversely, land holding and utilization are found to positively affect average consumption in non-arid zones in rural Kenya (Christiaensen and Subbarao, 2004) and decrease household vulnerability (Jha and Dong, 2008). 


\section{Livelihoods and assets}

With regards to the occupational sector, advanced poverty rates combined with lower per capita mean expenditures are higher for households mainly involved in the agriculture, followed by manufacture, trade, and services. In opposition, vulnerability assessment reverse this scale ordering (Pritchet et al. 2000), finding further support from Christiaensen and Subbarao (2004), where subsistence farmers in Kenya are found to be less vulnerable than unskilled private sector workers. With some exception, net food buyers appear to be more vulnerable compared to net food sellers (Sarris and Karfakis, 2006).

Assets possession, including agriculture properties and livestock, increases future consumption expectations. In particular vulnerability, differently from poverty, is reduced when households have "liquid" livestock, as-like sheep and goats, that are less productive than cattle but more likely are assumed to smooth consumption against idiosyncratic shocks (Christiaensen and Subbarao, 2004). 


\section{AN ECONOMETRIC ANALYSIS OF FOOD PRICE SHOCKS ON HOUSEHOLD VULNERABILITY IN RURAL BURUNDI}

\subsection{EMPIRICAL STRATEGY: ECONOMETRIC ISSUES}

As can be inferred, measuring vulnerability is highly data demanding. Being a dynamic concept, which may include several covariates other than unobserved effects, the best data requirement to get an appreciable achievement would be a households panel. Unfortunately, such a fair data copiousness hardly is available in developing countries. Yet, strong limitations arise from scanty or null panel data, whilst comparatively detailed surveys assessing household living standards are increasingly common.

This chapter is so organized: in the first part the empirical literature addressing vulnerability measures will be reviewed, with regards to the expected poverty approach and within a cross section frame. Subsequently, a multilevel model will be described, which better suits with the survey sampling available. Finally, the last part of this chapter will bestow the results out coming the Burundi case study.

\subsubsection{Empirical literature review}

A possible workaround is to exploit howsoever single cross sections. Basing on their relatively copiousness, an increasing literature firstly advanced by Christiaensen and Boisvert (2000) and Chauduri, Jalan and Suryahadi (2002) is developing.

This literature exploits and extends the shortcomings arising from the expected poverty approach, which molds household behavior through a vector of household 
characteristics $\left(X_{i}\right)$ affecting the mean and the variance of future consumption model $^{62}$, through a three-step feasible generalized least square methodology.

Chauduri, Jalan and Suryahadi (2002) first estimate log-consumption through OLS,

$\ln c_{i}=\beta X_{i}+\varepsilon_{i}$

where $\varepsilon_{i}$ is a zero-mean error term. The error term in the stochastic consumption function is assumed to depend linearly on vector $X_{i}$, and hence to be heteroscedastic $\left(\sigma_{\varepsilon_{i}}^{2}=\tau X_{i}\right)$. Thus, in a second step, with the squared residuals as left-handy variable, they estimate using OLS as follows:

$\hat{\varepsilon}_{i}^{2}=\tau X_{i}+\eta_{i}$

Finally, in the last step of their strategy, after dividing each term in 5.2 by $\hat{\tau} X_{i}$,

$\frac{\hat{\varepsilon}_{i}^{2}}{\hat{\tau}_{O L S} X_{i}}=\tau\left(\frac{X_{i}}{\hat{\tau}_{O L S} X_{i}}\right)+\frac{\eta_{i}}{\hat{\tau}_{O L S} X_{i}}$

the predictions are used to re-estimate [5.2'] using OLS in order to get an asymptotically efficient estimate $\hat{\tau}_{F G L S}$.

With the now consistent estimates $\left(\hat{\sigma}_{\varepsilon_{i}}^{2}=\hat{\tau}_{F G L S} X_{i}\right)$, equation [5.1] is similarly transformed

$\frac{\ln c_{i}}{\sqrt{\hat{\tau}_{F G L S} X_{i}}}=\beta\left(\frac{X_{i}}{\sqrt{\hat{\tau}_{F G L S} X_{i}}}\right)+\frac{e_{i}}{\sqrt{\hat{\tau}_{F G L S} X_{i}}}$

so that, expected log consumption and its variance can be finally estimated through $\hat{\beta}$ and $\hat{\tau}_{F G L S}$.

As already mentioned, poverty and vulnerability are two sides of the same coin (Chauduri, 2003; Bankoff, Frerks and Hilhorst, 2004). Hence, vulnerability may be expressed as the current probability of falling beyond a determined threshold in the

\footnotetext{
${ }^{62}$ See next section for further details.
} 
subsequent period, given the stream of expected consumption and the volatility of a household, defined under the normality assumptions, by its mean $\mu$ and variance $\sigma^{2}$. Recalling the set of equations in [4.2], it makes sense to define vulnerability in terms of the expected headcount index ${ }^{63}$, by specifically exploiting FGT index measures as follows

$\hat{V}_{i}=\hat{\operatorname{Pr}}\left(\ln c_{i}<\ln z \mid \hat{\mu}_{\ln c i}, \hat{\sigma}_{\ln c_{i}}^{2}\right)=\Phi\left(\frac{\ln z-\mu_{\ln c i}}{\hat{\sigma}_{\ln c i}}\right)$

where $\Phi(\cdot)$ denotes the cumulate density of the standard normal (Chauduri, 2003). Thus, vulnerability can be measured by substituting in [5.3] the estimated expected consumption and variance, thus allowing

$$
\hat{V}_{i}=\hat{\operatorname{Pr}}\left(\ln c_{i}<\ln z \mid X_{i}\right)=\Phi\left(\frac{\ln z-\hat{\beta} X_{i}}{\sqrt{\hat{\tau}_{F G L S} X_{i}}}\right)
$$

Such a three-step methodology was further implemented, including information on covariate shocks (Christiaensen and Subbarao, 2005), by utilizing historical information on price yields and production (Christiaensen and Sarris, 2007), allowing for instrumental variables for crop income (Sarris and Karfakis, 2006), and estimating with maximum likelihood allowing for multilevel-data (Günther and Harttgen, 2009; Jadotte, 2010).

Repeated cross-sections are also exploited by Bourguignon, Goh, and II Kim (2004). They compare, by means of true panel data, the accuracy of the estimates resulting from a pseudo-panel (Deaton, 1985; Verbeek and Nijman, 1993; Deaton and Paxson, 1994), formed by cohorts of randomly selected individuals born in a 5-year interval over time. They pursue with satisfactory outcomes the following hint: within a cohort certain characteristics may be common and recoverable at the aggregate level. So that, "observing the evolution of the mean and the variance of earnings within $a$ cohort is sufficient to estimate the common characteristics of individual earning processes" (Bourguignon et al., 2004). Moreover, Christiaensen and Subbarao (2004)

\footnotetext{
${ }^{63}$ Adding further complexity, vulnerability to poverty can also be defined in terms of expected poverty gap ratio or expected squared poverty gap. Nonetheless, as Chaudhuri (2003) points out, it is not possible to evaluate analytically these estimates of vulnerability, even though they can easily be obtained from Monte Carlo simulations.
} 
exploit pseudo-panel econometric techniques using two cross sections in rural Kenya, adding historical information on shocks and averaging the observations over households in each community of the sample.

\subsubsection{Expected mean and variance in consumption}

In their seminal paper, Chauduri, Jalan and Suryahadi (2002) assert that unexplained variation in consumption levels lies through the banks of households differences which, in panel data dictionary, would consist in unobserved and time-invariant determinants. When such claim holds, cross-sectional data would not be able to investigate and measure vulnerability by no means. Conversely, whereas the most of the variation could be ascribed directly to the household circumstances then allowing stringent assumptions on one side and, on the other relaxing somewhat the level of information that the resulting vulnerability measure would offer ${ }^{64}$ - crosssection data would also be a quite accurate tool in the vulnerability measurement.

According to this approach, household's vulnerability to poverty can be defined under a parametric framework, through a non-linear function of future consumption levels (Chauduri, Jalan and Suryahadi, 2002; Chauduri, 2003). The core assumption remarking from the uncertainty context assumed from the preceding - the volatility of consumption, here expressed in terms of consumption variance in a forwardlooking perspective - is thus implicitly put forward. Within this framework, not merely expected future consumption streams, but a buoyancy arising from household circumstances need be assessed, that is to say that "we need to [...] not only estimate [household] expected consumption in the future but also to be able to say something about the distribution of its future consumption" (Chauduri, Jalan and Sarayadi, 2002).

\footnotetext{
64 "We face a challenge of not only trying to overcome the lack of the time dimension, but also that of having no information on the risks faced and the options available to the household to mitigate such risks. We thus have to make simplifying assumptions about how shocks evolve over the cross-sectional space. But at the same time we recognize that large common shocks such as economic crises cannot be captured by our method" (Chauduri, Jalan and Sarayadi, 2002).
} 
As it can easily be inferred, this is not a toll free assumption. In fact, in order to draw advantage of the setting above depicted, this strand of literature allows consumption to be log-normally distributed, so that it is possible to argue that its mean and variance clutch expected consumption stream and volatility, respectively ${ }^{65}$. The latter, it is worth stressing, captures both idiosyncratic and covariate shocks being, in other words, the workaround to explain the ability to cope with uncertainty through household and community specific features (Günther and Harttgen, 2009).

In formal terms, recalling and readjusting equations [5.1] to expand the 3-step methodology with multilevel analysis (Goldstein, 1999; Günther and Harttgen, 2009; Jadotte, 2010) for the sake of next sections, consumption for the household $i$ is thus determined by a vector of household characteristics, $X_{i}^{66}$ :

$\ln c_{i}=\beta_{0}+\beta_{1} X_{i}+\varepsilon_{i}$

and the variance of the unexplained part $\varepsilon_{i}$ is defined by

$$
\sigma_{\varepsilon_{i}}^{2}=\tau_{0}+\tau_{1} X_{i}+\eta_{i}
$$

As already emphasized, the $X_{i}$ vector in equation [5.4] allows the variance of the disturbance term to be not the same for all households, hence reflecting how shocks affect household consumption. Chauduri (2003) further expand [5.4] including some time-invariant factor, which could be addressed as the impact of community-specific shocks on consumption (Günther and Harttgen, 2009).

Controlling for household heteroskedasticity guarantees the estimates to be efficient, thus allowing a proper estimation of a household's probability of being

65 Kamanou and Morduch (2002) propose a non-parametric approach focusing on Monte Carlo simulations of future consumption distribution, based on bootstrapping observable shocks. This model is yet based on the assumption that the shock distribution would be the same across all households, regardless the different circumstances they face, or, to put it differently, not allowing for heteroskedasticity (Chaudhuri, 2003).

${ }^{66}$ Besides, Chauduri (2003), further specifies the circumstances which can affect consumption: household and community characteristics, international (i.e. commodity price shocks) or locally covariate shocks (i.e. flood, drought, plague), idiosyncratic shocks (i.e. death, illness, unexpected unemployment inside the household), unobserved area-specific shocks, time invariant household effects and idiosyncratic time-varying disturbance terms. Such an extended form hardly may be available, and hence represent an almost ideal full set of information. 
poor, that is to say its vulnerability level. Conversely, that measure would be grounded on correlated disturbance term, which would be formally reflected in [5.3'] by the standard deviation in the denominator.

In economic terms Chaudhuri (2003) conjectures the variance of this disturbance term as the inter-temporal variance of log consumption. That is to say, whether the variance was deemed the same across all households and homoskedasticity is assumed, the disturbance term would consequently rely on measurement errors or unobserved factors, which would imply the mean and variance estimates to be monotonically related, "ruling out the possibility that a household with a lower mean consumption may nevertheless face greater consumption volatility than a household with a higher average level of consumption. Both formal and anecdotal evidence points to high levels of income and consumption volatility for poor households" (Chauduri et al. 2002).

Moreover, provided the marginal effects of the regressors on the ex-ante mean and variance of future consumption can differ in sign granted such a flexible heteroskedastic specification (Just and Pope, 1979), it could be possible to infer in risk-coping ability (Jadotte, 2010), firstly including consumption smoothing (Christiaensen and Subbarao 2004).

\subsubsection{A multilevel approach}

Following the aforementioned framework, vulnerability to poverty will be investigated through a hierarchical (or multi-level) modeling approach (Bryk and Raudenbush, 1992; Goldstein, 1999; Hox, 2002) addressing the Burundi Comprehensive Food Security and Vulnerability Survey carried out in 2008 by the World Food Programme. Hence, in order to allow an empirical strategy tailored on the sampling method, per capita consumption will be addressed in a three-level formulation, where the subscript $i$ reflects the household level, $j$ the sous-colline level, and $k$ the province level.

Besides, adopting an empirical strategy coherent with the survey plan at disposal, provides additional key information to the dataset taking advantage of clustered 
data ${ }^{67}$, where each individual is part of a cluster, so that households are clustered in sous-collines, which are correspondingly clustered in provinces. The households consumption function may partly be the outcome of the community they are settled in, hence determining that households within the same sous-colline tend to be more alike than households in different districts, "thus causing a greater dependency of observations, or high intra-class correlation" (Roberts, 2004).

With regards to the empirical strategy that will be exploited, several further returns shall be pondered as well. According to Goldstein (1999), tackling the hierarchical data structure without freely assigning community characteristics to each household, enables to gain more efficient estimates and correct standard errors, confidence intervals and significance test. Moreover, by allowing the use of covariates at any of the levels of the hierarchy, factors which differently influence consumption in terms of household or community characteristics become noticeable. Therefore, it would also be possible to rank provinces in terms of their reaction capabilities to different circumstances or, more specifically, to high food prices. Conversely, "neglecting the fact that individuals or measurement occasions may be nested inside other larger clusters will often lead researcher to erroneous conclusions about their data" (Roberts, 2004) and fail to acquire useful quantification of the variation among community in the population (Goldstein et al., 1998).

Accordingly, the above modeling requires that observations within the same cluster might be correlated as a result of an unobserved cluster effect (Woolridge, 2002), that can be generally shaped as follows:

$\ln c_{i j k}=\beta_{1}+\beta_{2} X_{i j k}+\varepsilon_{i j k}=\beta_{1}+\beta_{2} X_{i j k}+u_{k}+v_{j k}+e_{i j k}$

where $u_{k}$ is the random intercept featuring a main effect for province, and $v_{j k}$ is the random interaction of sous-collines by province which can be interpreted as a province-specific bias of the sous-collines (Dunn, 1992). The strict exogeneity assumption in the model requires the error term $e_{i j k}$ to be uncorrelated with the explanatory variables for all units within cluster $i$, whereas the random intercepts $u_{k}$

\footnotetext{
67 "The multilevel modeling approach views the population structure as of potential interest in itself, so that a sample designed to reflect that structure is not merely a matter of saving costs as in traditional survey design, but can be used to collect and analyse data about the higher level units in the population. The subsequent modeling can then incorporate this information and obviate the need to carry out special adjustment procedures, which are built into the analysis model directly" (Goldstein, 1999).
} 
and $v_{j k}$ are allowed to depend on cluster level covariates (Woolridge, 2002) and represent, respectively, the deviations of community $j$ 's and province $k$ 's intercepts from the mean intercept $B_{1}$. Consequently, "the random intercepts and the residual error term are assumed to be mutually independent and independent across replications" (Rabe-Hesketh and Skrondal, 2008):

$e_{i j k} \mid x_{i j k}, v_{j k}, u_{k} \sim N(0, \theta)$

$v_{j k} \mid x_{i j k}, u_{k} \sim N\left(0, \psi^{(2)}\right)$

$u_{k} \mid x_{i j k} \sim N\left(0, \psi^{(3)}\right)$

where $\psi^{(2)}$ and $\psi^{(3)}$ are the between-household variances and $\theta$ is the withinhousehold variance ${ }^{68}$.

Hence, taking advantage of such a decomposition at the different levels, it is possible to target the unexplained variance $\psi$ for the population of clusters and inference with relation to the population mean $\beta$ (Rabe-Hesketh and Skrondal, 2008). As already put forward, this is particularly convenient in a vulnerability analysis, where one of the goals is the impact assessment on households' consumption of idiosyncratic household-specific shocks and covariate community (here expressed both in terms of districts and provinces) shocks (Günther and Harttgen, 2009).

More, such an approach make further sense in survey analysis, where households sharing the same geographical circumstances, are likely to have some characteristics correlated, including having been affected by similar shocks or having adopted equivalent coping strategies. Moreover, in the frame of vulnerability analysis, several socio-economic characteristics are likely to be influenced by similar drivers as well.

Even though a source of inefficiency determined by data structure is thus depleted whenever household and community variables are used simultaneously, it comes out from the preceding that a strong assumption still holds. In fact, the effects of covariates might also vary over clusters. Hence, the hierarchical model with specific random intercepts $u_{k}$ and $v_{j k}$ can be further refined by including community and province random slopes as well,

\footnotetext{
${ }^{68}$ So that the variance of the model is $\sigma_{\varepsilon}^{2}=\theta+\psi^{(2)}+\psi^{(3)}$.
} 
$\ln c_{i j k}=\beta_{1}+\beta_{2} x_{i j k}+u_{1 k}+v_{1 j k}+u_{2 k} X_{i j k}+v_{2 j k} X_{i j k}+e_{i j k}$

where the household-specific expected outcome - by limiting at this level the speculation to a single covariate vector $X_{i j k}$ - would be

$$
E\left(\ln c_{i j k} \mid x_{i j k}, u_{1 k}, u_{2 k}, v_{1 j k}, v_{2 j k}\right)=\left(\beta_{1}+u_{1 k}+v_{1 j k}\right)+\left(\beta_{2}+u_{2 k}+v_{2 j k}\right) X_{i j k}
$$

where the overall cluster variance $\psi$ depends on the covariate $X_{i j k}$, providing further heteroskedasticity in the model.

\subsubsection{Model specification}

In the remainder the multi-level model will be specified using an alternative fashion than [5.5] and [5.6], where the distinction between level covariates and the subsequent dependencies in and across levels will be explicitly formulated (Raudenbush and Bryk, 2002). In fact, under such a specification, where levels are nested and specified through a sub-model, it is possible to isolate and conceptualize not only those covariates and shocks directly influencing consumption at the household level, but also those providing information at the different stages in the clusters, both directly and indirectly. Thus, level-1 model can be written as

$$
\ln c_{i j k}=\beta_{1 j k}+\beta_{2 j k} X_{i j k}+e_{i j k}
$$

whilst level-2 model can be written as

$$
\begin{aligned}
& \beta_{1 j k}=\beta_{11 k}+\beta_{12 k} Z_{j k}+v_{1 j k} \\
& \beta_{2 j k}=\beta_{21 k}+\beta_{22 k} Z_{j k}+v_{2 j k}
\end{aligned}
$$

Finally, level-3 model is

$$
\beta_{11 k}=\beta_{111}+\beta_{112} W_{k}+u_{11 k}
$$




$$
\begin{aligned}
& \beta_{12 k}=\beta_{121}+\beta_{122} W_{k}+u_{12 k} \\
& \beta_{21 k}=\beta_{211}+\beta_{212} W_{k}+u_{21 k} \\
& \beta_{22 k}=\beta_{221}+\beta_{222} W_{k}+u_{22 k}
\end{aligned}
$$

Substituting backwards level-2 into level-1

$$
\ln c_{i j k}=\beta_{11 k}+\beta_{12 k} Z_{j k}+v_{1 j k}+\left(\beta_{21 k}+\beta_{22 k} Z_{j k}+v_{2 j k}\right) X_{i j k}+e_{i j k}
$$

and level-3 into level-2

$$
\begin{aligned}
& \ln c_{i j k}=\beta_{111}+\beta_{112} W_{k}+u_{11 k}+\left(\beta_{121}+\beta_{122} W_{k}+u_{12 k}\right) Z_{j k}+v_{1 j k}+ \\
& +\left\lfloor\beta_{211}+\beta_{212} W_{k}+u_{21 k}+\left(\beta_{221}+\beta_{222} W_{k}+u_{22 k}\right) Z_{j k}+v_{2 j k} \mid X_{i j k}+e_{i j k}\right.
\end{aligned}
$$

the resulting model would be a combination of a deterministic and a stochastic part as follows:

$$
\begin{gathered}
\ln c_{i j k}=\underbrace{\beta_{111}+\beta_{112} W_{k}+\beta_{121} Z_{j k}+\beta_{122} W_{k} Z_{j k}+\left(\beta_{211}+\beta_{212} W_{k}+\beta_{221} Z_{j k}+\beta_{222} W_{k} Z_{j k}\right) X_{i j k}}_{\text {Deterministic }}+ \\
+\underbrace{\left(u_{12 k}+u_{22 k} X_{i j k}\right) Z_{j k}+\left(u_{21 k}+v_{2 j k}\right) X_{i j k}+u_{11 k}+v_{1 j k}+e_{i j k}}_{\text {Stochastic }}
\end{gathered}
$$

where the deterministic part of [5.7] is settled on:

$X_{i j k}$ : household characteristics;

$Z_{. j k}$ : household characteristics within the same sous-colline;

$W_{. . k}$ :household characteristics within the same province;

$X_{i j k} Z_{. j k}$ : interaction term which analyzes cross-level interactions between variables at the household and sous-colline level; 
$X_{i j k} W_{. . k}$ : interaction term which analyzes cross-level interactions between variables at the household and province level;

$Z_{. j k} W_{. . k}$ : interaction term which analyzes cross-level interactions between variables at the sous-colline and province level.

The stochastic part is characterized by:

$e_{i j k}$ : which represents the unexplained variance across households and captures the impact of idiosyncratic shocks;

$V_{. j k}$ : which represents level two residuals unexplained variance which captures the impact of covariate shocks at the sous-colline and province level;

$u_{. . k}:$ which represents level three residuals unexplained variance which captures the impact of covariate shocks at the province level;

$u_{. . k} Z_{. i k} X_{i j k}, u_{. . k} Z_{. i k}$ and $\left(u_{. . k}+V_{. j k}\right) X_{i j k}$ : that capture the impact of covariate shocks at the sous-colline $\left(v_{. j k}\right)$ and province $\left(u_{. . k}\right)$ level, including a deterministic part $\left(X_{i j k}\right.$ and $\left.Z_{. i k}\right)$.

\subsubsection{Empirical strategy}

The full model sketched above is somehow cumbersome, considering it comprises all possible cross-level effects and their interactions. In order to enable a straightforward strategy it may be useful to proceed incrementally - through a “model building” procedure (Raudenbush and Bryk, 2002; Roberts, 2004).

First, an unconditional or, so-called, empty model which includes no explanatory variables is regressed, aimed at estimating only the consumption grand mean as well as providing information on the variance at the individual and community-levels, on the basis of the sample structure. This will be the baseline to further develop the model, by means of comparing future models against it, up to its most comprehensive form. This strategy is quite handy because it enables to "enter each variable one at a time to see the unique contribution that each variable presents (or fails to present) to the total model" (Roberts, 2004). Once the household level covariates are tested, including the ones reviewed in section 4.3 , the model feature will be: 
$\ln c_{i j k}=\beta_{111}+\beta_{211} X_{i j k}+u_{11 k}+v_{1 j k}+e_{i j k}$

which can be expressed in a smoother way as

$\ln c_{i j k}=\alpha_{\cdots . .}+\beta_{\ldots . .} X_{i j k}+u_{\cdot \cdot k}+v_{\cdot j k}+e_{i j k}$

Second- and third-level predictors, as well as random slopes, are then included piecemeal in equation [5.8], whether found appropriate and convenient. In fact, not significant cross-level interaction terms should not be incorporated in the multilevel model (Hox, 2002). Within the frame of this strategy, special account will be granted in section 5.3.2 to the impact terms of vulnerability of high food prices at the province level (here expressed with $W_{k}$ ):

$\ln c_{i j k}=\beta_{111}+\beta_{112} W_{k}+\left(\beta_{211}+\beta_{212} W_{k}\right) X_{i j k}+\left(u_{21 k}+v_{2 j k}\right) X_{i j k}+u_{11 k}+v_{1 j k}+e_{i j k}$

In order to allow for efficient vulnerability measures, estimations along with the above strategy will be carry forward according to the methodology sketched in section 5.1.1, through restricted maximum likelihood estimation (REML) as proposed by Mason et al. (1983) and Bryk and Raudenbush (1986). This is in line with Jadotte (2010). Differently, taking their steps from a similar perspective and actually being the outrider to multilevel model application to vulnerability measures, Günther and Harttgen (2009) estimated via maximum likelihood.

The comparison between the two maximum likelihood estimates is debatable and depends on data availability. Maximum likelihood (ML) estimates are consistent, asymptotically efficient, with sampling distribution which approximates the normal, and the level-1-coefficient empirical Bayes (EB) estimates show good properties. Nonetheless, as emphasized by Bryk and Raudenbush (2002), all those properties hold if two requirements are satisfied: a) a large number of level-2 (and level-3) units and b) balanced level-1 data.

REML gets over these limits by automatically correcting for the degrees of freedom which are lost in estimating the regression vector, hence treating these coefficients as estimates - and not as known quantities - when the variance components are estimated (Bryk and Raudenbush, 1992). Specifically, REML accounts for the loss of 1 
degree of freedom arising from the estimation of the grand mean (Rabe-Hesketh and Skrondral, 2005) ${ }^{69}$.

However, in practice, the difference might not be very large (Kreft, De Leeuw and Kim, 1989), and basically depends whether data are balanced or not, and to what extent (Rabe-Hesketh and Skrondral, 2005).

One of the aims of the following analysis will also be to depict vulnerability outcomes to high food prices beyond the household-level, thus addressing the issue at a more aggregate level. Since the resulting measures could be quite notable under a policy perspective, they must be handled carefully. In fact, between-cluster can significantly differ from within-cluster relationships, thus determining a cluster-level confounding problem, determined by the so-called ecological fallacy issue (Robinson, 1950), where the mean response to omitted community-specific explanatory variables might affect both mean consumption and $v_{j k}$ and $u_{k}$.

This problem can be addressed using deviations from cluster mean per covariate ( $X_{i j k}-\bar{X}_{j k}$ or $X_{i j k}-\bar{X}_{k}$ ), thus using such deviations as instrumental variables, being uncorrelated with $v_{j k}$ and $u_{k}$ and correlated with $X_{i j k}$.

Epitomizing so far, once a proper model fit deriving from the most general form depicted in [5.7] is defined ${ }^{70}$, expected consumption per capita is computed through the likelihood estimates, thus having:

$$
\hat{E}\left(\ln c \mid X_{i j k} Z_{j k} W_{k}\right)
$$

Finally, recalling the $2^{\text {nd }}$ step in the methodology proposed by Chauduri et al. (2002), the idiosyncratic and covariate shocks are similarly computed through a skedastic function (Harvey, 1976),

\footnotetext{
${ }^{69}$ Nonetheless, Hox (1995) endows with some advantage ML because the overall chi-square test can be used to test for differences between two models that differ only in the regression coefficient and not only the variance components.

${ }^{70}$ Provided the full model in [5.7] is highly computational demanding and might produce convergence issues, in section 5.3 expected consumption will be investigated (see table 5.3) without interaction terms (random intercept model and group mean model) and with only one interaction term (random slope autarkic buyer/seller and autarkic models).
} 
$\hat{\sigma}^{2}=\exp (K \tau)$

where $K$ represents the covariates $X_{i j k}, Z_{j k}$, and $W_{k}$ at every single level, and [5.11] is modeled as a non linear-function of $K$ (Jadotte, 2010), to avoid negative variances.

The estimated variance is consequently

$\hat{v}_{i j k}=\hat{P}\left(\ln c_{i j k}<\ln z \mid X, W, Z\right)=\phi\left(\frac{\ln z-\left(\ln \hat{c}_{i j k}-v_{j k}-u_{k}\right)}{\sqrt{\sigma_{i j k}^{2}}}\right)$

where $v_{j k}$ and $u_{k}$ represent shocks at the province and sous-colline level affecting household consumption (Jadotte, 2010).

\subsection{THE CASE OF BURUNDI}

Burundi is a land-locked, resource-poor country with an estimated population of 8 million people and the second highest population density in Africa.

Its high population growth triggers enormous demands on land and on the environment. Nonetheless, while access to land is widespread, often the plot sizes are very small. Moreover, the complex problem of land remains a major challenge to the reintegration of returnees. The refugee issue dates back 1972, with other succeeding waves. It is possible to enlist four categories of returnees: a) those who fled to Tanzania after the civil war burst in 1972, who have been returning from 2002 and received a small cash allowance to return, b) the caseload of a later conflict in 1993, who were considered less self-sufficient than previous ones and received a stronger support, c) spontaneous returnees who have been hoping to recover their land and properties and d) those without a legal refugee status who were expelled from Tanzania without notice or time to recover their belongings or documentation (Bundervoet et al., 2007). Provided local authorities allured refugees to recover their land or relocate elsewhere to persuade their returning, a Land Commission was established to solve tenure disputes. In fact, since agriculture is the main economic resource, addressing the land issue is pivotal in promoting peace and development in 
Burundi, especially within the older claimers, who fled Burundi and quit for over a 30-year period.

Climatic shocks, erosion, land degradation and declining soil fertility affect hardly agricultural productivity especially in the lean season. Those failures also impact those workers who relied on harvesting other households' farms (OCHA, 2009). Yet, almost $90 \%$ of its population live in rural areas (World Bank, 2008) and depends its livelihood on subsistence farming.

The hunger status is defined to be extremely alarming, with a high GHI score (IFPRI, 2008). About 367 million households were deemed completely or moderately food insecure, representing respectively 4.8 percent and 23 percent of total households. Their food consumption consists of tubers or cereals supplemented with some vegetables and oil. Moderate food insecure households may also integrate their diet with pulses (WFP, 2008).

Burundi remains vulnerable to cereal price increases. Naturally, households that rely more on domestic production than imported commodities, have suffered less from international price hikes. Soaring food prices of cassava (20\%), rice $(29 \%)$ and beans $(55 \%)$ were reported to be a main shock by almost 34 percent of households in the period between June 2007 and June 2008 (WFP, 2008). Households are forced to sell their harvest when prices are low and buy in the lean season when prices are high (WFP, 2008). Thus, poor integrated markets due to high transaction costs, poor infrastructure and storage conditions affect hardly food security and household vulnerability.

Burundi, with its rural districts, adds to a natural - actually man made - chronic instability and insecurity, the peculiarities of a small landlocked country, with limited infrastructure and the vast majority of its population devoted, directly or indirectly, to the agricultural sector.

In a framework as such, where rural poverty is widespread, global inflation in food commodities may well be the driver to deepen vulnerability, as-like in the two-year period 2007-2008 peak.

In the following part, the model underlined above in section 5.1 .5 will be exploited using the WFP Comprehensive Food Security and Vulnerability Analysis survey, which 
was conducted in June-July 2008 and includes several aspects of the household circumstances $^{71}$.

The case of Burundi was selected for different reasons. First, the survey period is definitively straightforward to assess the impact of high food prices on households. Provided the commodity price peak occurred internationally in May (see figure 2.1), consumption expenditures, which were recorded using a 30-day recall period, should thus disclose the inflation upshots at the household level.

More, Burundi is administratively divided in provinces, communes, collines and souscollines. The survey was conducted through a two-stage cluster sampling strategy, where the sous-collines represent the primary sampling unit and a minimum target sample size at the province level is pursued $^{72}$. Final data cover 5,011 households, clustered in 96 sous-collines and 16 provinces, which provides the requirements to undertake a hierarchical model. A growing literature (Genicot and Ray, 2003; Morduch, 2005; Günther and Harttgen, 2009) takes advantage of communities as the covariate-level, basing their shot on a wider focus than the usually-exploited villages. In fact, in the frame of the present work, such an approach is worth covering too, granting it reflects price unevenness and vulnerability at a meso-level as well.

Finally, the poverty incidence is widespread, with a headcount ratio of $84.4 \%$, which is in line with previous studies ${ }^{73}$. The poverty line used is BIF 525 per adult equivalent

71 The questionnaire comprehends eleven sections: 1) demographics, (2) circumstances of the household, (3) housing structure and amenities, (4) assets, (5) land and agricultural production, (6) livelihood activities, (7) household expenditures, (8) food consumption, (9) exposure to shocks, (10) coping mechanisms, and (11) maternal health and nutrition.

${ }^{72}$ According to WFP (2008), the survey sampling method is described as follows: "a stratified two-stage cluster sampling strategy was used, with a minimum target sample size of 300 households by province. The primary sampling unit (cluster) was the sous-colline. There are 9,915 sous-collines in Burundi, the lowest administrative unit. A minimum of 25 sous-collines were sampled in each province, with at least one sous-colline per commune. In larger provinces the number of clusters was increased to ensure a good spatial distribution. Sous-collines were selected using a systematic random procedure adjusting for population size within the cluster. A total of 433 sous-collines were sampled. Within each sous-colline, a sample of 12 households was randomly selected from list of all the households in the sous-colline. The final expected sample size was 5,196 households".

${ }^{73}$ According to Human Development Report Statistical Tables, the incidence of people below the 1.25 US\$ PPP threshold was $81.32 \%$ in 2006 (UNDP, 2010). Previous figures sets the poverty line at BIF 8,173.25 in 1998 (Verwimp and Bundervoet, 2008), with a headcount ratio of 68\% (World Bank web site). 
per day in rural areas ${ }^{74}$ (IMF, 2009), thus determining an absolute poverty line at BIF 15.750 , which wipes out the great majority of the population into poverty.

Nonetheless, according to the vulnerability to poverty approach here outlined, and in line with previous literature (Chaudhuri et al., 2002; Günther and Harttgen, 2009; Jadotte, 2010), it would be valuable to breakdown the estimates into sources of vulnerability, in order to partitioning households on the basis of their low consumption prospects or higher consumption volatility. That is to say, whether households vulnerability prospects are determined by structural determinants, or by risk-induced and transitory events. Moreover, table 5.1 shows how the incidence of poverty is different amongst provinces, thus confirming the vulnerability investigation issue at different levels.

TABLE 5.1: POVERTY MEASURES

\begin{tabular}{|c|c|c|c|c|c|c|}
\hline & Obs. & Freq. & $\begin{array}{l}\text { Incidence } \\
\text { of poverty }\end{array}$ & Poverty gap & $\begin{array}{l}\text { Squared } \\
\text { poverty gap }\end{array}$ & $\begin{array}{l}\text { Gini } \\
\text { Coefficient }\end{array}$ \\
\hline Burundi & 5,011 & $100 \%$ & $84.4 \%$ & 53.376 & 38.611 & 0.519 \\
\hline Bubanza & 292 & $3.3 \%$ & $75.8 \%$ & 35.709 & 20.731 & 0.408 \\
\hline Bujumbura Rural & 228 & $8.4 \%$ & $58.9 \%$ & 25.675 & 14.146 & 0.458 \\
\hline Bururi & 300 & $6.7 \%$ & $62.8 \%$ & 30.753 & 18.173 & 0.433 \\
\hline Cankuzo & 291 & $3.7 \%$ & $83.3 \%$ & 50.534 & 36.284 & 0.502 \\
\hline Cibitoke & 298 & $6.6 \%$ & $77.5 \%$ & 44.318 & 29.427 & 0.450 \\
\hline Gitega & 382 & $8.4 \%$ & $93.0 \%$ & 67.876 & 53.714 & 0.606 \\
\hline Karusi & 295 & $5.9 \%$ & $91.9 \%$ & 71.732 & 58.653 & 0.589 \\
\hline Kayanza & 348 & $8.5 \%$ & $95.3 \%$ & 65.852 & 49.804 & 0.516 \\
\hline Kirundo & 356 & $8.7 \%$ & $90.8 \%$ & 54.010 & 36.940 & 0.430 \\
\hline Makamba & 299 & $4.9 \%$ & $79.2 \%$ & 43.550 & 28.817 & 0.433 \\
\hline Muramvya & 300 & $3.8 \%$ & $87.8 \%$ & 56.415 & 40.933 & 0.459 \\
\hline Muyinga & 351 & $8.0 \%$ & $86.3 \%$ & 52.007 & 36.244 & 0.437 \\
\hline Mwaro & 300 & $3.6 \%$ & $95.3 \%$ & 66.400 & 51.245 & 0.459 \\
\hline Ngozi & 384 & $9.8 \%$ & $90.1 \%$ & 60.128 & 44.620 & 0.477 \\
\hline Rutana & 298 & $4.2 \%$ & $91.9 \%$ & 61.507 & 46.056 & 0.471 \\
\hline Ruyigi & 289 & $5.7 \%$ & $92.9 \%$ & 66.961 & 51.456 & 0.502 \\
\hline
\end{tabular}

\footnotetext{
${ }^{74}$ In contrast with figures presented above, the poverty headcount ratio in rural areas set by the Poverty Reduction Strategy Paper was 69\% in 2006, whereas in 1998 was 83,7\% (IMF, 2009).
} 
Further evidence is granted from Figure 5.1, which shows province and commune residuals, with $95 \%$ confidence intervals. The residuals represent departures from the overall mean, so a province/commune whose confidence interval does not overlap the line at zero (representing the mean consumption value across between levels) is said to differ from the average at the $5 \%$ level of significance. Differently from the Province level, where only Gitega province outstands, on the condition that the Commune level is investigated, then all the communes belonging to the provinces of Karusi, Kayanza, Mwaro, Ruyigi (at the left-hand side of the plot in panel B), and of Bubanza, Bururi, Bujumbura rural (right-hand side) show relevant group-effects, where the former are widely under the average mean consumption, and the latter above. Moreover, here the interval widths are rather different, thus reflecting the sampling methodology.

Again, it is worth emphasizing that the aforementioned provinces outstanding from Figure $5.1 \mathrm{~B}$, are those where the incidence of poverty is respectively higher and lower (Table 5.1). The other FGT indexes generally strengthen this statement, with sparse exceptions.

FIGURE 5.1: ESTIMATING GROUP EFFECTS

A. Residuals rank per Province

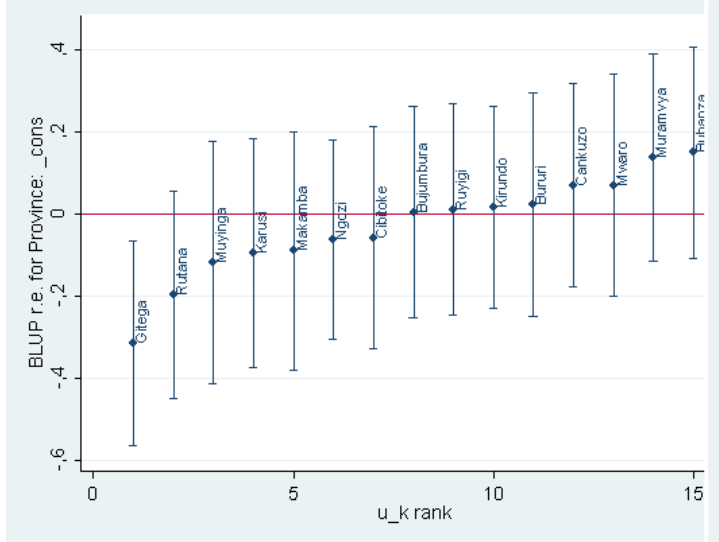

B. Residuals rank per Commune

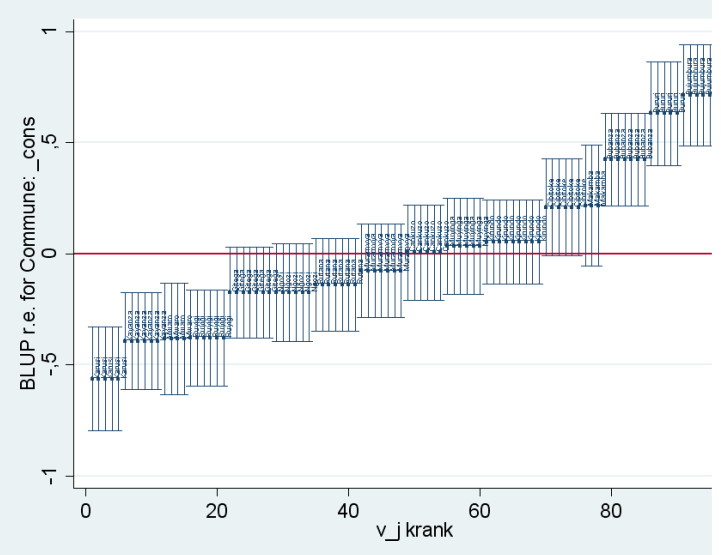

Note: Author's elaboration on World Food Programme data (Burundi Comprehensive and Food Security Analysis Survey 2008 provided by the Vulnerability and Analysis Mapping Unit ). The horizontal lines represent the overall mean per province and sous-colline. The residuals are ranked according to Best Linear Unbiased Predictors (B.L.U.P.) estimates. 


\subsection{EMPIRICAL RESULTS AND DISCUSSION}

Table 5.2 reports the summary statistics for covariates used to estimate vulnerability. The covariates age, number of activities, coping strategy index ${ }^{75}$ and food percentage on total expenditures are grand-mean centered to provide a straightforward interpretation and specifically represent the values adjusted for the average household with regards to every predictor.

Then, the covariates sex and those reflecting the prevalent net position in the cereal market (autarkic, buyer and seller) are group-averaged by province, and the covariates shocks, illiteracy and returnee are group-averaged by sous-colline. This allows to separate within and between unit effects providing useful understanding at the meso and higher levels and prevents the ecological fallacy issue already addressed in section 5.1.5.

In table 5.3, estimates deriving from Restricted Estimate Maximum Likelihood are presented as well with standard errors in brackets. The results deriving from five different models are shown, where the first column is provided as a benchmark for further refining. In terms of modeling structure presented in equation [5.6], it represents a model with random intercepts and only covariates at the household level.

By further implementing the model, covariate levels are introduced representing means by province and sous-colline. Finally, the presence of random slopes is tested - one by one - for the covariates accounting for the net positions in the market hired by the household. Such incremental strategy allows a better control in the estimates. It is worth recalling that the dependent variable is log consumption expenditures per adult equivalent, so that the interpretation of certain effects might be counterintuitive. Actually, most of the coefficients show the expected signs.

Female-headed households reflect a lower expected consumption level across all the proposed models. In fact, those households are strongly disadvantaged with regards

\footnotetext{
75 "The CSI measures behavior: the things that people do when they cannot access enough food. There are a number of fairly regular behavioral responses to food insecurity - or coping strategies - that people use to manage household food shortage" (Maxwell and Caldwell, 2008). The index measures both the frequency and the severity of coping behaviors and it is an indicator of food security status.
} 
to land access. Actually, one out of three has control over 0.25 -hectare plots or less, compared to the roughly one out of five ratio for male-headed households. Moreover, roughly the half of them are considered asset poor, and usually associated with marginal livelihoods group (WFP, 2008). An interesting notation arises from the significance level. Whilst at the lower level the coefficients are not statistically significant, at the province level a strong significance is found, with coefficients dramatically negative.

Asset and housing indexes (table 5.9) are built with Principal Component Analysis to be a measure of wealth with the aim of dimensional reduction ${ }^{76}$. Whilst the former is estimated through a set of dummy indicators, ranging over the ownership of agricultural tools, basic domestic and conveyance assets, the latter are constructed exploiting ordinal PCA. Here dwelling information ${ }^{77}$ is used retaining their ordinal values, recoded on the basis of a well-established category ordering ${ }^{78}$ and without breaking them into dummies (Filmer and Pritchett, 2001). This approach avoids the introduction of a large amount of distortion into the correlation matrix that would be determined by negative correlation outcomes amongst those newly established variables (Moser and Felton, 2009). In addition, it produces results very close to polychoric PCA, which is designed to directly address this issue (Kolenikiv and Angeles, 2009), gaining with simplification. Actually, the asset index coefficients strongly suggest a positive incidence on expected consumption.

With regards to the covariates describing the household net position in the market in terms of monthly spells within a year, being it autarkic, seller or buyer, it appears to be appropriate to allow for different within and between effects.

\footnotetext{
${ }^{76}$ Differently, Sahn and Stifel (2003), use factor analysis to build their asset index.

${ }^{77}$ Which are: wall (straw, clay, dried clay bricks, baked bricks) and roof building material (plastic, straw, sheet metal, tiles), lighting (brazier, firewood, oil lamp, electricity), toilet (traditional latrine - open hole, improved latrine, latrine with flush, fosse septic) and water source (basin, river or brook, free wheel, organized wheel, public pomp, running water).

78 "If there are several categories related to a single factor, such as the access of hygienic facilities or the quality of the dwelling materials, dividing the variable into a set of dummy indicators as suggested by Filmer and Pritchett (2001) leads to deterioration of performance, according to all of the performance measures we used" (Kolenikov and Angeles, 2009).
} 
Hence, the likely occurrence of some level-specific omitted variable is highlighted by contextual effects, which are definitively significant and with opposite signs compared to within estimates. In general, the resulting between effect, which is the sum of contextual and within effect, strongly corroborates the model structure being contrary to the latter. As an exception, it is worth mentioning the model where the seller variable is allowed to have a random slope. Here the buyers between effect on expected consumption expenditures is -0.856 whilst the within effect is -0.315 .

Drought and higher prices are the main shocks reported in the survey (respectively by $65.5 \%$ and $34.1 \%$ of respondents) and are both extremely significant at the household level (see table 5.11). The estimates report such shocks having a positive impact towards expected expenditures, which is a hint that needs be presumably matched with the information retained by the food share on total expenditures. Indeed, provided a shock would lead to augmented expenditures in order to secure one's consumption level, this response-effect is constrained by the ability to cope with adverse shocks which, in turn, might be a proxy of the ménage within the household. The greater the share on total expenditures devoted to food consumption, the tinier the coping strategies a household is able to carry forward.

The consequent upshot is thus reflected by an expected lower consumption. As proof, the food shares on total expenditure coefficients show an opposite sign than those pertaining shocks with a steady and trenchant incidence across models on consumption expenditures (ranging from -0.331 and -0.348). Furthermore, the coping strategy index, which is grand mean-centered, indicates that the average household cannot implement suitable strategies.

In general, this is howsoever reflected by the number of activities a household is involved in as a means of living, which is also reflected by its livelihood category. According to WFP (2008) such categories are: a) agriculturalist, with the highest dependency on agriculture production, roughly $90 \%$ of their livelihoods; b) agrosellers, mostly engaged into agriculture production with an additional contribution deriving from cash crops; c) agro-laborers, who get almost one third of their livelihoods from daily labor, whereas the rest still pertains to agriculture; d) laborers, with a higher relevance deriving from manual and seasonal labor; e) agrotraders, having their livelihoods source equally split between small trade and agriculture; f) agro-brewers, whose income is generated essentially by natural resources exploitation; g) employees and business households, with the highest 
average income derived from revenues and business profit; h) marginal households, whose livelihoods essentially derive from transfers, and in a limited number from pensions.

In general, whilst belonging to a given group is highly significant, the breakdown reported in table 5.2 fails to reflect it. Despite significance, which is granted for agro-laborer and employee/business household groups throughout all the models, and for agriculturalists erratically, both the signs and the relative incidence of estimates show the expected behavior.

Illiteracy refers to the lack of ability of the household head to read and write a simple message in any language, which is true for $46.6 \%$ of the survey respondents, with a remarkable difference among sex $(39.2 \%$ for male versus $74.9 \%$ for femaleheaded households). The result is strongly in line with the consolidated literature presented in section 4.3 .

Very significant returnee estimates do not show the expected signs but provide some caveat worth mentioning.

Indeed, insecurity remains an issue in Bujumbura rural, Bubanza and Kirundo where, at the time of the survey, internal displaced persons caused by armed group instability were twice as many than in the rest of the country. Still, around ten percent of the households reported having at least one household member displaced for some time during the two-year period prior to the survey (WFP, 2008). The presence of returnees can be interpreted as a proxy of improved security and also of an enhanced economic situation, where social fabric and personal relations resume. Nonetheless, this phenomenon is jeopardized by disputes over land tenures between returnees and residents, especially where population density is higher and land tenures quarreling causes strives. Howsoever, the major cause of displacement reported in the survey is related to economic issues, where two-thirds are principally linked to job seeking, thus probably in part overlapping with economic migrants. 


\begin{tabular}{|c|c|c|c|c|c|c|c|c|c|c|c|c|c|c|c|c|c|}
\hline & 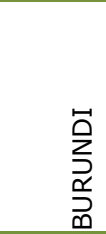 & $\begin{array}{l}\mathbb{N} \\
\stackrel{N}{ } \\
\mathbb{N} \\
\stackrel{0}{7} \\
\bar{n}\end{array}$ & 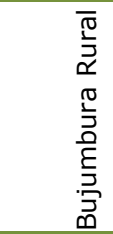 & $\begin{array}{l}\frac{1}{3} \\
\frac{1}{5} \\
0\end{array}$ & $\begin{array}{l}\stackrel{2}{N} \\
\overrightarrow{2} \\
\frac{v}{c} \\
\text { Ũ }\end{array}$ & 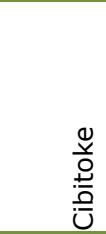 & $\begin{array}{l}\stackrel{0}{\Phi} \\
\stackrel{ \pm}{*}\end{array}$ & $\begin{array}{l}\bar{n} \\
\frac{1}{2} \\
\underline{n}\end{array}$ & 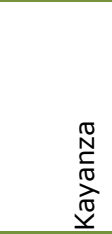 & 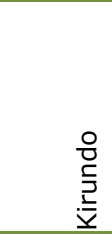 & 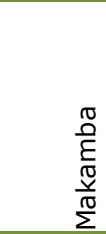 & 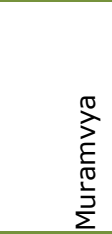 & 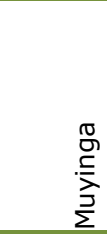 & $\begin{array}{l}\frac{0}{10} \\
\frac{10}{3} \\
\Sigma\end{array}$ & $\begin{array}{l}\bar{N} \\
\text { ờ } \\
\text { Z }\end{array}$ & 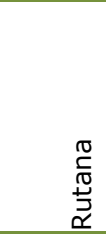 & 힉 \\
\hline Age (head of the household) & 43.6 & 40.9 & 47.5 & 43.3 & 42.6 & 41.0 & 47.0 & 43.0 & 46.3 & 39.2 & 42.7 & 46.8 & 42.0 & 47.9 & 44.1 & 40.6 & 41.3 \\
\hline Sex (head of the household) & $16.4 \%$ & $14.5 \%$ & $16.8 \%$ & $12.2 \%$ & $15.1 \%$ & $17.3 \%$ & $21.4 \%$ & $19.3 \%$ & $18.9 \%$ & $10.5 \%$ & $17.0 \%$ & $13.7 \%$ & $12.5 \%$ & $19.8 \%$ & $20.7 \%$ & $12.3 \%$ & $16.8 \%$ \\
\hline Dependency ratio & 1.1 & 1.2 & 1.1 & 1.2 & 1.2 & 1.1 & 0.9 & 1.1 & 1.1 & 1.3 & 1.2 & 1.0 & 1.2 & 0.9 & 1.1 & 1.2 & 1.3 \\
\hline Autarkic cereal position (spells/12) & 5.2 & 3.2 & 3.1 & 6.4 & 5.4 & 4.0 & 7.4 & 6.3 & 5.1 & 4.4 & 6.5 & 5.1 & 5.0 & 7.3 & 4.2 & 6.2 & 4.3 \\
\hline Seller cereal position (spells/12) & 0.6 & 1.0 & 0.2 & 0.1 & 0.7 & 0.8 & 0.4 & 0.4 & 0.3 & 1.5 & 0.4 & 0.1 & 1.1 & 0.3 & 0.6 & 0.5 & 0.7 \\
\hline Buyer cereal position (spells/12) & 5.9 & 7.4 & 8.6 & 5.5 & 4.9 & 6.2 & 4.1 & 5.2 & 6.5 & 5.6 & 4.8 & 6.8 & 5.0 & 4.3 & 7.0 & 4.7 & 6.4 \\
\hline Shock: drought & $67.2 \%$ & $54.7 \%$ & $66.7 \%$ & $84.8 \%$ & $96.5 \%$ & $68.1 \%$ & $83.7 \%$ & $74.4 \%$ & $33.2 \%$ & $56.3 \%$ & $98.7 \%$ & $41.8 \%$ & $69.2 \%$ & $81.8 \%$ & $31.1 \%$ & $85.5 \%$ & $100.0 \%$ \\
\hline Shock: inflation & $33.6 \%$ & $35.5 \%$ & $45.6 \%$ & $48.5 \%$ & $19.1 \%$ & $40.5 \%$ & $28.3 \%$ & $7.6 \%$ & $52.4 \%$ & $41.0 \%$ & $44.3 \%$ & $47.7 \%$ & $17.5 \%$ & $26.9 \%$ & $34.2 \%$ & $6.5 \%$ & $21.5 \%$ \\
\hline Nr. of livelihood activities $(1 / 2 / 3)$ & 2.1 & 2.1 & 2.2 & 2.5 & 2.1 & 2.2 & 2.0 & 1.8 & 2.4 & 2.0 & 2.3 & 2.3 & 2.0 & 2.2 & 2.1 & 2.1 & 2.1 \\
\hline Coping strategy index & 50.0 & 60.3 & 60.1 & 46.2 & 61.3 & 46.4 & 37.6 & 43.3 & 61.5 & 51.5 & 42.2 & 62.5 & 49.2 & 37.7 & 50.2 & 39.5 & 51.6 \\
\hline $\begin{array}{l}\text { Illiteracy } \\
\text { Livelihood Group }\end{array}$ & $55.3 \%$ & $52.0 \%$ & $55.5 \%$ & $62.7 \%$ & $57.8 \%$ & $54.5 \%$ & $60.2 \%$ & $51.5 \%$ & $49.4 \%$ & $58.5 \%$ & $55.5 \%$ & $57.5 \%$ & $57.7 \%$ & $46.3 \%$ & $52.0 \%$ & $54.4 \%$ & $55.9 \%$ \\
\hline Other & $1.2 \%$ & $0.0 \%$ & $0.2 \%$ & $0.0 \%$ & $0.0 \%$ & $0.2 \%$ & $0.1 \%$ & $0.1 \%$ & $0.1 \%$ & $0.2 \%$ & $0.0 \%$ & $0.0 \%$ & $0.2 \%$ & $0.0 \%$ & $0.0 \%$ & $0.0 \%$ & $0.0 \%$ \\
\hline Agriculturalist & $33.9 \%$ & $0.4 \%$ & $1.0 \%$ & $1.5 \%$ & $1.7 \%$ & $2.1 \%$ & $3.0 \%$ & $3.1 \%$ & $2.4 \%$ & $2.8 \%$ & $2.1 \%$ & $1.5 \%$ & $3.2 \%$ & $1.1 \%$ & $4.5 \%$ & $1.2 \%$ & $2.4 \%$ \\
\hline Agro-Seller & $17.6 \%$ & $0.5 \%$ & $1.0 \%$ & $2.4 \%$ & $0.8 \%$ & $0.9 \%$ & $0.9 \%$ & $0.4 \%$ & $1.9 \%$ & $1.0 \%$ & $1.2 \%$ & $1.0 \%$ & $1.4 \%$ & $0.9 \%$ & $2.0 \%$ & $1.0 \%$ & $0.4 \%$ \\
\hline Agro-Laborer & $20.8 \%$ & $1.2 \%$ & $1.3 \%$ & $1.5 \%$ & $0.5 \%$ & $1.4 \%$ & $1.9 \%$ & $1.2 \%$ & $1.8 \%$ & $2.3 \%$ & $1.0 \%$ & $0.6 \%$ & $1.5 \%$ & $0.9 \%$ & $1.1 \%$ & $0.8 \%$ & $2.0 \%$ \\
\hline Laborer & $14.7 \%$ & $0.9 \%$ & $2.7 \%$ & $0.4 \%$ & $0.5 \%$ & $1.2 \%$ & $1.0 \%$ & $0.6 \%$ & $1.6 \%$ & $1.6 \%$ & $0.2 \%$ & $0.3 \%$ & $0.8 \%$ & $0.3 \%$ & $1.4 \%$ & $0.7 \%$ & $0.5 \%$ \\
\hline Agro-Traders & $4.6 \%$ & $0.1 \%$ & $1.0 \%$ & $0.5 \%$ & $0.1 \%$ & $0.2 \%$ & $0.4 \%$ & $0.4 \%$ & $0.1 \%$ & $0.4 \%$ & $0.2 \%$ & $0.0 \%$ & $0.4 \%$ & $0.1 \%$ & $0.2 \%$ & $0.3 \%$ & $0.2 \%$ \\
\hline Agro-Brewer & $2.5 \%$ & $0.1 \%$ & $0.0 \%$ & $0.0 \%$ & $0.0 \%$ & $0.2 \%$ & $0.4 \%$ & $0.0 \%$ & $0.4 \%$ & $0.2 \%$ & $0.0 \%$ & $0.1 \%$ & $0.4 \%$ & $0.2 \%$ & $0.4 \%$ & $0.0 \%$ & $0.1 \%$ \\
\hline Agro-Exploiter & $1.2 \%$ & $0.0 \%$ & $0.5 \%$ & $0.0 \%$ & $0.0 \%$ & $0.2 \%$ & $0.0 \%$ & $0.0 \%$ & $0.0 \%$ & $0.1 \%$ & $0.1 \%$ & $0.0 \%$ & $0.1 \%$ & $0.0 \%$ & $0.0 \%$ & $0.0 \%$ & $0.0 \%$ \\
\hline Employee/Business & $2.3 \%$ & $0.1 \%$ & $0.5 \%$ & $0.3 \%$ & $0.0 \%$ & $0.1 \%$ & $0.5 \%$ & $0.1 \%$ & $0.3 \%$ & $0.0 \%$ & $0.1 \%$ & $0.0 \%$ & $0.0 \%$ & $0.1 \%$ & $0.1 \%$ & $0.1 \%$ & $0.0 \%$ \\
\hline Marginal & $1.2 \%$ & $0.0 \%$ & $0.2 \%$ & $0.1 \%$ & $0.0 \%$ & $0.2 \%$ & $0.2 \%$ & $0.1 \%$ & $0.1 \%$ & $0.0 \%$ & $0.0 \%$ & $0.0 \%$ & $0.0 \%$ & $0.1 \%$ & $0.1 \%$ & $0.0 \%$ & $0.0 \%$ \\
\hline Food share on total expenditures & $91.6 \%$ & $89.1 \%$ & $89.6 \%$ & $92.4 \%$ & $95.4 \%$ & $94.4 \%$ & $93.1 \%$ & $97.1 \%$ & $84.1 \%$ & $87.4 \%$ & $94.2 \%$ & $84.9 \%$ & $94.7 \%$ & $92.7 \%$ & $89.9 \%$ & $95.1 \%$ & $96.3 \%$ \\
\hline Cash crop - plantain $(\mathrm{Y} / \mathrm{N})$ & $49.4 \%$ & $27.3 \%$ & $28.9 \%$ & $24.6 \%$ & $32.1 \%$ & $53.8 \%$ & $71.5 \%$ & $64.6 \%$ & $66.0 \%$ & $44.8 \%$ & $42.1 \%$ & $63.9 \%$ & $59.3 \%$ & $64.4 \%$ & $57.8 \%$ & $39.3 \%$ & $23.7 \%$ \\
\hline Stock reserve in months & 6.7 & 5.4 & 2.8 & 6.8 & 5.8 & 6.2 & 6.0 & 5.2 & 6.6 & 8.6 & 6.8 & 7.5 & 10.3 & 5.2 & 7.3 & 7.0 & 6.8 \\
\hline Returnee & $41.4 \%$ & $71.8 \%$ & $73.9 \%$ & $44.6 \%$ & $30.5 \%$ & $71.1 \%$ & $15.6 \%$ & $35.8 \%$ & $35.5 \%$ & $32.4 \%$ & $58.3 \%$ & $35.2 \%$ & $41.7 \%$ & $8.2 \%$ & $31.1 \%$ & $36.4 \%$ & $51.1 \%$ \\
\hline $\mathrm{Nr}$ of goats & 0.9 & 0.3 & 0.4 & 1.0 & 1.1 & 0.8 & 0.7 & 0.9 & 0.6 & 0.9 & 1.4 & 0.9 & 0.9 & 0.8 & 0.8 & 1.6 & 1.3 \\
\hline $\mathrm{Nr}$ of poultry & 0.9 & 0.5 & 1.0 & 1.4 & 1.3 & 1.2 & 0.7 & 0.8 & 0.1 & 0.9 & 1.8 & 0.4 & 1.0 & 0.9 & 0.3 & 2.0 & 1.1 \\
\hline
\end{tabular}


TABLE 5.3: RESTRICTED MAXIMUM LIKELIHOOD RESULT OF (LOG) CONSUMPTION PER ADULT EQUIVALENT

\begin{tabular}{|c|c|c|c|c|c|c|c|c|c|c|}
\hline \multirow[b]{2}{*}{ Age (head of the household) } & \multicolumn{2}{|c|}{ R. intercept Model } & \multicolumn{2}{|c|}{ Group mean model } & \multicolumn{2}{|c|}{ R. slope Autarkic } & \multicolumn{2}{|c|}{ R. Slope Buyer } & \multicolumn{2}{|c|}{ R. Slope Seller } \\
\hline & $-0.006 * * *$ & $(0)$ & $-0.006 * * *$ & $(0)$ & $-0.006 * * *$ & (0) & $-0.006 * * *$ & $(0)$ & $-0.006 * * *$ & (0) \\
\hline Sex (head of the household) & -0.042 & $(0.03)$ & -0.042 & $(0.03)$ & -0.038 & $(0.03)$ & -0.036 & $(0.03)$ & -0.045 & $(0.03)$ \\
\hline mean per province & & & $-4.6 * * *$ & $(1.53)$ & $-4.684 * * *$ & $(1.52)$ & $-4.427 * * *$ & $(1.46)$ & $-4.697 * * *$ & $(1.55)$ \\
\hline Dependency ratio & $-0.069 * * *$ & $(0.01)$ & $-0.069 * * *$ & $(0.01)$ & $-0.068 * * *$ & $(0.01)$ & $-0.068 * * *$ & $(0.01)$ & $-0.07 * * *$ & $(0.01)$ \\
\hline Housing index & 0.012 & $(0.01)$ & 0.012 & $(0.01)$ & 0.011 & $(0.01)$ & 0.011 & $(0.01)$ & 0.014 & $(0.01)$ \\
\hline Asset index & $0.074 * * *$ & $(0.01)$ & $0.075^{* * *}$ & $(0.01)$ & $0.075^{* * *}$ & $(0.01)$ & $0.074 * * *$ & $(0.01)$ & $0.074 * * *$ & $(0.01)$ \\
\hline Autarkic cereal position (month spells/12) & $0.022 * *$ & $(0.01)$ & $0.023 * *$ & $(0.01)$ & $0.025 * *$ & $(0.01)$ & $0.023 * *$ & $(0.01)$ & $0.023 * *$ & $(0.01)$ \\
\hline mean per province & & & $-0.308 * *$ & $(0.12)$ & $-0.327 * *$ & $(0.12)$ & $-0.341 * * *$ & $(0.12)$ & 0.012 & $(0.02)$ \\
\hline Seller cereal position (month spells/12) & 0.009 & $(0.01)$ & 0.009 & $(0.01)$ & 0.009 & $(0.01)$ & 0.01 & $(0.01)$ & $-0.283 *$ & $(0.16)$ \\
\hline mean per province & & & $-0.543 * *$ & $(0.25)$ & $-0.595^{* *}$ & $(0.25)$ & $-0.63 * *$ & $(0.24)$ & $0.04 * * *$ & $(0.01)$ \\
\hline Buyer cereal position (month spells/12) & $0.04 * * *$ & $(0.01)$ & $0.04 * * *$ & $(0.01)$ & $0.041 * * *$ & $(0.01)$ & $0.039 * * *$ & $(0.01)$ & $-0.315^{* *}$ & $(0.12)$ \\
\hline mean per province & & & $-0.273 *$ & $(0.16)$ & $-0.299 *$ & $(0.16)$ & $-0.315^{* *}$ & $(0.15)$ & $-0.541 * *$ & $(0.25)$ \\
\hline Shock: drought & $0.075 * *$ & $(0.03)$ & $0.07 * *$ & $(0.03)$ & $0.072 * *$ & $(0.03)$ & $0.071 * *$ & $(0.03)$ & $0.064 * *$ & $(0.03)$ \\
\hline mean per sous colline & & & 0.113 & $(0.12)$ & 0.093 & $(0.12)$ & 0.134 & $(0.13)$ & 0.102 & $(0.13)$ \\
\hline Shock: inflation & $0.21 * * *$ & $(0.03)$ & $0.205^{* * *}$ & $(0.03)$ & $0.201 * * *$ & $(0.03)$ & $0.203 * * *$ & $(0.03)$ & $0.207 * * *$ & $(0.03)$ \\
\hline mean per sous colline & & & 0.166 & $(0.12)$ & 0.188 & $(0.12)$ & $0.21 *$ & $(0.12)$ & 0.188 & $(0.12)$ \\
\hline Nr. of livelihood activities $(1 / 2 / 3)$ & $0.044 *$ & $(0.02)$ & $0.043 *$ & $(0.02)$ & $0.04 *$ & $(0.02)$ & $0.043^{*}$ & $(0.02)$ & $0.04 *$ & $(0.02)$ \\
\hline Coping strategy index & $-0.001 * * *$ & (0) & $-0.002 * * *$ & (0) & $-0.002 * * *$ & (0) & $-0.002 * * *$ & $(0)$ & $-0.002 * * *$ & (0) \\
\hline Illiteracy & $0.101 * * *$ & $(0.03)$ & $0.101^{* * *}$ & $(0.03)$ & $0.105^{* * *}$ & $(0.03)$ & $0.104 * * *$ & $(0.03)$ & $0.098 * * *$ & $(0.03)$ \\
\hline mean per sous colline & & & -0.076 & $(0.19)$ & -0.062 & $(0.19)$ & -0.18 & $(0.19)$ & -0.057 & $(0.2)$ \\
\hline Livelihood Group & & & & & & & & & & \\
\hline Agriculturalist & $-0.244 *$ & $(0.14)$ & -0.226 & $(0.14)$ & $-0.245 *$ & $(0.14)$ & -0.228 & $(0.14)$ & -0.213 & $(0.14)$ \\
\hline Agro-Seller & -0.068 & $(0.15)$ & -0.052 & $(0.15)$ & -0.072 & $(0.14)$ & -0.051 & $(0.14)$ & -0.039 & $(0.15)$ \\
\hline Agro-Laborer & $-0.327 * *$ & $(0.14)$ & $-0.312 * *$ & $(0.14)$ & $-0.332 * *$ & $(0.14)$ & $-0.313 * *$ & $(0.14)$ & $-0.296 * *$ & $(0.14)$ \\
\hline Laborer & -0.108 & $(0.15)$ & -0.092 & $(0.15)$ & -0.109 & $(0.15)$ & -0.096 & $(0.15)$ & -0.084 & $(0.15)$ \\
\hline Agro-Traders & 0.134 & $(0.15)$ & 0.151 & $(0.15)$ & 0.133 & $(0.15)$ & 0.147 & $(0.15)$ & 0.162 & $(0.15)$ \\
\hline
\end{tabular}




\begin{tabular}{|c|c|c|c|c|c|c|c|c|c|c|}
\hline Agro-Brewer & -0.125 & $(0.16)$ & -0.112 & $(0.16)$ & -0.127 & $(0.16)$ & -0.11 & $(0.16)$ & -0.1 & $(0.16)$ \\
\hline Agro-Exploiter & -0.124 & $(0.19)$ & -0.11 & $(0.19)$ & -0.119 & $(0.19)$ & -0.101 & $(0.19)$ & -0.092 & $(0.19)$ \\
\hline Employee/Business & $0.564 * * *$ & $(0.17)$ & $0.574 * * *$ & $(0.17)$ & $0.574 * * *$ & $(0.17)$ & $0.58 * * *$ & $(0.17)$ & $0.594 * * *$ & $(0.17)$ \\
\hline Marginal & -0.249 & $(0.22)$ & -0.225 & $(0.22)$ & -0.238 & $(0.22)$ & -0.224 & $(0.22)$ & -0.211 & $(0.22)$ \\
\hline Food share on total expenditures & $-0.347 * * *$ & $(0.08)$ & $-0.344 * * *$ & $(0.08)$ & $-0.331 * * *$ & $(0.08)$ & $-0.34 * * *$ & $(0.08)$ & $-0.348 * * *$ & $(0.08)$ \\
\hline Pop. density * $100 \%$ land ownership & $0 * * *$ & $(0)$ & $0 * * *$ & $(0)$ & $0 * * *$ & $(0)$ & $0 * * *$ & $(0)$ & $0 * * *$ & $(0)$ \\
\hline Cash crop - plantain $(\mathrm{Y} / \mathrm{N})$ & $-0.054 * *$ & $(0.03)$ & $-0.051 *$ & $(0.03)$ & $-0.045^{*}$ & $(0.03)$ & $-0.047 *$ & $(0.03)$ & $-0.048 *$ & $(0.03)$ \\
\hline Stock reserve in months & 0.003 & $(0)$ & 0.003 & $(0)$ & 0.004 & $(0)$ & 0.003 & $(0)$ & 0.003 & $(0)$ \\
\hline Returnee & $0.067 * *$ & $(0.03)$ & $0.052 *$ & $(0.03)$ & $0.052 *$ & $(0.03)$ & $0.053 *$ & $(0.03)$ & 0.044 & $(0.03)$ \\
\hline mean per sous colline & & & $0.3 * *$ & $(0.12)$ & $0.281 * *$ & $(0.12)$ & $0.295^{* *}$ & $(0.12)$ & $0.3 * *$ & $(0.13)$ \\
\hline $\mathrm{Nr}$ of goats & $-0.025 * * *$ & $(0.01)$ & $-0.024 * * *$ & $(0.01)$ & $-0.024 * * *$ & $(0.01)$ & $-0.024 * * *$ & $(0.01)$ & $-0.025 * * *$ & $(0.01)$ \\
\hline $\mathrm{Nr}$ of poultry & $0.022 * * *$ & $(0.01)$ & $0.021 * * *$ & $(0.01)$ & $0.021 * * *$ & $(0.01)$ & $0.021 * * *$ & $(0.01)$ & $0.021 * * *$ & $(0.01)$ \\
\hline Constant & $8.461^{* * *}$ & $(0.2)$ & $12.406 * * *$ & $(1.67)$ & $12.697 * * *$ & $(1.67)$ & $12.848^{* * *}$ & $(1.61)$ & $12.503 * * *$ & $(1.69)$ \\
\hline \multicolumn{11}{|l|}{ Province level } \\
\hline$\sigma^{2} u_{k}$ & $0.113 * * *$ & $(0.043)$ & $0.035 * * *$ & $(0.017)$ & $0.035^{* * *}$ & $(0.02)$ & $0.034 * * *$ & $(0.02)$ & $0.034 * * *$ & $(0.02)$ \\
\hline \multicolumn{11}{|l|}{ Sous-colline level } \\
\hline$\sigma^{2}$ autarkic/buyer/seller & & & & & $0.001 * * *$ & $(0)$ & $0.001 * * *$ & $(0)$ & $0.001 * * *$ & $(0)$ \\
\hline $\operatorname{cov}\left(\right.$ autarkic/buyer/seller and $\left.v_{j k}\right)$ & & & & & $-0.004 * * *$ & $(0)$ & $-0.004 * * *$ & $(0)$ & $-0.004 * * *$ & $(0)$ \\
\hline$\sigma^{2} v_{j k}$ & $0.007 * * *$ & $(0.004)$ & $0.007 * * *$ & $(0.004)$ & $0.038 * * *$ & $(0.01)$ & $0.023 * * *$ & $(0.01)$ & $0.023 * * *$ & $(0.01)$ \\
\hline \multicolumn{11}{|l|}{ Household level } \\
\hline$\sigma^{2} e_{i j k}$ & $0.618^{* * *}$ & $(0.013)$ & $0.617 * * *$ & $(0.013)$ & $0.612 * * *$ & $(0.01)$ & $0.61 * * *$ & $(0.01)$ & $0.61 * * *$ & $(0.01)$ \\
\hline $\mathrm{N}$ & 4,524 & & 4,524 & & 4,524 & & 4,524 & & 4,524 & \\
\hline DF & 31 & & 37 & & 37 & & 37 & & 37 & \\
\hline Likelihood & $-5,457.218$ & & $-5,449.313$ & & $-5,449.276$ & & $-5,444.799$ & & $-5,445.788$ & \\
\hline BIC & $11,209.04$ & 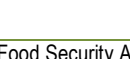 & $11,243.73$ & & $11,252.07$ & & $11,243.12$ & & $11,245.1$ & \\
\hline
\end{tabular}




\subsubsection{A profile of vulnerability: households characteristics}

In chapter 4, vulnerability was defined in terms of the household likelihood to fall beyond a given threshold in the next future, which usually is set against the poverty line (Pritchet, Suryahadi and Sumarto, 2000).

Recalling equation [5.7], it is hence possible to derive a vulnerability estimate from the previous section results.

In figure 5.2, the expected (log) consumption per adult equivalent $\ln \hat{c}_{i j k}$, deriving from the estimates presented above, is compared towards (log) consumption per adult equivalent $\ln c_{i j k}$, resulting from the survey. The poverty line $\ln z$ is the vertical red line. Some clear clues encouraging vulnerability breakdown into its different sources arise from a comprehensive evaluation of households outstanding (Chauduri et al., 2002).

Actually, this is a straightforward exercise in a country like Burundi, where there is a vast majority of the population whose consumption lies behind the poverty line, and it would be of restricted interest limiting the analysis to a clear shortcut between those who are vulnerable and those who are not.

FIGURE 5.2: CONSUMPTION AND EXPECTED CONSUMPTION

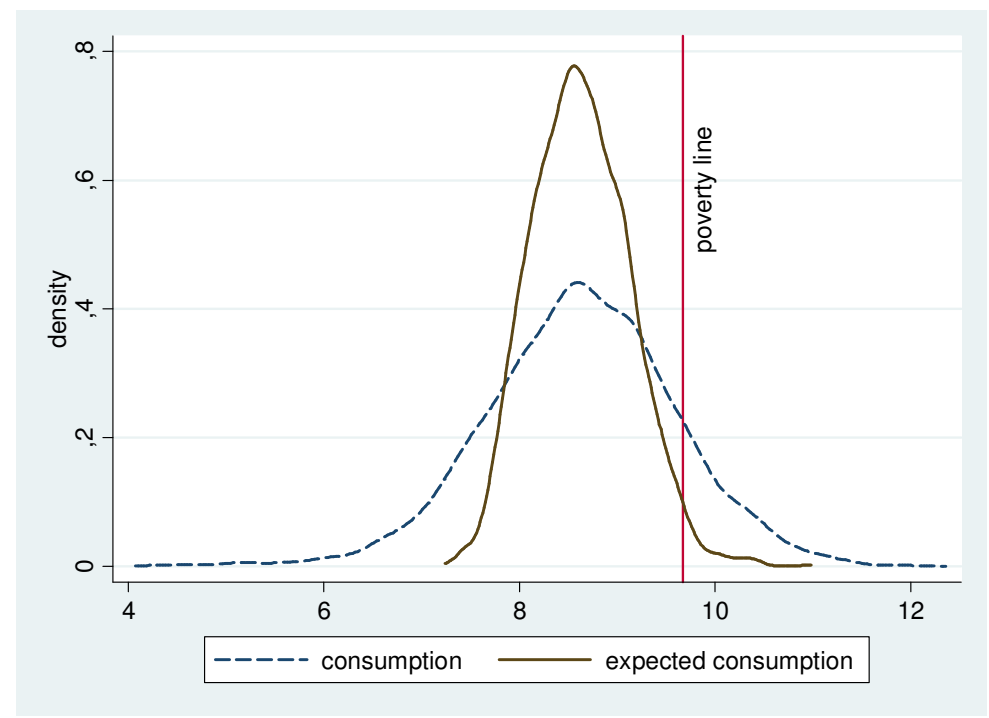


Note: Author's elaboration on World Food Programme data (Burundi Comprehensive and Food Security Analysis Survey 2008 provided by the Vulnerability and Analysis Mapping Unit ). The vertical line indicates the $50 \%$ odds-ratio of being poor. Estimated consumption per adult equivalent data is expressed in (log) Burundi Franc (BIF). Poverty line set at 9.6645956 which is equivalent to $15,750 \mathrm{BIF}$.

Hence, it is possible to distinguish among four different household categories:

1. Those whose observed consumption and expected consumption lie behind the poverty line and are thence trapped into poverty;

2. Those who are risk induced vulnerable, since their consumption lies above the poverty line but their expected consumption is lower depending on their high variability of consumption;

3. Those who are distinguished by their uneven prospects, because their expected consumption is higher than the poverty line, even though their observed consumption is lower;

4. Those whose consumption and expected consumption are both above the poverty line.

The first two categories are included into the vulnerable group, because their probability of being poor in the following period is above the set threshold, the latter two into the not vulnerable. Specifically, households in group two are prone to bear with higher variability and have a higher probability to be poor on the occurrence of a shock.

In view of the fact that poverty is so widespread, by no means it is surprising that almost $98 \%$ of the households in the survey are deemed vulnerable (figure 5.3). Once purged from covariate shocks, idiosyncratic vulnerability accounts for the great majority of the overall vulnerability. Thus, it can be inferred that the probability of being poor is mostly household specific ${ }^{79}$.

\footnotetext{
${ }^{79}$ Nonetheless, province level will be found to be definitely relevant in the vulnerability breakdown.
} 
FIGURE 5.3: CUMULATE PROBABILITY OF BEING POOR

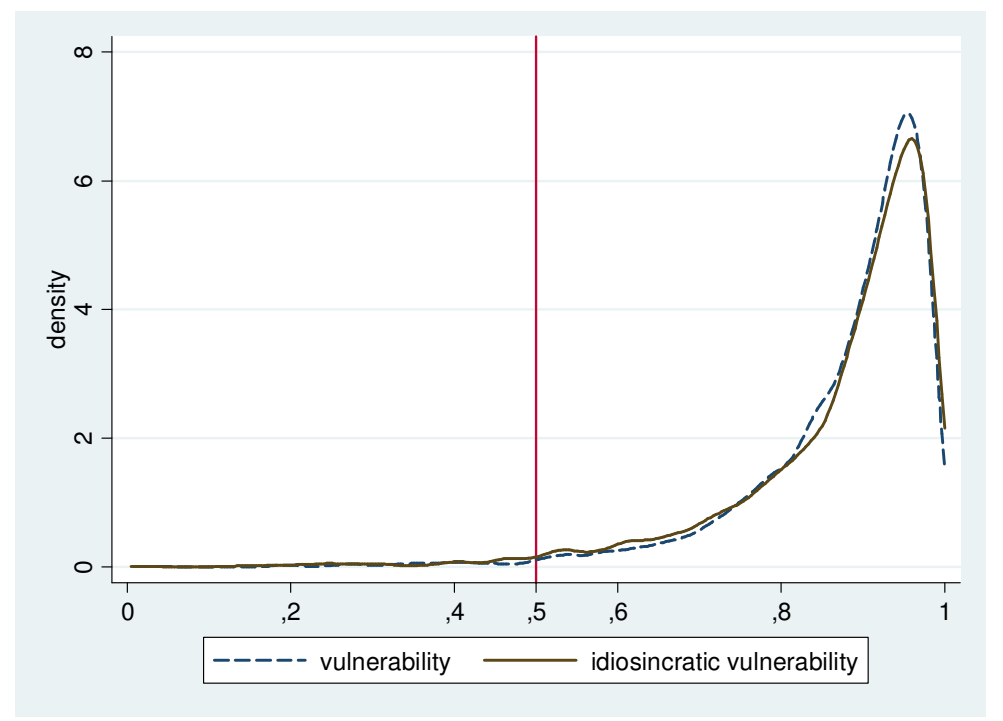

Note: Author's elaboration on World Food Programme data (Burundi Comprehensive and Food Security Analysis Survey 2008 provided by the Vulnerability and Analysis Mapping Unit ). The vertical line indicates the $50 \%$ odds-ratio of being poor.

The share of household trapped into poverty is $86.8 \%$. As a double check, to test the goodness of the results (Chauduri et al., 2002), the headcount poverty ratio $(86.7 \%)$ and the average probability to fall below the poverty line, i.e. the mean vulnerability (86.6\%), are reported in table 5.4. All the above estimates are concordant in setting the incidence of poverty between the surveyed households. The poverty-trappedrisk-induced vulnerability ratio is 7.81 , which means that almost $11.1 \%$ of the vulnerable are risk induced, with a relevant difference between sexes (10.47 for female versus 7.39 for male headed households). Actually, female-headed households are relatively less prone to risk induced vulnerability (8.7\% versus $11.6 \%$ ), even though the incidence of poverty is definitely higher among this group. These results are in line with Glewwe and Hall (1998) and Rayhan (2010).

TABLE 5.4: VULNERABILITY IN BURUNDI BY SEX

\begin{tabular}{lrrr} 
& Total & Female & Male \\
\hline $\mathrm{N}$ & 4,524 & 784 & 3,740 \\
Estimated log consumption per adult equivalent & 5,638 & 4,516 & 5,906 \\
Log poverty line & 15,750 & 15,750 & 15,750 \\
Poverty incidence & $86.7 \%$ & $90.2 \%$ & $85.9 \%$ \\
Mean Vulnerability & & & \\
\end{tabular}




\begin{tabular}{|c|c|c|c|}
\hline Vulnerability to poverty ratio & 1.13 & 1.10 & 1.14 \\
\hline Vulnerability rate & $97.9 \%$ & $99.5 \%$ & $97.6 \%$ \\
\hline Poverty trapped & $86.8 \%$ & $90.8 \%$ & $85.9 \%$ \\
\hline Risk induced & $11.1 \%$ & $8.7 \%$ & $11.6 \%$ \\
\hline Poverty/Risk vulnerability ratio & 7.81 & 10.47 & 7.39 \\
\hline Not Vulnerable & $2.1 \%$ & $0.5 \%$ & $2.4 \%$ \\
\hline Uneven prospects & $0.7 \%$ & $0.3 \%$ & $0.7 \%$ \\
\hline Relatively well-off & $1.5 \%$ & $0.3 \%$ & $1.7 \%$ \\
\hline Idiosyncratic variance & 0.79 & 0.72 & 0.59 \\
\hline Covariate variance per sous colline & 0.08 & 0.00 & 0.01 \\
\hline $\begin{array}{l}\text { Covariate variance per province } \\
\text { Note: Author's elaboration on World Food Programme data (Burundi Comprehensive and Food Security Analysis } \\
\text { Analysis Mapping Unit ). Expected consumption per adult equivalent and poverty line is in Burundi Franc (BIF). }\end{array}$ & $\begin{array}{l}0.26 \\
\text { is Survey } 200\end{array}$ & $\begin{array}{l}0.06 \\
\text { vided by the }\end{array}$ & $\begin{array}{r}0.07 \\
\text { erability and }\end{array}$ \\
\hline
\end{tabular}

The geographical distribution shows a complementary pattern between poverty trapped and risk induced vulnerable households (figure 5.4 panels $A$ and $B$ ). According to the geographical aggregation proposed by WFP ${ }^{80}(2008)$, there is a province belt, which includes central and north-western provinces (including Cankuzo to a lesser extent) plus two southern provinces (Ruyigi and Rutana), where poverty trapped households are relatively more than in the rest of the country. The opposite is true when risk induced households are taken into account.

In all the northern provinces, households included in the agriculturalist livelihood group account for more than $40 \%$ of the population and rely almost exclusively on agriculture. It makes an exception the province of Kirundo, where several households shifted from the agriculturalist into the agro-laborer group, probably depending on "several successive better than average agricultural seasons; a decrease in losses due to cassava mosaic; a concentration of investment and assistance in the province, including high labor intensity projects such as road building and increased trade with neighboring Rwanda and other provinces in Burundi" (WFP, 2008). Thence, provided the number of poverty trapped households which is similar to the whole region, those circumstances might have determined a relatively higher density of not vulnerable but with uneven prospects households in that province (panel C).

80 North-eastern provinces include Cankuzo, Karusi, Kirundo, Muyinga and Ngozi; North-western provinces include Cibitoke, Bubanza and Bujumbura Rural; the Central region provinces include Kayanza, Muramvya, Mwaro and Gitega; the southern provinces include Bururi, Makamba, Rutana and Ruyigi. 
Poverty is less widespread in Bururi and Bujumbura Rural, which are conversely those provinces where the occurrence of risk-induced households is higher. It probably depends on agro-sellers prevalence (35.4\%) and high exposure to drought in the first, and widespread insecurity in the area plus a higher number of laborers (32.3\%) compared to agriculturalists $(11.5 \%)$ in the second. Incidentally, Bujumbura Rural, being in the neighborhood of the capital city, is also the only province where not vulnerable households are found (panel D).

FIGURE 5.4: VULNERABILITY PER PROVINCE

A) VULNERABLE : POVERTY TRAPPED

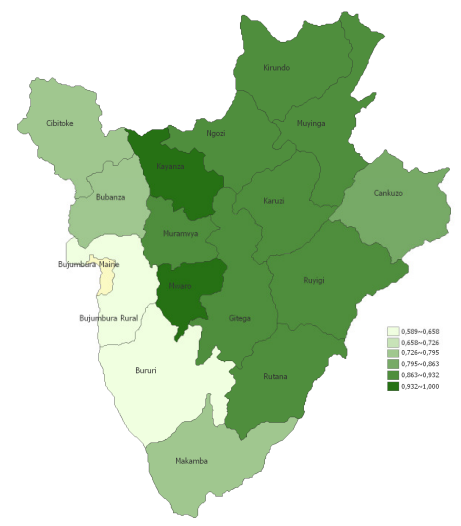

C) NOT VULNERABLE: UNEVEN PROSPECTS

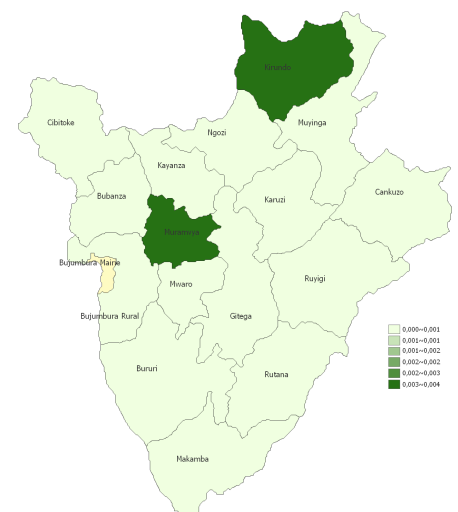

B) VULNERABLE: RISK INDUCED

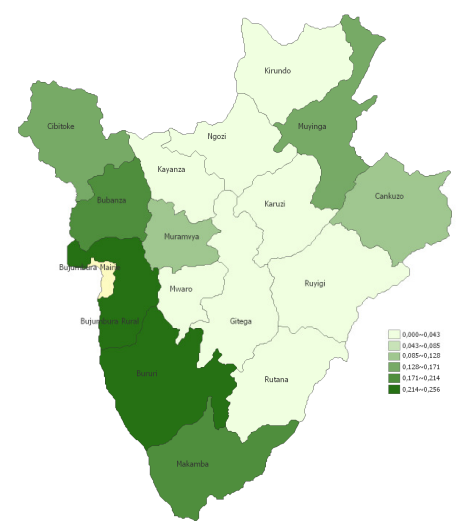

D) NOT

VULNERABLE: RELATIVELY WELL-OFF

Note: Author's elaboration on World Food Programme data (Burundi Comprehensive and Food Security Analysis Survey 2008 provided by the Vulnerability and Analysis Mapping Unit). Households within vulnerable and not vulnerable groups are indicated in each panel, with a gradient color spanning from white to dark-green that denotes an increasing household density. No data was available for Bujumbura Marie province which is colored in ocher. 


\subsubsection{A profile of vulnerability including price effects}

In this section price effects are included in the vulnerability analysis. A strong limitation affects this section. In fact, according to the survey exploited, household consumption expenditures data was collected without mentioning quantities consumed $^{81}$. It was hence not possible to directly address price effects on consumption, provided it would have been the first best strategy to be pursued.

Price data is provided from FAO commodity price dataset. The set of information ranges from cereal to non-cereal commodities - including bean, sweet potato, cassava flour, banana, rice, corn and sorghum. Monthly prices are available for 6 out of 16 Burundian provinces from September 2005 up to March 2010. Hence, with the aim of merging the available datasets, the WFP household dataset was reduced accordingly for the sake of this section only.

Nonetheless, the geographical distribution is interesting yet. Out of 6 provinces, market data is available for two north-eastern provinces at the border with Rwanda (Kirundo and Ngozi), two eastern provinces at the border with Tanzania (Muyinga and Ruyigi), one central province (Gitega) and the capital city Bujumbura ${ }^{82}$ (see figure 5.6 in the appendix).

Prices have an upward trend and it is more difficult to find a clear peak, unlike for international commodity prices. Actually, as of September 2007, prices have constantly been increasing, with a drop recognizable across the first semester of 2009 limited to bean, corn and sorghum commodities. Here, the general trends are quite in line with the international ones, that is to say the price surge reprises after a limited steady period. Still, prices have remained constantly higher in the whole specified time if compared with their pre-crisis levels.

With such a data restraint, it does not make much sense to investigate price transmission from international into domestic market. The limited information

\footnotetext{
81 Actually, these data is limited to self-consumed food quantities as a percentage of household production. Nonetheless, no additional information is further recognizable in order to presume the household net position, i.e. the overall consumption as the balance between self-consumed quantities plus those purchased and/or sold.

82 For geographical reasons, price data for Bujumbura are referred to Bujumbura Rural to avoid excessive data reduction.
} 
available stops at the principal province market and by no means it succeeds in providing any track to the door-prices households face. In the view of seeking price adjustments along the value chain, despite transmission would be an interesting feature to address, limited data would offer only a ramble into household vulnerability setbacks.

Conversely, provided the proposed methodology is helpful in a developing country framework, where all-embracing data is seldom at hand, in this section the focus will be on the interaction effects that prices may have with other variables. Considering the aim of the present research, these interactions enter the multilevel model only when found significant (Hox, 2002). Furthermore, pondering on the implications in terms of household behavior, they are implemented only for those variables pertaining this information, as such inferring at the household's net position in the market and their livelihood group.

Considering the survey is designed somehow statically, which means that it would not be possible to estimate expected consumption patterns along the year, another issue refers to price data handling. Hence, the interaction terms are considered in terms of coefficients of variation - that is a measure of price volatility - of monthly prices per commodity in the one-year period behind the survey (August 2007 - July 2008).

Having in mind these background specifications, the proposed methodology depicted in previous section is replicated with this limited dataset (6 provinces instead of 16). For the sake of comparison, table 5.5 reports the REML coefficients when no price effects are included, as well as those with price effects. Levels of significance and coefficient signs generally replicate those presented in table 5.3 within the full dataset, so the critical discussion is somehow akin. The newly established interaction terms are all significant, but it would be tricky to provide a general picture from a mere coefficient analysis.

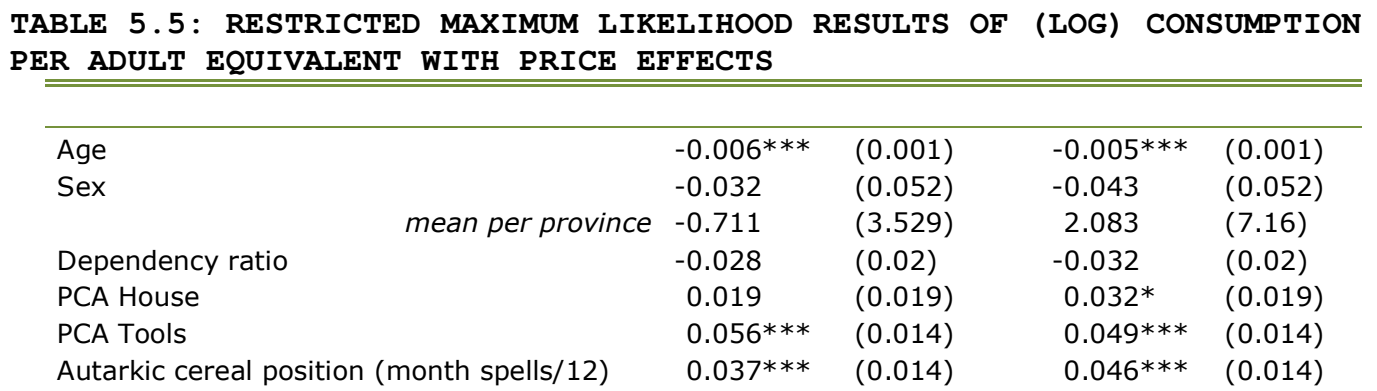




\begin{tabular}{|c|c|c|c|c|}
\hline mean per province & $0.059 * * *$ & $(0.022)$ & $-0.361 *$ & $(0.219)$ \\
\hline Seller cereal position (month spells/12) & $0.078 * * *$ & $(0.015)$ & 0.02 & $(0.025)$ \\
\hline mean per province & $-0.484 *$ & $(0.259)$ & -0.722 & $(0.561)$ \\
\hline Buyer cereal position (month spells/12) & $-0.733 * *$ & $(0.349)$ & -1.117 & $(0.723)$ \\
\hline mean per province & $-0.628 * *$ & $(0.313)$ & -1.024 & $(0.661)$ \\
\hline Shock: drought & 0.037 & $(0.048)$ & 0.038 & $(0.048)$ \\
\hline mean per sous colline & 0.123 & $(0.168)$ & 0.113 & $(0.177)$ \\
\hline Shock: inflation & $0.253 * * *$ & $(0.045)$ & $0.244 * * *$ & $(0.045)$ \\
\hline mean per sous colline & 0.131 & $(0.153)$ & 0.109 & $(0.16)$ \\
\hline $\mathrm{Nr}$ of livelihood activities $(1 / 2 / 3)$ & $0.183^{* * *}$ & $(0.036)$ & $0.181^{* * *}$ & $(0.037)$ \\
\hline Coping strategy index & $-0.002 * *$ & $(0.001)$ & $-0.002 * * *$ & $(0.001)$ \\
\hline Illiteracy & $0.112 * * *$ & $(0.041)$ & $0.102 * *$ & $(0.041)$ \\
\hline mean per sous colline & -0.238 & $(0.255)$ & -0.211 & $(0.268)$ \\
\hline Livelihood Group & & & & \\
\hline Agriculturalist & -0.149 & $(0.2)$ & -0.2 & $(0.209)$ \\
\hline Agro-Seller & 0.03 & $(0.202)$ & -0.08 & $(0.247)$ \\
\hline Agro-Laborer & -0.258 & $(0.2)$ & -0.443 & $(0.295)$ \\
\hline Laborer & -0.1 & $(0.203)$ & -0.384 & $(0.355)$ \\
\hline Agro-Traders & 0.245 & $(0.216)$ & -0.118 & $(0.421)$ \\
\hline Agro-Brewer & 0.025 & $(0.222)$ & -0.371 & $(0.498)$ \\
\hline Agro-Exploiter & -0.113 & $(0.269)$ & -0.645 & $(0.563)$ \\
\hline Employee/Business & $0.642 * *$ & $(0.262)$ & 0.097 & $(0.615)$ \\
\hline Marginal & 0.215 & $(0.328)$ & -0.465 & $(0.679)$ \\
\hline Food share on total expenditures & $-0.304 * * *$ & $(0.114)$ & $-0.279 * *$ & $(0.114)$ \\
\hline Pop. density $\times 100 \%$ land ownership & $0 * * *$ & (0) & $0 * * *$ & (0) \\
\hline Cash crop - plantain $(\mathrm{Y} / \mathrm{N})$ & $-0.07 *$ & $(0.04)$ & $-0.078 *$ & $(0.04)$ \\
\hline Stock reserve in months & 0.002 & $(0.003)$ & 0.003 & $(0.003)$ \\
\hline Returnee & 0.068 & $(0.042)$ & 0.048 & $(0.042)$ \\
\hline mean per sous colline & $0.289 *$ & $(0.164)$ & $0.313^{*}$ & $(0.171)$ \\
\hline $\mathrm{Nr}$ of goats & $-0.026 * *$ & $(0.011)$ & $-0.025 * *$ & $(0.011)$ \\
\hline $\mathrm{Nr}$ of poultry & 0.008 & $(0.009)$ & 0.011 & $(0.009)$ \\
\hline Livelihood Group x p. Bean & & & $-0.056 * * *$ & $(0.02)$ \\
\hline Livelihood Group x p. Sweet Potato & & & $0.018^{* *}$ & $(0.007)$ \\
\hline Livelihood Group x p. Cassava Flour & & & $-0.031 * *$ & $(0.014)$ \\
\hline Livelihood Group x p. Rice & & & $0.041 * * *$ & $(0.013)$ \\
\hline Livelihood Group x p. Corn & & & $0.011^{*}$ & $(0.006)$ \\
\hline Seller x p. Sweet Potato & & & $0.568 * * *$ & $(0.174)$ \\
\hline Seller $x \mathrm{p}$. Beans & & & $-0.133 * * *$ & $(0.041)$ \\
\hline Seller x p. Cassava Flour & & & $-0.458 * * *$ & $(0.142)$ \\
\hline Seller $\times$ p. Corn & & & $0.752 * * *$ & $(0.23)$ \\
\hline Seller $x \mathrm{p}$. Sorghum & & & $-0.46 * * *$ & $(0.138)$ \\
\hline Buyer x p. Sorghum & & & $0.003 * * *$ & $(0.001)$ \\
\hline Constant & $15.295 * * *$ & $(3.001)$ & $18.846 * * *$ & $(6.344)$ \\
\hline Province level & & & & \\
\hline $\begin{array}{l}\sigma^{2} u_{k} \\
\text { Sous-colline level }\end{array}$ & $0.02 *$ & $(0.032)$ & 0.096 & $(0.149)$ \\
\hline$\sigma^{2} v_{i k}$ & $0 * * *$ & (0) & $0.002 *$ & $(0.005)$ \\
\hline Household level & & & & \\
\hline$\sigma^{2} e_{i j k}$ & $0.601 * * *$ & $(0.02)$ & $0.586 * * *$ & $(0.02)$ \\
\hline$N$ & 1,809 & & 1,809 & \\
\hline DF & 37 & & 48 & \\
\hline Likelihood & $-2,182.26$ & & $-2,206.04$ & \\
\hline $\begin{array}{l}\text { BIC } \\
\text { Note: Author's elaboration on World Food Programme and Food and Ag } \\
\text { and Food Security Analysis Survey 2008, provided by WFP - Vulnerabili } \\
\text { provided by FAO - FAOBI unit). The following notations represent differen }\end{array}$ & $\begin{array}{l}\text { 4,672.046 } \\
\text { griculture Organizatic } \\
\text { lity and Analysis Ma } \\
\text { th level of significanc }\end{array}$ & data (Hous & $\begin{array}{l}4,802.116 \\
\text { is from the Burundi } \\
\text { rom the Commodity } \\
\text { k** at } 1 \% \text {. }\end{array}$ & $\begin{array}{l}\text { Comprehensive } \\
\text { price database }\end{array}$ \\
\hline
\end{tabular}


Conversely, some interesting information arises from vulnerability analysis. In figure 5.5 , expected consumption per adult equivalent density functions are drawn in the two scenarios where price effects are accounted for or not. Price interactions make the expected consumption curve steeper, shifting down household consumption levels considerably. It is possible to emphasize three different trends. At the very bottom levels of consumption and up to the distribution peak, price effects are moderately penalizing. Afterwards, so far the distribution goes to its higher consumption levels, then these adverse effects sharpen up to the crossing point. From this level on, price effects virtuously affect consumption.

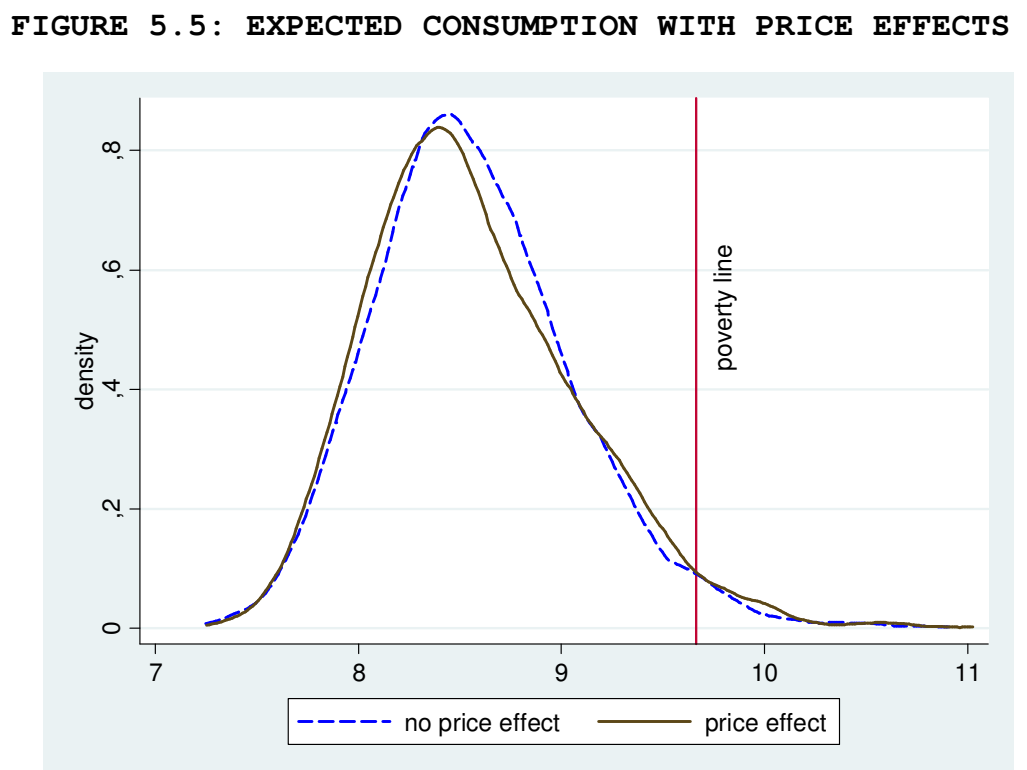

Note: Author's elaboration on World Food Programme and Food and Agriculture Organization data (Households data is from the Burundi Comprehensive and Food Security Analysis Survey 2008, provided by WFP - Vulnerability and Analysis Mapping Unit; price data is from the Commodity price database, provided by FAO FAOBI unit). Estimated consumption per adult equivalent data is expressed in (log) Burundi Franc (BIF). Poverty line set at 9.6645956 which is equivalent to 15,750 BIF.

Table 5.6 provides additional evidence. If considering consumption remainders per household percentiles without taking into account livelihood groups, then price interactions show adverse effects up to the $75^{\text {th }}$ percentile. Higher price volatility is hence consumption sound depressing for the vast majority of rural households in Burundi, with the exception of relative better-off households that would experience advantages from higher prices. These findings are in line with Barrett and Dorosh 
(1996) and contrast somehow with Deaton (1989), and Hoang and Glewwe (2009), because middle-in-distribution households are here found to be adversely affected.

This outcome is quite remarkable in the view of the model depicted in section 3.5. Provided households are well below the poverty line even at higher percentiles, most of them are trapped into poverty and might not pursue a utility maximization framework. Thus, as already emphasized, those households would need a strong push in order to move from disaster avoidance into a utility maximization framework.

Actually, higher food prices fail to provide such a push and are conversely found to severely embitter those who are less in the condition of coping with them. The opposite is true for wealthier households that seem to behave maximizing their utility.

Agriculturalists, that account for the $34 \%$ of the population (WFP, 2008), are throughout adversely affected if the upper percentile is excluded. This group basically relies on its food production, and might be pushed to adopt short-sighted coping strategies, including seeds consumption and early harvesting. This can also be associated with stock depletion, that in case of higher food prices might hinder the chance of purchasing needed food directly in the market. A tiny exception accounts to the bottom percentile for household belonging to the agro-laborers, whose agriculture livelihoods are supported by another main activity.

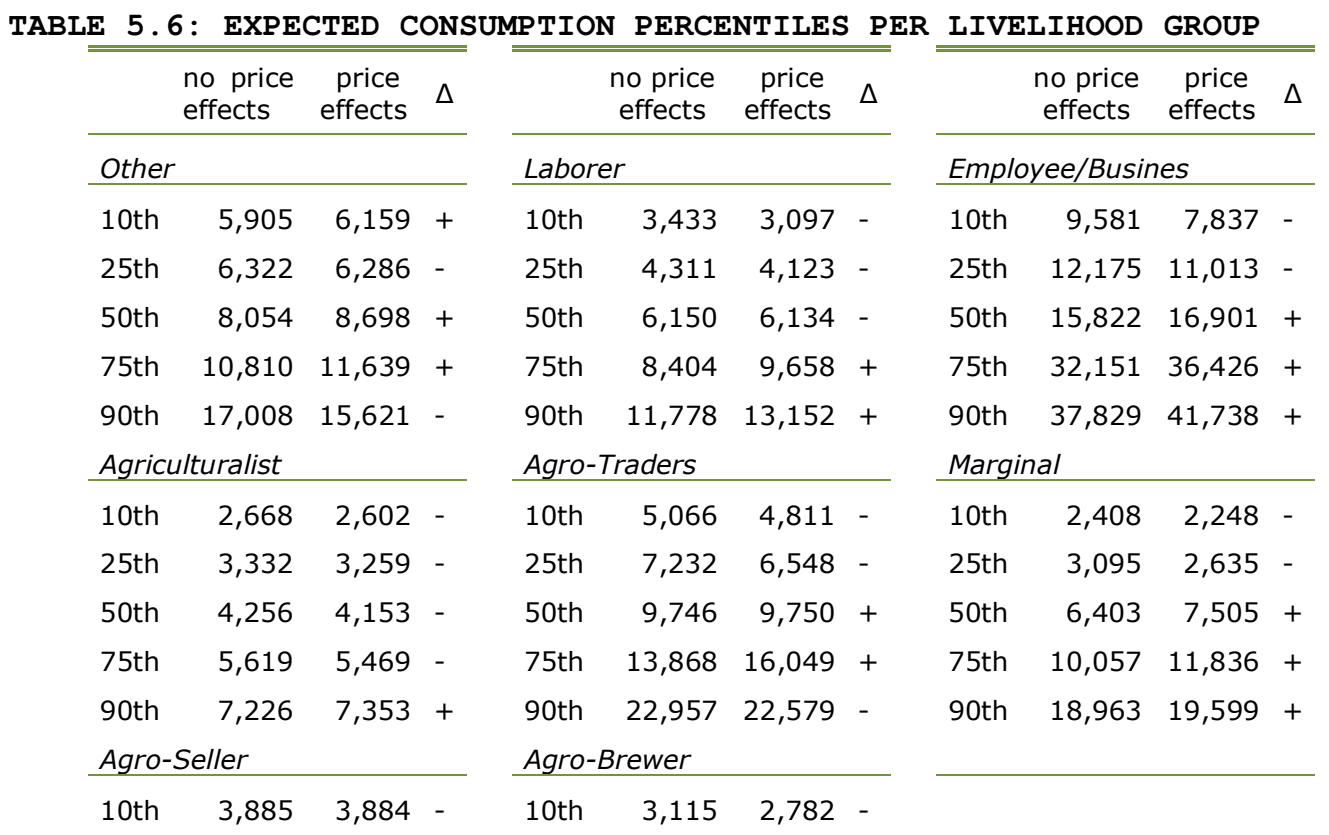




\begin{tabular}{|c|c|c|c|c|c|c|c|c|c|c|c|}
\hline 25th & 4,919 & 4,761 & - & 25 th & 4,033 & 3,606 & - & & & & \\
\hline 50th & 6,383 & 6,078 & - & 50th & 5,868 & 5,568 & - & & & & \\
\hline 75th & 8,317 & 8,174 & - & 75th & 7,400 & 8,258 & + & & & & \\
\hline 90th & 11,114 & 11,636 & + & 90th & 10,388 & 12,772 & + & & & & \\
\hline \multicolumn{4}{|c|}{ Agro-Laborer } & \multicolumn{4}{|c|}{ Agro-Exploiter } & \multicolumn{4}{|l|}{ Total } \\
\hline 10th & 2,753 & 2,849 & + & 10th & 3,780 & 2,943 & - & 10th & 2,908 & 2,881 & - \\
\hline 25th & 3,550 & 3,542 & - & 25th & 6,148 & 4,706 & - & 25th & 3,755 & 3,635 & - \\
\hline 50th & 4,656 & 4,530 & - & 50th & 8,327 & 9,795 & + & 50th & 5,050 & 4,914 & - \\
\hline 75th & 5,950 & 6,443 & + & 75th & 12,532 & 13,405 & + & 75th & 7,088 & 7,221 & + \\
\hline 90th & 8,606 & 9,361 & + & 90th & 17,893 & 20,206 & + & 90th & 10,131 & 10,754 & + \\
\hline
\end{tabular}

In table 5.7 vulnerability breakdown is presented. The estimated consumption per adult equivalent on average is reduced when price volatility is accounted for. Nonetheless, a very slight reduction in the vulnerability rate and consequently in the vulnerability to poverty ratio is envisaged. Variability in consumption is somehow reduced for a very limited number of households, especially among those who were risk-induced vulnerable. As aftermath, the non vulnerable households, which presumably are found in the consumption percentiles showing a positive change, increase in number.

TABLE 5.7: VULNERABILITY WITH PRICE AND NO PRICE EFFECTS

\begin{tabular}{|c|c|c|c|c|}
\hline & \multicolumn{2}{|c|}{ no price effect } & \multicolumn{2}{|c|}{ price effect } \\
\hline N & 1,809 & & 1,809 & \\
\hline Estimated consumption per adult equivalent & & 5,277 & & 5,265 \\
\hline Poverty line & & 15,750 & & 15,750 \\
\hline Poverty incidence & & $88.01 \%$ & & $88.01 \%$ \\
\hline Mean Vulnerability & & $88.65 \%$ & & $89.25 \%$ \\
\hline Vulnerability to poverty ratio & & 1.108 & & 1.107 \\
\hline Vulnerability rate & 1,764 & $97.51 \%$ & 1,764 & $97.46 \%$ \\
\hline Poverty trapped & 1,593 & $88.06 \%$ & 1,597 & $88.28 \%$ \\
\hline Risk induced & 171 & $9.45 \%$ & 167 & $9.23 \%$ \\
\hline Poverty/Risk vulnerability ratio & & 9.316 & & 9.563 \\
\hline Not Vulnerable & 45 & $2.49 \%$ & 45 & $2.54 \%$ \\
\hline Uneven prospects & 20 & $1.11 \%$ & 16 & $0.88 \%$ \\
\hline Relatively well-off & 25 & $1.38 \%$ & 29 & $1.60 \%$ \\
\hline
\end{tabular}


Note: Author's elaboration on World Food Programme and Food and Agriculture Organization data (Households data is from the Burundi Comprehensive and Food Security Analysis Survey 2008, provided by WFP - Vulnerability and Analysis Mapping Unit; price data is from the Commodity price database, provided by FAO - FAOBI unit). Expected consumption per adult equivalent and poverty line are in Burundi Franc (BIF).

In fact, in table 5.8 the ratios split between vulnerable and not vulnerable households by livelihood group are compared in the price and no price scenarios.

When the ratio is equal the unit, none of the households changed its belonging group. Otherwise, when it is less than the unit, at least one household quits its group, whereas the opposite occurs when the ratio is greater than unit.

At first glance, the price effect determined no worsening alteration, confirming previous caveats. Actually, the scant number of the non-vulnerable is confirmed to have been slightly enlarged. Thence, it cannot be argued that such shifts might be considered proof for the alleged positive impact of high food prices on the most vulnerable. In spite of the fact that a small number of households have gauged some benefit from price rises in absolute terms, it is unquestionable that some benefits have actually occurred.

Nonetheless, when focusing on livelihood groups, the picture gets clearer. Within those households having experienced some positive impacts, the distribution is unequal.

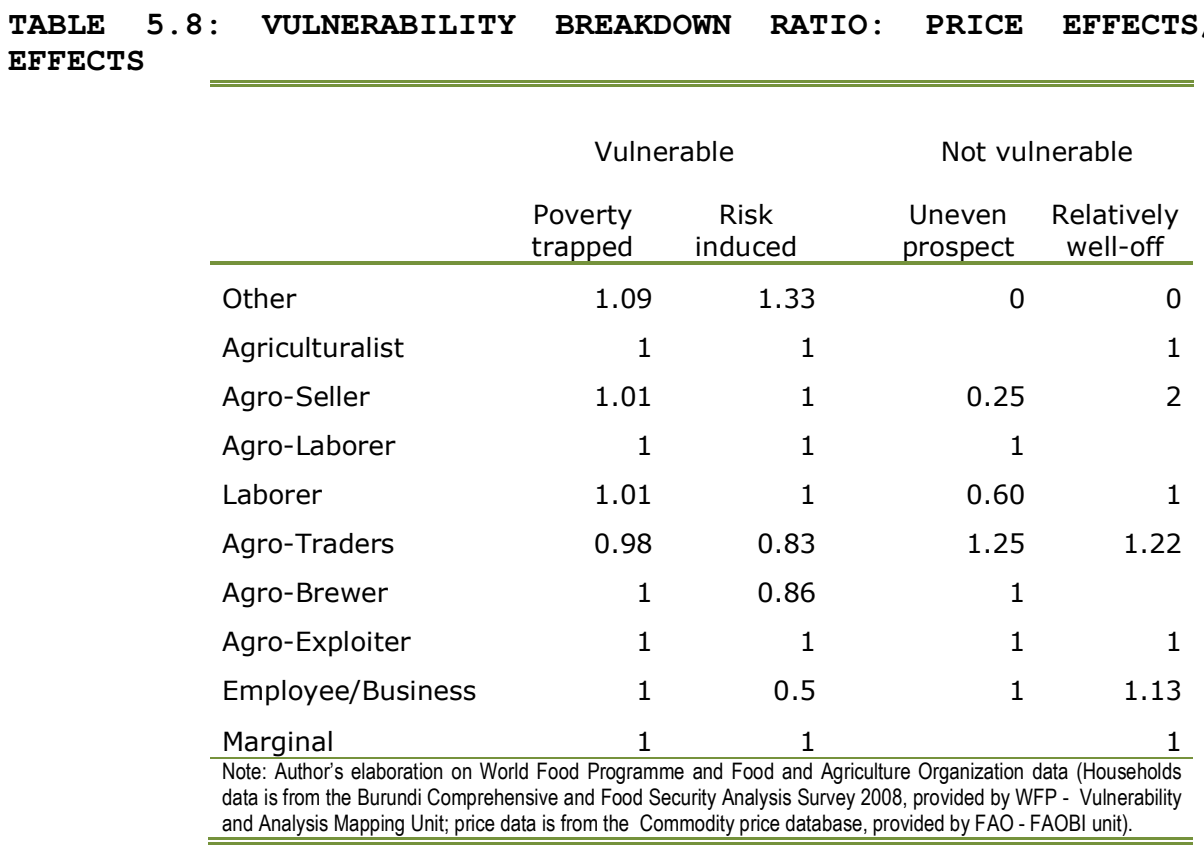


Again, only few elements from the agro-seller, agro-traders and employee/business groups became non vulnerable as a consequence of price volatility.

This evidence is also supported by figure 5.6 that shows price effect outcomes on vulnerability. Again, Bujumbura Rural is the only province where the presence of not vulnerable households occurs, depending also on the higher prevalence of agrotraders $(12.35 \%)$ compared to the other provinces (spanning from $2.13 \%$ in Ngozi to $4.52 \%$ in Kirundo).

FIGURE 5.6: VULNERABILITY WITH PRICE EFFECTS

A) VULNERABLE: POVERTY TRAPPED

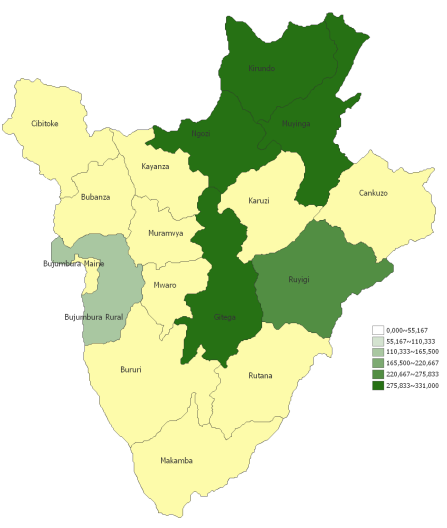

C) NOT VULNERABLE: UNEVEN PROSPECTS

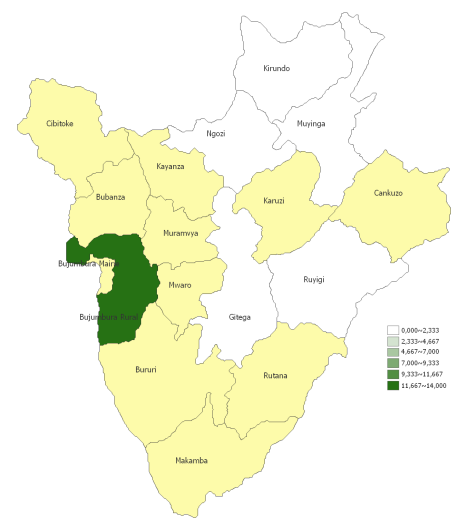

B) VULNERABLE: RISK INDUCED

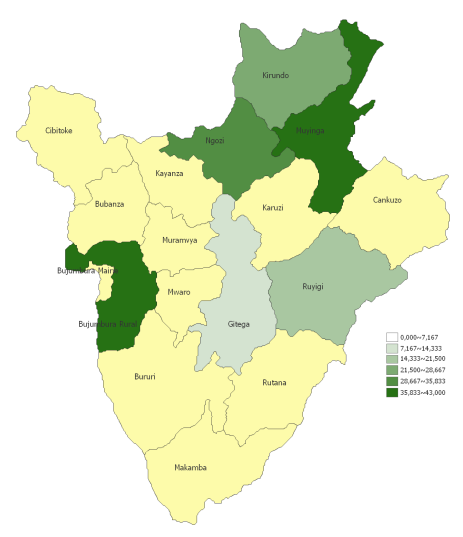

D) NOT

VULNERABLE: RELATIVELY WELL-OFF

Note: Author's elaboration on World Food Programme and Food and Agriculture Organization data (Households data is from the Burundi Comprehensive and Food Security Analysis Survey 2008, provided by WFP - Vulnerability and Analysis Mapping Unit; price data is from the Commodity price database, provided by FAO FAOBI unit). Households within vulnerable and not vulnerable groups are indicated in each panel, with a gradient color spanning from white to dark-green that denotes an increasing household density. No data was available for provinces colored in ocher. 
In the frame of this dissertation, these results are in line with theoretical expectations. In fact, only those households with higher expected consumption associated with lower variability (see figure 5.7 in the appendix)) can somehow relax their vulnerability status, and find an opportunity in higher food prices. Those rural households, who secure their livelihoods relying not only on the agricultural activities, are also inclined towards market oriented choices and might be positively influenced by higher food prices. Inversely, all the others, which constitutes the vast majority of the population, have in general remained vulnerable. Among those, the households who were trapped into poverty stay put and deemed vulnerable with even worst consumption expectations.

Nonetheless, considering the slight number of households involved and the overall poverty figures, these results need be interpreted cautiously and in the view of the limitations put forward at the beginning of this section. 


\subsection{ANNEX TO THE CHAPTER}

TABLE 5.9: WEALTH INDEXES

\begin{tabular}{llll}
\hline \hline Assets & \multicolumn{3}{l}{ Housing } \\
Sewing machine & 0.11 & Wall building & 0.68 \\
Table & 0.42 & Roof & 0.68 \\
Chair & 0.40 & Lighting & 0.07 \\
Iron & 0.28 & Toilet & 0.17 \\
Hoe & 0.04 & Water source & 0.19 \\
Axe & 0.32 & & \\
Sickle & 0.28 & \\
Billhook & 0.17 & \\
Machete & 0.24 & \\
Canoe & 0.07 & \\
Radio & 0.39 & \\
Bike & 0.26 & \\
Motorbike & 0.16 & \\
Tv & 0.15 & \\
Automotive & 0.12 & \\
Mill & 0.08 & \\
Fishing equipment & 0.07 & \\
Note: Author's elaboration on World Food Programme data (Burundi Comprehensive and Food Security \\
Analysis Survey 2008 provided by the Vulnerability and Analysis Mapping Unit).
\end{tabular}

TABLE 5.10: CORRELATION OF HOUSEHOLD MARKET POSITIONS

\begin{tabular}{|c|c|c|c|}
\hline & $\frac{\frac{u}{x}}{\frac{1}{\frac{1}{U}}}$ & 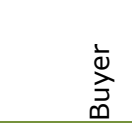 & $\frac{\grave{D}}{\bar{D}}$ \\
\hline Autarkic & 1 & & \\
\hline Buyer & -0.65 & 1 & \\
\hline $\begin{array}{l}\text { Seller } \\
\text { Note: Author's elaboration on World Food Programme data } \\
\text { Security Analysis Survey } 2008 \text { provided by the Vulnerability and }\end{array}$ & $\begin{array}{l}-0.21 \\
\text { (Burundi } \\
\text { d Analysis M }\end{array}$ & $\begin{array}{l}-0.15 \\
\text { Comprehensive } \\
\text { Mapping Unit). }\end{array}$ & 1 \\
\hline
\end{tabular}


FIGURE 5.7: ESTIMATED CONSUMPTION AND VARIANCE

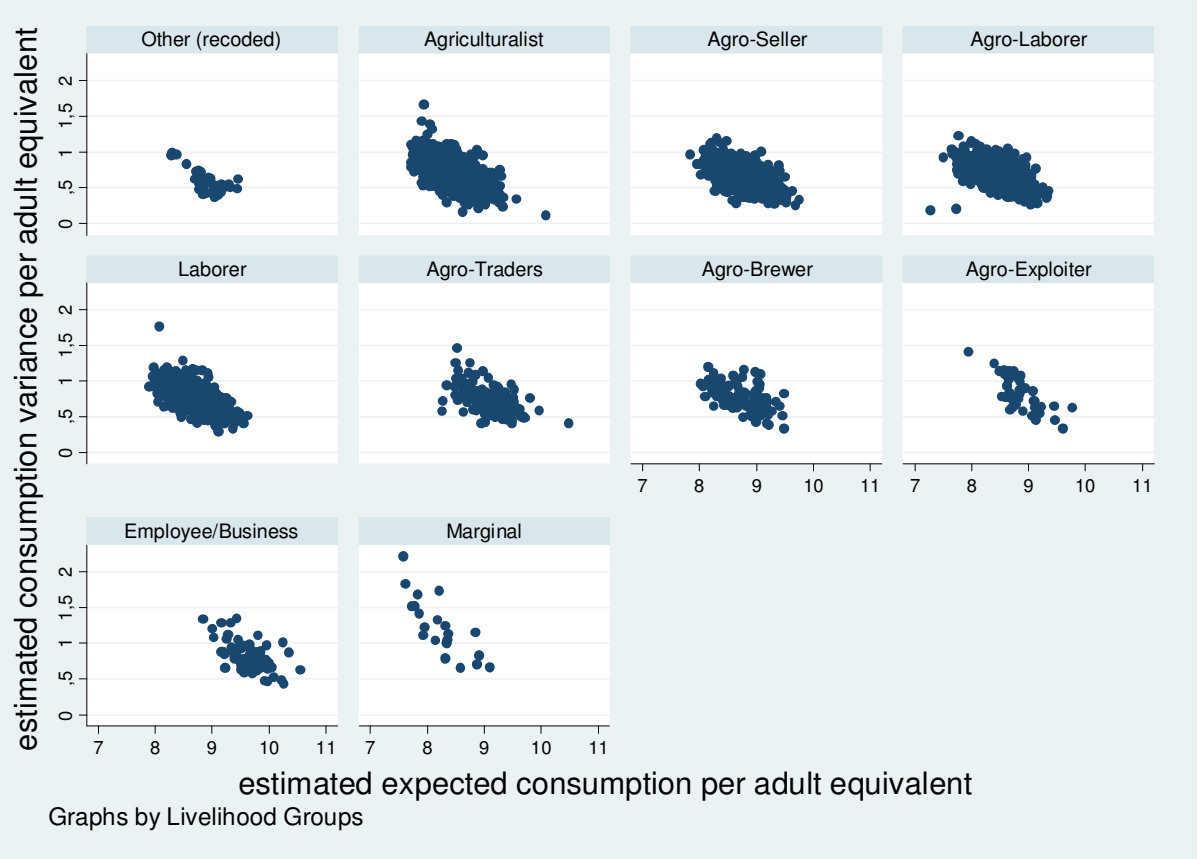

Note: Author's elaboration on World Food Programme data (Burundi Comprehensive and Food Security Analysis Survey 2008 provided by the Vulnerability and Analysis Mapping Unit ).

FIGURE 5.8: PRICE TRENDS PER PROVINCE
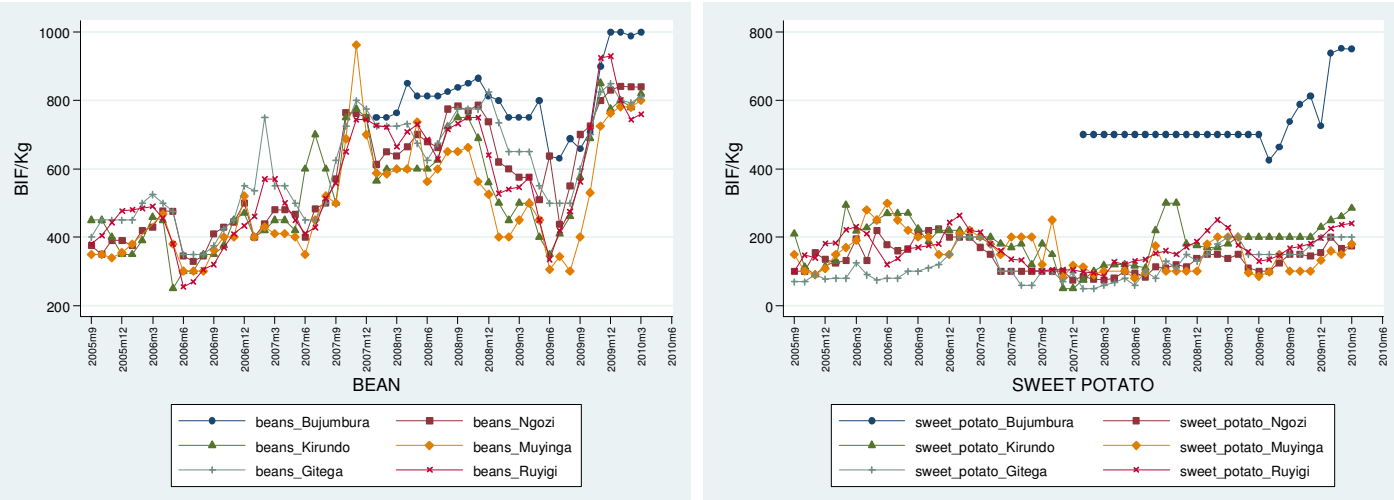

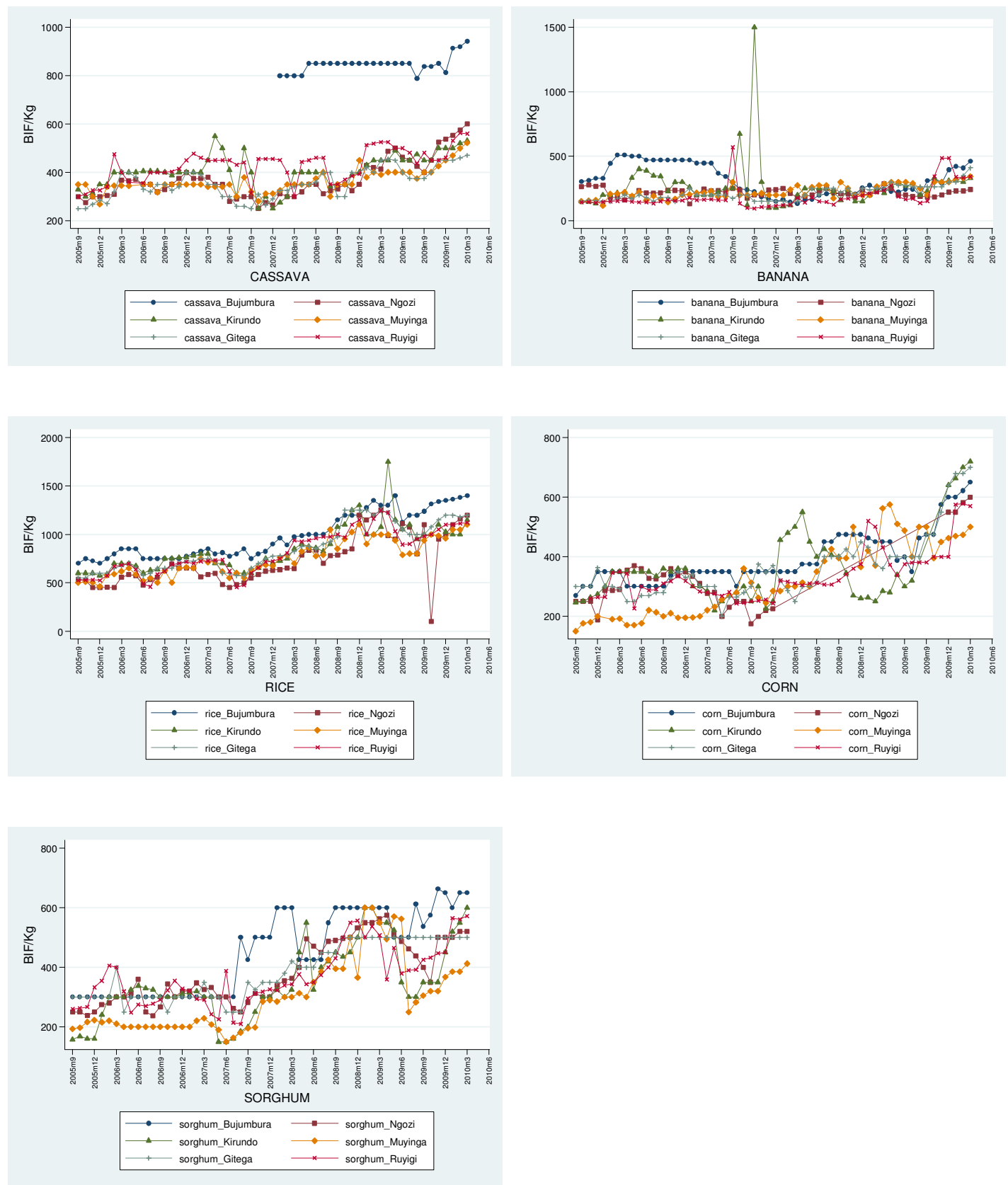

Note: Author's elaboration on FAO data (price data is from the Commodity price database, provided by FAO - FAOBI unit). 
TABLE 5.11: CORRELATION OF SHOCKS

\begin{tabular}{|c|c|c|c|c|c|c|c|c|c|c|c|c|c|}
\hline & 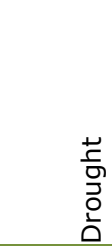 & 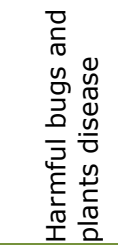 & $\begin{array}{l}\overline{\bar{\pi}} \\
\bar{I}\end{array}$ & 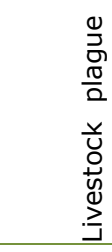 & $\begin{array}{l}\text { 므 } \\
\text { 은 }\end{array}$ & $\begin{array}{l}\text { 음 } \\
\text { ㅇ } \\
\text { 누 }\end{array}$ & 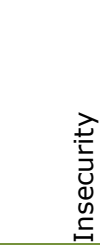 & 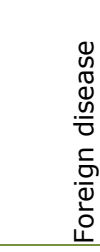 & $\begin{array}{l}\text { 壳 } \\
\mathbb{0} \\
0\end{array}$ & 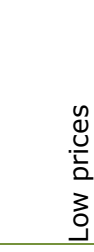 & $\stackrel{0}{i}$ & 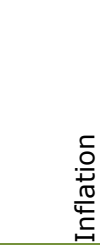 & $\begin{array}{l}\frac{1}{0} \\
\frac{1}{4} \\
0\end{array}$ \\
\hline Drought & 1 & & & & & & & & & & & & \\
\hline Harmful bugs and plants disease & 0.02 & 1 & & & & & & & & & & & \\
\hline Hail & -0.04 & -0.06 & 1 & & & & & & & & & & \\
\hline Livestock plague & 0.00 & 0.00 & 0.00 & 1 & & & & & & & & & \\
\hline Flood & 0.01 & -0.07 & -0.01 & -0.01 & 1 & & & & & & & & \\
\hline Erosion & 0.06 & -0.07 & -0.02 & 0.01 & -0.10 & 1 & & & & & & & \\
\hline Insecurity & -0.07 & 0.00 & -0.06 & -0.01 & -0.03 & -0.01 & 1 & & & & & & \\
\hline Foreign disease & -0.11 & -0.06 & -0.04 & -0.01 & -0.06 & -0.04 & 0.01 & 1 & & & & & \\
\hline Death & -0.01 & 0.00 & -0.04 & -0.01 & -0.01 & 0.00 & -0.02 & 0.03 & 1 & & & & \\
\hline Low prices & -0.01 & -0.01 & -0.01 & 0.00 & -0.01 & -0.01 & 0.00 & 0.00 & 0.10 & 1 & & & \\
\hline Fire & -0.03 & -0.01 & -0.01 & 0.00 & -0.01 & 0.01 & -0.01 & -0.01 & 0.00 & 0.00 & 1 & & \\
\hline Inflation & -0.25 & -0.02 & -0.09 & -0.02 & -0.06 & -0.05 & -0.03 & -0.01 & -0.02 & 0.01 & -0.02 & 1 & \\
\hline Other & -0.05 & -0.03 & -0.01 & 0.05 & 0.00 & -0.03 & -0.03 & -0.01 & -0.01 & 0.00 & 0.00 & -0.03 & 1 \\
\hline
\end{tabular}

Note: Author's elaboration on World Food Programme data (Burundi Comprehensive and Food Security Analysis Survey 2008 provided by the Vulnerability and Analysis Mapping Unit ). 


\section{CONCLUDING REMARKS}

In this dissertation an attempt to go beyond the plain commoditization of the subject related to high food prices was provided. Since the crisis spurred attention to the food issue, which was marginalized for decades and reckoned as a problem cramped to developing countries, and within those to the poorest segments of the populations, a number of contributions drew increasing attention to omnifarious aspects that might be considered determining factors to gauge the inner part of the crisis.

There is an achieved consensus that not a single, rather a set of different grounds are to be considered at the basis of the crisis, spanning in a very general inventory from changes in food demand and supply, shocks occurrence and reoccurrence with subsequent (often) inappropriate responses, and the structure of the world food market.

The food crisis was tackled through two distinct viewpoints. On the one hand, international price surge was addressed in its most financial fashion - i.e. the price generation process - and the related information within connected. On the other, the vulnerability drawbacks that such dynamics may have triggered in terms of household food consumption were investigated, that is to say how the crisis turned from being purely financial into an issue affecting food provision, and therefore a matter of adequate feeding for a great part of world population.

The question whether high food prices are pro-poor has been pursued, considering possible poverty relief through consumption and income channels. Provided the field of investigation focuses on rural households, where poverty figures are dramatic, higher prices are expected to determine an uncertain payoff resulting from a consumption effect, that is undoubtedly adverse in case the household was about to secure its consumption level at a fixed level. Furthermore an income effect may be accounted for, which occurs when the same household was engaged in agricultural sound livelihoods, and therefore is consequently and positively proved by increasing price volatility. Actually, this might lead to an agriculture-oriented resources redistribution, income-bounded by higher profits and wages. 
Besides theory, food inflation appears to be a pervasive source of vulnerability and income effects are fenced not only with regards to net food buyers, which are usually the poorest households, but throughout the whole set of livelihood categories within whom rural households may be partitioned in. All things considered, drawbacks may well jump across categories, thus determining net food sellers to be adversely affected as well, since a clear cut-off line is hardly recognizable and the same household may shift between a net position to the other according to the season (see table 5.10). Nonetheless, the distinguishing difference over household welfare in terms of livelihood source seems to play a key role in addressing the impact of higher prices, provided it reflects rural household compounding firm and ménage units, and as such is preserved through the lines of the dissertation, with a further implication.

Typically, rural household faces a subjective price determined by its supply-demand balance, which determines its decision to participate in the market as a seller or a buyer, or to quit it choosing for self-sufficiency, as far price volatility dampens its power and convenience to remain in the market. Since higher prices affect households simultaneously, these movements in and out the markets are prone to be highly correlated and pro-cyclical.

As a corollary, transaction costs, limited endowments and covariate risks result into coping strategies aimed at limiting the drawbacks following a price shock, and need be addressed under uncertainty and household subjective probabilities associated to uneven prospects.

At very low levels of wealth, the presence of a discontinuity point, where households are trapped into poverty and the decision whether to participate or not in the market is a matter of starvation rather than utility maximization, is strongly fostered throughout the dissertation. Here, despite their risk attitude, households do not plumb wealth worsening and improvement according to the same rule of thumb, and are bounded by their own circumstances to long-term poverty perspectives. In other words, some households would be pushed against a consumption level that (hopefully) avoids starvation, rather than pursuing higher utilities associated with different choices. By doing so, only an exogenous push would quit these households from the poverty trap to maximize its consumption/producing decisions.

Would it be possible that such a push might be granted by higher food prices? In order to award an answer, a framework where households are poverty-trapped needs 
be implemented, with the further improvement granted by addressing the probability of being poor in the future. In fact, provided price volatility pertains to a process in fieri, limiting the analysis only to its poverty outcomes would mean curtailing it into a static form.

By doing so, the concept of vulnerability in its forward looking nuance, introduces the odds that a household might find itself below a given consumption threshold in the next period, where this threshold can be set at the poverty line itself, adding instability and unpredictability to an already hard set up.

So that, household endowments and a set of unpredictable circumstances are likely to determine tomorrow's expected consumption to be at a different level than observed consumption, with the practical result of determining who is more likely to be engaged into poverty under the definition of a probability distribution.

This work attempted to take advantage of this framework and shed some light on price volatility effects on vulnerability in a deprived contest like Burundi.

Consistently to what expected, the bulk of the households surveyed are trapped into poverty. The vulnerability analysis, with a break-down into its sources, tends to confirm that no significant shifts are recognizable within households. Actually, the limited impacts are positive, granting a very faint number of households to be less vulnerable. This is limited to certain households categories, such as agro-sellers who base their livelihoods on self consumption agriculture and a limited contribution of cash crops, agro-traders involved both into small-trade and in a limited part in agriculture and, most specifically, employees and business households - which depend their livelihoods on revenues or business profit and also on agriculture in a very limited part.

Additionally, taking advantage from the hierarchical model presented, which properly takes into account the structure of the sample, covariate consumption variance is found to be negligible respect to idiosyncratic variance, which means that vulnerability is strictly the result of deprivation lots households are settled in, rather than being the result of major covariate shocks.

Thence, higher food prices are definitively not pro-poor, if considered with regards to the belonging livelihood group, but can positively affect those who are in a relatively well-off situation. Or, to say it differently and taking into account a household partition into livelihood classes, those who are naturally less constrained 
by poverty, gain the most from increased food prices, whilst the other stay put. Net positions assumed within the market is therefore less valuable to gauge the effects of food prices rather than their starting wealth point. So that, the discontinuity point bites, and those households who are trapped into poverty find themselves in the same circumstances well beyond any price shock.

This work suffers from two main sources of limitations that arise mostly from data constraints. The first is determined by the lack of knowledge about subjective prices. Conversely, the issue of price bands would have been addressed directly, rather than using self-indicated spells within a year a household defines itself net buyer, seller or self sufficient. Moreover, no comprehensive information about quantities consumed has further limited the chance of directly addressing price effects on consumption, and consequently on vulnerability.

The second limitation is well known in this strand of literature and resides in the strict assumptions required to address a dynamic process like vulnerability within a cross section survey and can be addressed through panel data. Still, provided such a data is seldom available in developing countries, the latter might also be considered an opportunity to investigate otherwise unpredictable vulnerability.

Finally, notwithstanding these limitations, this work tries to depict a comprehensive framework where households vulnerability is addressed in a contest of price volatility, which takes its steps from a household model where a discontinuity point might occur.

Besides, despite the outcomes of high food prices on households poverty have been investigated by several authors, this dissertation tries to improve the field of investigation providing a non-anecdotal analysis of vulnerability in times of high food prices. 


\section{REFERENCES}

Abbott P.C., Hurt C., Tyner W.E., (2008): “What's Driving Food Prices?”, Farm Foundation, Issue Report July 2008.

Addison T., Hulme D., Kanbur R., (2009) eds.: "Poverty Dynamics: Interdisciplinary Perspectives", Oxford: Oxford University Press.

Ahn, C.Y., Singh I.J., Squire L., (1981): “A Model of an Agricultural Household in a Multicrop Economy: The Case of Korea", Review of Economics and Statistics 63(4):5220-525.

Aksoy M., Isik-Dikmelik A., (2008): “Are Low Food Prices Pro-Poor? Net Food Buyers and Sellers in Low-Income Countries", Policy Research Working Paper 4642, World Bank.

Alderman H., Paxson C., (1994): "Do the Poor Insure? A Synthesis of the Literature on Risk and Consumption in Developing Countries", in International Economics Association, Moscow meeting, Proceedings Vol. 4.

Amin S., Rai A., Topa G., (2003): “Does Microcredit Reach the Poor and Vulnerable? Evidence from Northern Bangladesh", Journal of Development Economics, 70(1), 59-82.

Banerjee A., Lumsdaine R.L., Stock J.H., (1992): "Recursive and Sequential Tests of the UnitRoot and Trend-Break Hypotheses: Theory and International Evidence", Journal of Business \& Economic Statistics, 10, 271-287.

Banerjee A.V., (2001): “The Two Poverties”, Nordic Journal of Political Economy 26(2):129141.

Bankoff G., Frerks G., Hilhorst D., (2004): “Mapping Vulnerability: Disasters, Development, and People", London: Earthscan.

Barrett C.B., Dorosh P.A., (1996): "Farmers' Welfare and Changing Food Prices: Nonparametric Evidence from Rice in Madagascar", American Journal of Agricultural Economics, Vol. 78, No. 3 (Aug., 1996), pp. 656-669.

Barrett C.B., Reardon T., Webb P., (2001): “Nonfarm Income Diversification and Household Livelihood Strategies in Rural Africa: Concepts, Dynamics and Policy Implications", Food Policy No. 26, 315-331. 
Basu K., Nolen P., (2006): “Vulnerability, Unemployment and Poverty: A Class of Distribution Sensitive Measures, its Axiomatic Properties and Applications", University of Essex, Discussion Paper Series, No. 623.

Benson T., Minot N., Pender J., Robles M., von Braun J., (2009): "Global Food Crisis: Monitoring and Assessing Impact to Inform Policy Responses", International Food Policy Research Institute, Washington D.C.

Block S., (1999): "Agriculture and Economic Growth in Ethiopia: Growth Multipliers from a Four-Sector Simulation Model", Agricultural Economics 20: 241-252.

Bourguignon F., Goh C., Kim D., (2004): "Estimating Individual Vulnerability Using PseudoPanel Data", World Bank Policy Research Working Paper 3375.

Boyce J.K., Ravallion M., (1991): “A Dynamic Econometric Model Of Agricultural Wage Determination In Bangladesh", Oxford Bulletin of Economics and Statistics 53(4): 361376.

Brambila J., Caracciolo F., Depalo D., (2009): "Poverty Impact of Commodity Price Boom Using Household Survey. The Case of Maize in Zambia", available at: http://ssrn.com/abstract=1408499.

Brown G., (1979): “Agricultural Pricing Policies in Developing Countries", In T. W. Schultz (ed.), Distortions of Agricultural Incentives, Bloomington, Indiana: Indiana University Press.

Budd J.W., (1993): "Changing Food Prices and Rural Welfare: A Nonparametric Examination of the Cote d'Ivoire", Economic Development and Cultural Change No. 41 (April 1993): 587-603.

Bundervoet T., Verwimp P., Akresh R., (2007): "Health and Civil War in Rural Burundi", IZA DP no. 2951, The Institute for the Study of Labor, Bonn.

Bussolo M., De Hoyos R., Medvedev D., (2009): “Global Income Distribution and Poverty in the Absence of Agricultural Distortions", in Anderson, K. (ed.) Distortions to Agricultural Incentives: A Global Perspective, London: Palgrave Macmillan and Washington DC: World Bank, forthcoming. Also World Bank Policy Research Working Paper 4849.

Byerlee D., Myers R., Jayne T., (2006): “Managing Food Price Risks and Instability in an Environment of Market Liberalization", Agriculture and Rural Development Department, The World Bank: Washington, D.C. 
Caccavale O.M., (2005): "Land Reform in Tajikistan: Economic Effects on Private Farms", working paper, FAO, Emergency Coordination Unit.

Calvo C., (2008): "Vulnerability to Multidimensional Poverty: Peru 1998-2002", World Development, 36(6), 1011-1020. A26

Calvo C., Dercon S., (2005): “Measuring Individual Vulnerability”, Discussion Paper No. 229, Department of Economics, University of Oxford.

Calvo C., Dercon S., (2007): “Chronic Poverty and All That: The Measurement of Poverty over Time", CSAE Working Paper Series, WPS/2007-04, Oxford University, Oxford.

Campbell J.Y., Perron P., (1991): "Pitfalls and Opportunities: What Macroeconomics Should Know about Unit Roots", in O. J. Blanchard and S. Fisher (eds.), NBER Macroeconomics Annual, The MIT Press, 141-201.

Chant S., (2008): "Dangerous Equations? How Female-Headed Households Became the Poorest of the Poor: Causes, Consequences and Cautions", in Momsen and Janet (eds.), Gender and development: critical concepts in development studies, Critical concepts in development, No. 1 - Theory and classics. Routledge, London, UK.

Chaudhuri S., (2001): "Empirical Methods for Assessing Household Vulnerability to Poverty", Department of Economics, Columbia University, mimeographed.

Chaudhuri S., (2003): "Assessing Vulnerability to Poverty: Concepts, Empirical Methods and Illustrative Examples", Department of Economics, Columbia University.

Chauduri S., Jalan J., Suryahadi A., (2002): “Assessing Household Vulnerability to Poverty From Cross-Sectional Data: A Methodology and Estimates from Indonesia", Discussion Paper \#:0102-52, Department of Economics, Columbia University.

Chen S., Ravallion M., (2003): "Household Welfare Impacts of China's Accession to the World Trade Organization", Policy Research Working Paper 3040, World Bank, Washington D.C.

Choi I., Chung B., (1995): "Sampling Frequency and the Power of Tests for a Unit Root: A Simulation Study", Economics Letters, 49, 131-136.

Christiaensen L., Boisvert R.N., (2000): “On Measuring Household Food Vulnerability: Case evidence from Northern Mali", Department of Agricultural, Resource, and Managerial Economics, Cornell University, mimeographed. 
Christiaensen L., Subbarao K., (2005): "Toward an Understanding of Household Vulnerability in Rural Kenya", Journal of African Economies, 14-4: pp. 520-558.

Christiaensen, L., Demery L., (2007): “Down to Earth: Agriculture and Poverty Reduction in Africa", Directions in Development, World Bank, Washington, D.C.

Clemente J., Montañés A., Reyes M., (1998): “Testing for a Unit Root in Variables with a Double Change in the Mean", Economics Letters 59, 175-182.

Cook S., (1966): “The Obsolete 'Anti-Market' Mentality: A Critique of the Substantive Approach to Economic Anthropology", American Anthropologist, vol. 68, pp. 323-45.

Cunningham W., Maloney W., (2000): “Measuring Vulnerability: Who Suffered in the 1995 Mexican Crisis?", IBRD mimeo.

Dalton G., (1961): "Economic Theory and Primitive Society", American Anthropologist: vol. 62, pp. 1-25.

Dasgupta P., (1993): “An Inquiry into Well-Being and Destitution", Oxford: Clarendon Press.

Dasgupta P., (1997): "Nutritional Status, the Capacity for Work, and Poverty Traps", Journal of Econometrics, 77 (1), 5-37.

Datt G., Ravallion M., (1998): “Why Have Some Indian States Done Better than Others at Reducing Rural Poverty?", Economica 65: 17-38.

De Hoyos R.E., Medvedev D., (2009): “Poverty Effects of Higher Food Prices. A Global Perspective", Policy Research Working Paper 4887, World Bank, Washington D.C.

De Janvry A., Fafchamps M., Sadoulet E., (1991): "Peasant Household Behaviour with Missing Markets: Some Paradoxes Explained", Economic Journal 101(409):1400-17.

De Janvry A., Saudolet E., (1995): “Quantitative Development Policy Analysis", The John Hopkins University Press, Baltimore and London.

De Janvry A., Saudolet E., (2004): “Progress in the Modeling Of Rural Households' Behavior Under Market Failures", in Poverty, Inequality and Development, Essays in Honor of Erik Thorbecke, Chapter 8, Edited by Alain de Janvry and Ravi Kanbur, Kluwer publishing.

De Janvry A., Saudolet E., (2008) : "The Global Food Crisis: Identification of the Vulnerable and Policy Responses", Giannini Foundation of Agricultural Economics, University of California. 
De Jong D.N., Nankervis J.C., Savin N.E., Whiteman C.H., (1992): "The Power Problems of Unit Root Tests for Time Series with Autoregressive Errors", Journal of Econometrics, 19, 295-310.

De Maio L., Stewart F., Van Der Hoeven R., (1999): “Computable General Equilibrium Models, Adjustment and the Poor in Africa", World Development Vol. 27, No. 3, pp. 453470 .

Deaton A., (1985): "Panel Data From Time Series of Cross Sections", Journal of Econometrics, 30: 109-126.

Deaton A., (1989): "Rice Prices and Income Distribution in Thailand: A Non-Parametric Analysis", The Economic Journal, Vol. 99, No. 395, Supplement: Conference Papers (1989), pp. 1-37.

Deaton A., (1992): “Understanding Consumption”, Oxford: Clarendon Press.

Deaton A., (1997): "The Analysis of Household Surveys. A Microeconometric Approach to Development Policy", Baltimore, The World Bank and Johns Hopkins University Press.

Deaton A., Laroque G., (1992): “On the Behavior Of Commodity Prices”, Review of Economic Studies, 59:1, 1-23.

Deaton A., Paxson C., (1994): "Intertemporal Choice And Inequality", Journal of Political Economy, vol. 102, 437-67.

Dercon S., (1998): “Wealth, Risk and Activity Choice: Cattle in Western Tanzania”, Journal of Development Economics 55:1-42

Dercon S., (2005) eds.: "Insurance Against Poverty", World Institute for Development Economics Research of the United Nations University (UNU-WIDER), Oxford, New York: Oxford University Press xvi.

Dercon S., Krishnan P., (2000): “Vulnerability, Seasonality and Poverty in Ethiopia”, Journal of Development Studies, Vol. 36, No.6, pp. 25-53.

Dercon S., Christiaensen L., (2007): “Consumption Risk, Technology Adoption and Poverty Traps: Evidence from Ethiopia", World Bank Policy Research Working Paper 4257, Washington, DC.

Dessus S., Herrera, S., de Hoyos, R., (2008): "The Impact of Food Inflation on Urban Poverty and Its Monetary Cost: Some Back-of-the-Envelope Calculations", World Bank Policy 
Research Working Paper, 4666, Washington, DC and (forthcoming) Agricultural Economics

Dickey D.A, Fuller W.A., (1979): "Distribution of the Estimators for Autoregressive Time Series with a Unit Root", Journal of the American Statistical Association, 74, 427-431.

Dolado J.J., Jenkinson T., Sosvilla-Rivero S., (1990): “Cointegration and Unit Roots”, Journal Of Economic Surveys, Vol. 4, No. 3.

Duflo E., (2000): “Poor but Rational”, MIT, Department of Economics.

Dunn G., (1992): “Design and Analysis of Reliability Studies”, Statistical Methods in Medical Research, 1, pp. 123-157.

Dutilly-Diane C., Saudolet E., De Janvry A., (2003), “Household Behavior Under Market Failures: How Natural Resource Management in Agriculture Promotes Livestock Production in the Sahel", Journal of African Economies.

Dyer G.A., Boucher S., Taylor J.E., (2005): "Subsistence Response to Market Shocks", American Journal of Agricultural Economics.

Elbers C., Gunning J., (2003): “Growth and Risk: Methodology and Micro-evidence", Tinbergen Institute Discussion Papers, 03-068/2.

Ellis, F., (1992): “Peasant Economics”, Cambridge: Cambridge University Press.

Enders W., (1995): “Applied Econometric Time Series”, Wiley, New York, NY.

Erasado L., (2008): “Rural Vulnerability in Serbia”, Working Paper 4010, World Bank.

Eswaran M., Kotwal A., (1986): "Access to Capital and Agrarian Production Organisation", Economic Journal 96:482-98.

Eswaran M., Kotwal A., (1989): "Credit as Insurance in Agrarian Economies", Journal of Development Economics 31:37-53.

Eswaran M., Kotwal A., (1990): "Implications of Credit Constraints for Risk Behaviour in Less Developed Economies", Oxford University Papers 6:87-103

Fama E., (1970): "Efficient Capital Markets: A Review of Theory and Empirical Work", The Journal of Finance, Vol. 25, No. 2, Papers and Proceedings of the Twenty-Eighth Annual Meeting of the American Finance Association New York, N.Y. December, 28-30, 1969. (May, 1970), pp. 383-417. 
FAO, (2008): “Soaring Food Prices: Facts, Perspectives, Impacts and Actions Required", Highlevel conference on world food security: the challenges of climate change and bioenergy, Rome, 3 - 5 June 2008.

FAO, (2007): "The State of Food and Agriculture. Paying Farmers for Environment Services", Rome.

FAO, (2009): "The State of Agricultural Commodity Markets. High Food Prices and the Food Crisis - experience and lessons learned", Rome.

Filmer D., Pritchett L.H., (2001): "Estimating Wealth Effects Without Expenditure Data - Or Tears: An Application To Educational Enrollments In States Of India", Demography, 38(1), 115-132.

Firth R., (1946): “Malay Fishermen: Their Peasant Economy", Routledge, London.

Forman S., (1975): “The Brazilian Peasantry”, Columbia University Press, New York.

Foster A., Rosenzweig M., (2004): “Agricultural Productivity Growth, Rural Economic Diversity, and Economic Reforms: India, 1970-2000", Economic Development and Cultural Change: 509-542.

Foster J.E., (2009): "A Class of Chronic Poverty Measures", in Poverty Dynamics: interdisciplinary perspectives, Eds. T. Addison, D. Hulme \& R. Kanbur, Oxford University Press.

Foster J.E., Greer J., Thornbecke E., (1984): “A Class of Decomposable Poverty Measures", Econometrica, 52(3), 761-766.

Fox A.J., (1972): “Outliers in Time Series", Journal of Royal Statistical Society, Series B, 34, 350-363.

Friedman J., Levinsohn J., (2002): “The Distributional Impacts of Indonesia's Financial Crisis on Household Welfare: A "Rapid Response" Methodology" The World Bank Economic Review, vol. 16 No. 3.

Friedmann H., (1980): "Household Production and the National Economy: Concepts for the Analysis of Agrarian Formations", Journal of Peasant Studies, Vol. 7, No. 2.

Gaiha R., Imai K., (2004), "Vulnerability, Shocks and Persistence of Poverty - Estimates for Semi-Arid Rural South India", Oxford Development Studies, Vol. 32, No. 2, June, pp. 261281. 
Giesbert L., Schindler K., (2009): “Assets, Shocks and Poverty Traps in Rural Mozambique”, draft paper.

Gilbert C.L., (2008): “How to understand high food prices”, Paper presented at FAO Experts' Meeting on Policies for the Effective Management of Sustained Food Price Increases, Trade and Markets Division, Rome, 10-11 July 2008.

Glewwe P., Hall G., (1998): “Are Some Groups More Vulnerable to Macroeconomic Shocks than Others? Hypothesis Tests Based on Panel Data from Peru", Journal of Development Economics, Vol. 56, No. 1, pp. 181-206.

Goldstein H., (1999): “Multilevel Statistical Models”, London: Arnold.

Goldstein H., Rasbash J., Plewis I., Draper D., Browne W., Yang M., Woodhouse G., Healy M., (1998): “A User's Guide to MlwiN", Multilevel Models Project, Institute of Education, University of London.

Griffin J.P., (1986): “Well-being: Its Meaning, Measurement and Moral Importance”, Oxford: Clarendon Press.

Gubert F., Robilliard A., (2008): "Risk and Schooling Decisions in Rural Madagascar: A Panel Data-Analysis", Journal of African Economics, No. 17 (2), 207-38.

Günther I., Harttgen K., (2009): “Estimating Households Vulnerability to Idiosyncratic and Covariate Shocks: A Novel Method Applied in Madagascar", World Development Vol. 37, No. 7.

Haggblade S., Hazell P.B., (1989): “Agriculture Technology and Farm/Non-farm Growth Linkages", Agriculture Economics 3: 345-364.

Haggblade S., Hazell P.B., Dorosh P.A., (2007): "Sectoral Growth Linkages Between Agriculture and the Rural Nonfarm Economy" in Transforming the Rural Nonfarm Economy, Haggblade S., Hazell S.P., and Dorosh P.A. (eds), John Hopkins University Press, Baltimore.

Hardaker J.B., Huirne R.M.B., Anderson J.R., Lien G., (2004): “Coping with Risk in Agriculture", 2nd edition, CAB International, Wallingford.

Harvey A.C., (1976): "Estimating Regression Models With Multiplicative Heteroskedasticity", Econometrica, vol. 44, No. 3

Haughton J., Khandker S.R., (2009): "Handbook on Poverty + Inequality", World Bank, Washington DC. 
Hertel T.W., Keeney R., Ivanic M., Winters L.A., (2006): “Distributional Effects of WTO Agricultural Reforms in Rich and Poor Countries", WPS4060, Preliminary version of a paper prepared for the 44th Panel Meeting of Economic Policy, Helsinki, Finland, October 20-21, 2006.

High-Level Task Force on the Global Food Security Crisis - HLTF, (2008): “Comprehensive Framework For Action".

Hoang V.H., Glewwe P., (2009): "Impacts of Rising Food Prices on Poverty and Welfare in Vietnam", Depocen Working Paper Series, No. 13.

Hoddinott J., (2006): "Shocks and their Consequences Across and Within Households in Rural Zimbabwe", Journal of Development Studies, Vol. 42, No. 2, 301-21.

Holzmann R., Jørgensen S. (2000), “Social Risk Management: A New Conceptual Framework for Social Protection, and Beyond", Social Protection Discussion Paper No. 0006, Washington DC, World Bank, February.

IFPRI/CGIAR, (2008): "High Food Prices: The What, Who and How of Proposed Policy Actions".

IMF, (2008): "Financial Stress, Downturns and Recoveries", World Economic Outlook, Occasional paper, Washington, DC.

Ivanic M., Martin W., (2008): "Implications of Higher Global Food Prices for Poverty in LowIncome Countries", Policy Research Working Paper 4594, World Bank.

Jadotte E., (2010): “Vulnerability to Poverty: A Microeconometric Approach and Application to the Republic of Haiti", Working paper 10.04, Department de Economia Aplicada, Universitat Autònoma de Barcelona.

James W.E., Jha S., Sumulong L., Son H.H., Hasan R., Khan M.E., Sugiyarto G., Zhai F., (2008): "Food Prices and Inflation in Developing Asia: Is Poverty Reduction Coming to an End?", Special Report, Asian Development Bank, Economic and Research Department.

Jha R., Dang T., (2008): “Vulnerability to Poverty in Select Central Asian Countries”, The Australian National University, Working papers in Trade and Development, Working Paper No. 2008/10.

Just R.E., Pope R.D., (2003): “Agricultural Risk Analysis: Adequacy of Models, Data and Issues", American Journal of Agricultural Economics, 85-5, pp. 1249-1256. 
Kahneman D., Tversky A., (1979): "Prospect Theory: an Analysis of Decision under Risk", Econometrica, Vol. 47 (2). p 263-91.

Kamanou, G., Morduch J., (2004): “Measuring Vulnerability to Poverty”, chapter in S. Dercon (ed.), Insurance against Poverty, Oxford University Press.

Kanbur R., (1987): "The Standard of Living: Uncertainty, Inequality and Opportunity", in The Standard of Living, edited by G. Hawthorn. New York: Cambridge University Press.

Kataoka S., (1963): “A Stochastic Programming Model”, Econometrica, 31(1/2):181-196.

Key N., Sadoulet E., de Janvry A., (2000): "Transaction Costs and Agricultural Household Supply Response”, American Journal of Agricultural Economics 82(2):245-259 (May).

Kindleberger C., (1978): “Manias, Panics, and Crashes: A History of Financial Crises", New York: Basic Books.

Klasen S., Lechtenfeld T., Povel F., (2010): “What about the Women? Female Headship, Poverty and Vulnerability in Thailand and Vietnam", available draft version at http://econpapers.repec.org/paper/zbwgdec10/43.htm, as of 10/11/2010.

Klytchnikova I., Diop N., (2006): "Trade Reforms, Farm Productivity and Poverty in Bangladesh", World Bank Working Paper No. 3980, The World Bank: Washington, D.C.

Kolenikiv S., Angeles G., (2009): “Socioeconomic Status Measurement With Discrete Proxy Variables: Is Principal Component Analysis a Reliable Answer?", Review of Income and Wealth, Series 55, Number 1, March.

Kunreuther H., Wright G., (1979): “Safety-First, Gambling and the Subsistence Farmers", in James A.R., Boussard J.M., and Singh I., eds, Risk, Uncertainty and Agricultural Development, Agricultural development Council, New York, 213-230.

Lau L.J., Yotopoulos P, Chou E.C., Lin W., (1981): "The Microeconomics of Distribution: A Simulation of the Farm Economy", Journal of Policy Modelling 3, Issue 2:175-206.

Levinsohn J., (1996): “Competition Policy and International Trade”, In: Bhagwati J. And Hudec R.E. (Eds.), Fair Trade and Harmonization: Prerequisites for Free Trade? Volume One: Economic Analysis, 1st edition.

Ligon E., Schechter L., (2003): “Measuring Vulnerability", The Economic Journal, 113(486), C95-C102.

Ligon E., Schechter L., (2004): "Evaluating Different Approaches To Estimating Vulnerability", Social Protection Discussion Paper 0410, World Bank. 
Lipton M., (1968): "The Theory of the Optimizing Peasant", Journal of Development Studies $4(3): 327-51$.

Lipton M., (1984): “Urban Bias Revisited”, Journal of Development Studies, 20, 139-166.

Lipton M., Ravallion M., (1995): "Poverty and Policy", in Behrman and Srinivasan (eds.), Handbook of Development Economics, Vol. 3., North Holland, Amsterdam.

Lo A.W., (2004): “The Adaptive Markets Hypothesis: Market Efficiency From an Evolutionary Perspective", MIT Sloan School, 15 August, Journal of Portfolio Management 30, 15-29.

Loening J., Oseni G., (2007): “Approximating Urban and Rural Welfare Effects of Food Price Inflation in Ethiopia", mimeo, The World Bank, Washington, DC.

Løvendal C.R., Knowles M., (2005): “Tomorrow's Hunger: A Framework for Analysing Vulnerability to Food Insecurity", Agricultural and Development Economics Division, FAO, ESA Working Paper No. 05-07.

Løvendal C.R., Knowles M., Horii N., (2004): “Understanding Vulnerability to Food Insecurity Lessons from Vulnerable Livelihood Profiling", Agricultural and Development Economics Division, FAO, ESA Working Paper No. 04-18.

Maddala G.S., Kim I-M., (1998): “Unit Roots, Cointegration And Structural Change", Cambridge University Press.

Masson R.T., (1974): "Utility Functions with Jump Discontinuities: Some Evidence and Implications for Peasant Agriculture", Economic Inquiry 12:559-66.

Maxwell D., Caldwell R., (2008): “The Coping Strategies Index", Fields Method Manual, Second edition.

Mellor J., (1976): "The New Economics of Growth: A Strategy for India and the Developing World", Ithaca: Cornell University Press.

Mendola M., (2007): "Farm Household Production Theories: A Review of "Institutional" and "Behavioral" Responses", Asian Development Review, vol. 24, no. 1, pp. 49-68.

Minot N., Goletti F., (2000): "Rice market Liberalization and Poverty in Viet Nam", Research Report 114, International Food Policy Research Institute, Washington, D.C..

Morduch J., (1993): "Risk Production and Saving: Theory and Evidence From Indian Households" Mimeo, Harvard University. 
Morduch J., (1995): "Income Smoothing and Consumption Smoothing", Journal of Economic Perspectives, 9(3), 103-114.

Moscardi E., De Janvry A., (1977): “Attitudes Towards Risk Among Peasant: An Econometric Study", American Journal of Agricultural Economics, 59, 710-716.

Moser C., Felton A., (2009): "The Construction of an Asset Index. Measuring Asset Accumulation in Ecuador", in Poverty Dynamics: interdisciplinary perspectives, Eds. T. Addison, D. Hulme \& R. Kanbur, Oxford University Press.

Mosley P., Verschoor A., (2005): "Risk Attitudes and Vicious Circle of Poverty", The European Journal of Development Research 17(1): 55-88.

Mullainathan S., Thaler R., (2000): "Behavioral Economics", Massachusetts Institute of Technology, Department of Economics, Working Paper Series, Working Paper 00-27.

Nelson C.R., Plosser C. I., (1982): "Trends and Random Walks in Macroeconomic Time Series", Journal of Monetary Economics, 10, 139-162.

OECD \& FAO, (2008): “Agricultural Outlook 2008-2017”, Paris, OECD.

OECD, (2008): "The Relative Impact on World Commodity Prices of Temporal and Longer Term Structural Changes in Agricultural Markets", Document: TAD/CA/APM/CFS/MD(2008)6, Paris, OECD.

Omamo S.W., (1998): "Transport Costs and Smallholder Cropping Choices: An Application to Siaya District”, Kenya, American Journal of Agricultural Economics, Vol. 80, No. 1 (Feb., 1998), pp. 116-123

Perron P., (1989): "The Great Crash, the Oil Price Shock, and the Unit Root Hypothesis", Econometrica, Vol. 57, No. 6, 1361-1401.

Perron P., (1990a): "Testing For a Unit Root in a Time Series with a Changing Mean", Journal of Business \& Economic Statistics, 8, 153-162.

Perron P., (1990b): "Further Evidence on Breaking Trend Functions in Macroeconomic Variables", Memorandum 350, Princeton University, Econometric Research Program.

Perron P., (1997): "Further Evidence on Breaking Trend Functions in Macroeconomic Variables", Journal of Econometrics, 80 (2), pp.355-385.

Perron P., Ng S., (1996): “Useful Modifications to Some Unit Root Tests With Dependent Errors and Their Local Asymptotic Properties", The Review of Economic Studies, Vol. 63, No. 3, pp. 435-463. 
Perron P., Rodriguez G., (2003): "Searching for Additive Outliers in Nonstationary Time Series", Journal of Time Series Analysis Vol. 24, No. 2.

Perron P., Vogelsang T., (1992): “Nonstationarity and Level Shifts With an Application to Purchasing Power Parity", Journal of Business \& Economic Statistics, Vol. 10, No. 3.

Phillips P.C.B., Perron P., (1988): “Testing For A Unit Root In Time Series Regression", Biometrika 75, 335-346.

Piesse J., Thirtle C., (2009): "Three Bubbles and a Panic: An Explanatory Review Of Recent Food Commodity Price Events", Food Policy.

Polanyi K., (1944): "The Great Transformation", Holt, Rinehart, and Winston, Inc., New York; also Beacon Press, 1957, Boston.

Polaski S., Ganesh-Kumar A., McDonald S., Panda M., Robinson S., (2008): “India's Trade Policy Choices: Managing Diverse Challenges", Carnegie Endowment for International Peace, Washington, D.C., 2008.

Porto, G., (2005) "Estimating Household Responses to Trade Reforms", Policy Research Working Paper No.3695, World Bank, Washington, D.C.

Povel F., (2010): "Perceived Vulnerability to Downside Risk", Discussion Paper, No. 43, Courant Research Centre, University of Göttingen.

Pritchett L., Suryahadi A., Sumarto S., (2000): "Quantifying Vulnerability to Poverty: A Proposed Measure with Application to Indonesia", mimeo, Social Monitoring and Early Response Unit, Jakarta.

Quisumbing A., Haddad L., Peña C., (2001): “Are Women Overrepresented among the Poor? An Analysis of Poverty in ten Developing Countries", IFPRI, FCND discussion paper No. 11.

Rabe-Hesketh S., Skrondal A., (2008): "Multilevel and Longitudinal Modeling Using Stata", Stata press, College Station, Texas, Second Edition.

Rapsomanikis G., (2009): “The 2007-2008 food price episode: Impact and Policies in Eastern and South Africa", Trade Markets Division, FAO.

Rashid S., (2002): "Dynamics of Agricultural Wage and Rice Price in Bangladesh: a Reexamination", MSSD Discussion Paper No. 44, International Food Policy Research Institute, Washington DC. 
Raudenbush S.W., Bryk A.S., (2002): "Hierarchical Linear Models", Thousand Oaks, CA: Sage.

Ravallion M., (1988): “Expected Poverty under Risk-Induced Welfare Variability", The Economic Journal, 98(393), 1171-1182.

Ravallion M., (1990): "Rural Welfare Changes of Food Prices Under Induced Wage Responses: Theory and Evidence from Bangladesh", Oxford Economic Papers, 42, 574-85.

Ravallion M., Chen S., (2001): "Measuring pro-poor Growth", Policy Research Working Paper, No. 2666, World Bank, Washington DC.

Ravallion M., Van de Walle D., (1991): "The Impact On Poverty Of Food Pricing Reforms: A Welfare Analysis For Indonesia", Journal of Policy Modeling, Elsevier, vol. 13(2), pages 281-299.

Rayhan M.I., (2010): “Assessing Poverty, Risk and Vulnerability: A Study on Flooded Households in Rural Bangladesh", Journal of Flood Risk Management, 3(1): 18-24, Blackwell.

Rios A.R., Masters W.A., Shively G.E., (2008): “Agricultural Prices and Income Distribution among Framers: A Whole-Household, Multi-Country, Multi-Year Analysis", Purdue University, Mimeo, May 25.

Roberts J.K., (2004): "An Introductory Primer on Multilevel and Hierarchical Linear Modeling", Learning disabilities: A Contemporary Journal, vol. 2(1), pp. 30-38.

Robles M., Torero M., von Braun J., (2009): “When Speculation Matters”, IFPRI Issue Brief 57.

Rock M., (2002): "Exploring the Impact of Selective Interventions in Agriculture on the Growth of Manufactures in Indonesia, Malaysia, and Thailand", Journal of International Development 14(4): 1-26.

Rosenzweig M.R., Binswanger, H.P., (1993): “Wealth, Weather Risk and the Composition and Profitability of Agricultural Investments", Economic Journal 103:56-78.

Roumasset J., (1976): "Rice and Risk: Decision Making among Low-income Farmers", Amsterdam: North-Holland Publishing.

Roy A.D., (1952): “Safety First and the Holding of Assets", Econometrica, 20(3):431-449.

Sahn D., Stifel D., (2003): “Exploring Alternative Measures of Welfare in the Absence of Expenditure Data", Review of income wealth, 49(4): 463-489. 
Sanders D.R., Irwin S.H., (2009): "A Speculative Bubble in Commodity Futures Prices? CrossSectional Evidence", Forthcoming in Agricultural Economics.

Sanders D.R., Irwin S.H., Merrin R.P., (2008): "The Adequacy of Speculation in Agricultural Futures Markets: Too Much of a Good Thing?", Marketing and Outlook Research Report 2008-02, Department of Agricultural and Consumer Economics, University of Illinois at Urbana-Champaign.

Sarris A., Karfakis P., (2007): "Household Vulnerability", in Rural household vulnerability and insurance against commodity risks: Evidence from the United Republic of Tanzania, eds. L. J. Christiaensen and A. Sarris, FAO Trade and Market Division.

Scaramozzino P., (2006): "Measuring Vulnerability to Food Insecurity”, FAO, ESA Working Paper No. 06-12.

Schechter L., (2006): “Vulnerability as a Measure of Chronic Poverty”, working paper.

Schultz T.W., (1960): “Transforming Traditional Agriculture”, New Haven: Yale University Press.

Schultz T.W., (1975): "The Value of the Ability to Deal with Disequilibria", Journal of Economic Literature, 13-3, pp. 827-846.

Schwert C.W., (1989): "Testing for Unit Roots: a Monte Carlo Investigation", Journal of Business \& Economic Statistics, 147-160.

Sen A., (1981): "Poverty and Famines: An Essay on Entitlement and Deprivation", Oxford, Clarendon Press.

Seshan G., Umali-Deininger D., (2007): “Agriculture and Import Liberalization and Household Welfare in Sri Lanka", Mimeographed.

Shackle G.L.S., (1965): “Comment on Two Papers on Time in Economics”, Artha Vijnana.

Shahabuddin Q., Feeny D., (1987): "Efficiency, Share Tenancy and Allocative Behaviour in Peasant Farming: A Safety First Approach", Journal of Economic Development, Volume 12, No. 1.

Singh I., Squire L., Strauss J., (1986): “Agricultural Household Models: Extensions, Applications and Policy", John Hopkins University Press, Baltimore.

Stock J.H., (1994): “Unit Roots, Structural Breaks and Trends", Harvard University. 
Stoja E., Tucker J., (2004): “Target Gearing in UK: A Time Series Unit Root and Cointegration Methodology Approach".

Strauss J., (1986): “Appendix: The Theory and Comparative Statics of Agricultural Household Models: A General Approach", In Inderjit J. Singh, Lyn Squire and John Strauss (eds.), Agricultural Household Models-Extensions, Applications and Policy. Baltimore: The Johns Hopkins University Press.

Suryahadi A., Sumarto S., (2003): "Poverty and Vulnerability in Indonesia Before and After the Economic Crisis", Asian Economic Journal, 17(1), 45-64.

Tax S., (1953): "Penny Capitalism: A Guatemalan Indian Economy", Smithsonian Institute, Institute of Social Anthropology, Publication No. 16, Washington, D.C.

Taylor J.E., Adelman I., (2003): “Agricultural Household Models: Genesis, Evolution, and Extensions", Review of Economics of the Household, Vol. 1, No. 1.

Telser L.G., (1955): “Safety first and hedging”, The Review of Economic Studies, 23(1):1-16.

Thomas W., Hertel T.W., Keeney R., Ivanic M., Winters L.A., (2006): "Distributional Effects of WTO Agricultural Reforms in Rich and Poor Countries", Policy Research Working Paper 4060, World Bank, Washington, D.C., November 2006.

Thorner D., Kerblay B., Smith R.E.F., (1966): “Chayanov on the Theory of Peasant Economy”, Homewood, Illinois: Richard D. Irwin.

Timmer C.P., (2008): “Causes of High Food Prices”, ADB Economic Working Paper Series, No. 128.

Timmer C.P., (2010): "Reflections on Food Crisis Past", Food Policy, No. 35, 1-11.

Trostle R., (2008): “Global Agricultural Supply and Demand: Factors Contributing to the Recent Increase in Food Commodity Prices", WRS-0801, Economic Research Service, USDA, Washington, DC

Tsay R.S., (1988): “Outliers, Level Shifts, And Variance Changes In Time Series”, Journal of Forecasting, 7, 1-20.

Tyagi D.S., (1979): "Farm Prices and Class Bias in India", Economic and Political Weekly, 14. Verbeek, M., Nijman T., (1993): "Minimum MSE Estimation of a Regression Model with Fixed Effects From a Series of Cross Sections", Journal of Econometrics, 59: 125-136. 
Vergopoulos K., (1978): “Capitalism and Peasant Productivity", Journal of Peasant Studies, vol. 5, pp. 446-65.

Verwimp P., Bundervoet T., (2008): “Consumption Growth, Households Splits and Civil War", ECARES Working Paper, No 23.

von Neumann J., Morgenstern O., (1944): "Theory of Games and Economic Behavior", Princeton University Press.

Waite L., (2000): "How Is Household Vulnerability Gendered? Female-headed Households in the Collectives of Suleimaniyah, Iraqi Kurdistan", Disasters, No 24(2):153-172

WFP, (2008): "Comprehensive Food Security and Vulnerability Analysis: Burundi", VAM, World Food Programme Food Security Analysis.

WFP, (2009): “World Hunger Series: Hunger and Markets", Earthscan.

Wiggins S., (2008): “Is the Global Food System Broken?”, ODI, London.

Wiggins S., Compton J., Keats S., (2010): "Food Crisis FAQs", Background paper, ODI, London.

Wodon Q., Zaman H., (2008a): "Rising Food Prices in Sub-Saharan Africa: Poverty Impact and Policy Responses", Policy Research Working Paper 4738, World Bank.

Wodon, Q., Tsimpo, C., Backiny-Yetna, P., Joseph, G., Adoho, F., Coulombe, H., (2008b): "Potential Impact of Higher Food Prices on Poverty", Policy Research Working Paper No. 4745, Washington, DC, World Bank.

World Bank, (2000): “Voices of the Poor", World Development Report.

World Bank, (2007): “Global Monitoring Report: Millennium Development Goals, Confronting the Challenges of Gender Equality and Fragile States", World Bank, Washington, DC.

World Bank, (2008a): "Global Economic Prospects 2009: Commodities at the Crossroad", Washington D.C..

World Bank, (2008b): “World Development Report 2008: Agriculture for Development", Washington D.C.

Yesuf M., Bluffstone R.A., (2009): "Poverty, Risk Aversion, and Path Dependence in LowIncome Countries: Experimental Evidence From Ethiopia", American Journal of Agricultural Economics 91(4): 1022-1037. 
Young J.E., (2008): “Speculation and World Food Market”, IFPRI Forum, July.

Zezza A., Davis B., Azzarri C., Covarrubias K., Tasciotti L., Anriquez G., (2008): “The Impact of Rising Food Prices on the Poor", ESA Working Paper No. 08-07, FAO.

Zimmerman F. J., Carter M. R., (2003): “Asset Smoothing, Consumption Smoothing and the Reproduction of Inequality Under Risk and Subsistence Constraints", Journal of Development Economics 71 (2003) 233- 260.

Zivot E., Andrews D.W.K., (1992): "Further Evidence on the Great Crash, the Oil-Price Shock, and the Unit-Root Hypothesis", Journal of Business \& Economic Statistics, 10, 251-270. 